\title{
Late-Stage Solubilization of Poorly Soluble Peptides Using Hydrazide Chemistry
}

Kohei Sato, ${ }^{* \dagger,}, \S$ Shoko Tanaka, ${ }^{\S}$ Junzhen Wang, ${ }^{\dagger}$ Kenya Ishikawa, ${ }^{\dagger}$ Shugo Tsuda,

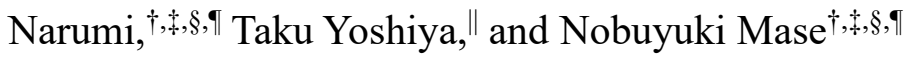

'Department of Applied Chemistry and Biochemical Engineering, Faculty of Engineering, Shizuoka University, 3-5-1 Johoku, Hamamatsu, Shizuoka 432-8561, Japan

*Course of Applied Chemistry and Biochemical Engineering, Department of Engineering, Graduate School of Integrated Science and Technology, Shizuoka University, 3-5-1 Johoku, Hamamatsu, Shizuoka 432-8561, Japan

${ }^{\S}$ Graduate School of Science and Technology, Shizuoka University, 3-5-1 Johoku, Hamamatsu, Shizuoka 432-8561, Japan

"Peptide Institute, Inc., 7-2-9 Saito-Asagi, Ibaraki, Osaka 567-0085, Japan

"Research Institute of Green Science and Technology, Shizuoka University, 3-5-1 Johoku, Hamamatsu, Shizuoka 432-8561, Japan

sato.kohei@shizuoka.ac.jp

Table of Contents

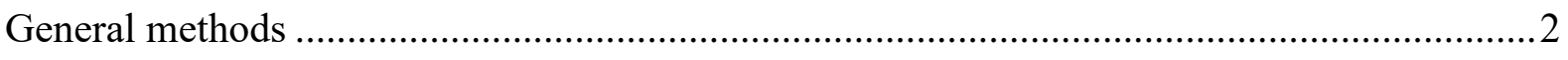

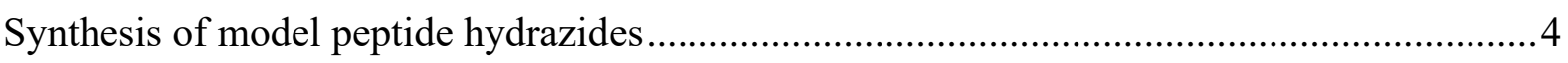

Reductive alkylation followed by Cu-mediated oxidative hydrolysis of peptide hydrazides ...8

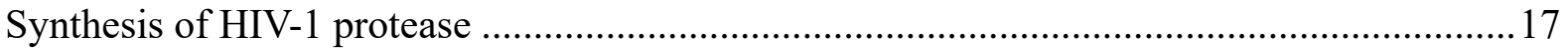

Assay for protease activity of synthesized HIV-1 protease .................................................25

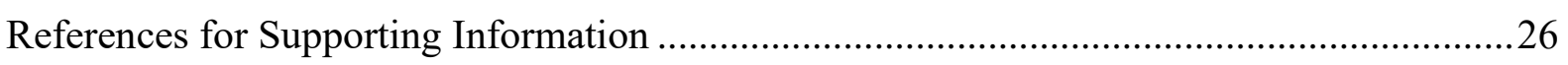

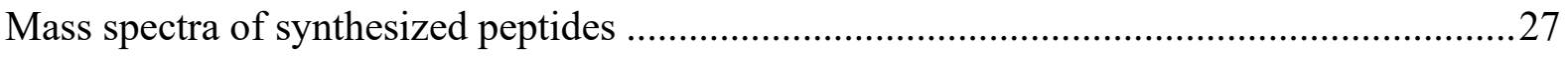

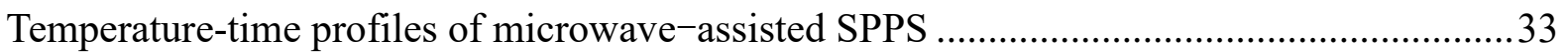




\section{General methods}

\section{Materials}

All commercially available reagents and protected amino acids were purchased and used without further purification.

Trityl-OH ChemMatrix resin, HMPB ChemMatrix resin and Rink Amide ChemMatrix resin were purchased from Biotage Japan Ltd. Dry dichloromethane $\left(\mathrm{CH}_{2} \mathrm{Cl}_{2}\right)$, thionyl chloride, dry $N, N$ dimethylformamide (DMF), methanol $(\mathrm{MeOH})$, acetic acid $(\mathrm{AcOH})$, diethyl ether $\left(\mathrm{Et}_{2} \mathrm{O}\right)$, copper (II) sulfate, 5-hydrate $\left(\mathrm{CuSO}_{4} \cdot 5 \mathrm{H}_{2} \mathrm{O}\right)$, 4-anisaldehyde, sodium nitrite $\left(\mathrm{NaNO}_{2}\right)$, sodium hydrogen carbonate $\left(\mathrm{NaHCO}_{3}\right)$, disodium hydrogenphosphate, Nitric acid (1.42) and sodium acetate were purchased from KANTO CHEMICAL CO., INC. 9-Fluorenylmethyl carbazate, trifluoroacetic acid (TFA), triisopropylsilane (TIS), $m$-cresol, 2-picoline-borane complex (pic- $\mathrm{BH}_{3}$ ), 4-methoxybenzyl alcohol, 4formylbenzoic acid, 4-formylphenoxyacetic acid, 2-[4-(2-hydroxyethyl)-1-piperazinyl]-ethanesulfonic acid (HEPES), ritonavir, sodium 2-mercaptoethanesulfonate (MESNa) and piperidine were purchased from Tokyo Chemical Industry Co., Ltd. DMF, $\mathrm{Et}_{2} \mathrm{O}$, acetonitrile $\left(\mathrm{CH}_{3} \mathrm{CN}\right)$, dimethyl sulfoxide (DMSO), 1,1,1,3,3,3-hexafluoro-2-propanol (HFIP), isobutyl chloroformate, 25\% $\mathrm{NH}_{3}$ aq., ( \pm )dithiothreitol (DTT), tris(2-carboxyethyl)phosphine hydrochloride (TCEP· $\mathrm{HCl}$ ) and 2,2'-azobis[2-(2imidazolin-2-yl)propane] dihydrochloride (VA-044) were purchased from FUJIFILM Wako Pure Chemical Corporation. Thioanisole, guanidine hydrochloride $(\mathrm{Gn} \cdot \mathrm{HCl}), \mathrm{N}$-methylmorholine and $O$ methylhydroxylamine hydrochloride $\left(\mathrm{CH}_{3} \mathrm{ONH}_{2} \cdot \mathrm{HCl}\right)$ were purchased from NACALAI TESQUE, INC. $N, N$ '-Diisopropylcarbodiimide (DIPCI), Fmoc-D-Ala-OH· $\mathrm{H}_{2} \mathrm{O}$, Fmoc-D-Val-OH, Fmoc-Nle-OH, Fmoc-Abu-OH, Boc-Thz-OH and DMF were purchased from WATANABE CHEMICAL INDUSTRIES, LTD. $N, N$-Diisopropylethylamine (DIPEA), citric acid and 4-mercaptophenylacetic acid (MPAA) were purchased from Sigma-Aldrich Co. LLC. Ethyl cyanohydroxyiminoacetate (Oxyma

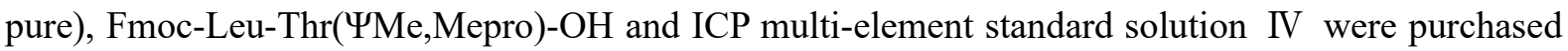
from Merck KGaA. Sodium hydroxide $(\mathrm{NaOH})$ and sodium sulfate $\left(\mathrm{Na}_{2} \mathrm{SO}_{4}\right)$ were purchased from Kishida Chemical Co., Ltd. Sodium chloride $(\mathrm{NaCl})$ was purchased from Nihonkaisui Co., Ltd. FmocAla-OH $\cdot \mathrm{H}_{2} \mathrm{O}$ and Fmoc-Met-OH were purchased from Bachem AG. Fmoc-Asp(Ot-Bu)-OH, Fmoc$\mathrm{Glu}(\mathrm{O} t-\mathrm{Bu})-\mathrm{OH}$, Fmoc-Phe-OH, Fmoc-Gly-OH, Fmoc-His(Trt)-OH, Fmoc-Ile-OH, Fmoc-Lys(Boc)$\mathrm{OH}$, Fmoc-Leu-OH, Fmoc-Asn(Trt)-OH, Fmoc-Pro-OH, Fmoc-Gln(Trt)-OH, Fmoc-Arg(Pbf)-OH, Fmoc-Ser( $t$-Bu)-OH, Fmoc-Thr( $t$-Bu)-OH, Fmoc-Val-OH, Fmoc-Trp(Boc)-OH, Fmoc-Tyr( $t$-Bu)-OH were purchased from CEM corporation. Slide-A-Lyzer Dialysis Cassette G2 (3500 MW cutoff) was purchased from Thermo Fisher Scientific, Inc. Purified water for batteries 20L was purchased from MISHIMA SHOKUSAN INC. 


\section{HPLC and Mass spectrometry}

LC analyses were carried out on a system using JASCO PU-2089 Plus, UV-2070 Plus, AS-2057 Plus, and CO-2060 Plus (set temperature was $30^{\circ} \mathrm{C}$ ). Mass spectra of peptides were recorded on a Bruker Compact (ESI-Q-TOF). For HPLC separations, a YMC-Triart C8 analytical column (YMC, $4.6 \times 250$ $\mathrm{mm}$, flow rate $1.0 \mathrm{~mL} / \mathrm{min}$ ), a YMC-Triart C18 analytical column (YMC, $4.6 \times 250 \mathrm{~mm}$, flow rate 1.0 $\mathrm{mL} / \mathrm{min}$ ), a Cosmosil 5C8-AR-300 analytical column (Nacalai Tesque, $4.6 \times 250 \mathrm{~mm}$, flow rate 1.0 $\mathrm{mL} / \mathrm{min}$ ), a Cosmosil 5C 18 -AR-II analytical column (Nacalai Tesque, $4.6 \times 250 \mathrm{~mm}$, flow rate 1.0 $\mathrm{mL} / \mathrm{min}$ ), a Cosmosil 2.5Cholester analytical column (Nacalai Tesque, $3.0 \times 75 \mathrm{~mm}$, flow rate 1.0 $\mathrm{mL} / \mathrm{min}$ ), a YMC-Triart C8 semi-preparative column (YMC, $10 \times 250 \mathrm{~mm}$, flow rate $3.0 \mathrm{~mL} / \mathrm{min}$ ), or a Cosmosil 5C8-AR-300 preparative column (Nacalai Tesque, $20 \times 250 \mathrm{~mm}$, flow rate $8.0 \mathrm{~mL} / \mathrm{min}$ ) were employed, and the eluted products were detected by UV at $220 \mathrm{~nm}$. A solvent system consisting of $0.1 \%$ TFA aqueous solution ( $v / v$, solvent $\mathrm{A})$ and $0.1 \%$ TFA in $\mathrm{CH}_{3} \mathrm{CN}(v / v$, solvent $\mathrm{B})$ was used for HPLC elution.

\section{Inductivity coupled plasma optical emission spectrometry (ICP-OES)}

The $\mathrm{Cu}$ content was determined with PerkinElmer Optima 2100 DV Optical Emission Spectrometer.

\section{Solid-phase peptide synthesis}

Fmoc SPPS was performed with an automated microwave-assisted synthesis or a manual synthesis. The microwave-assisted SPPS using by a Biotage Initiator ${ }^{+}$Alstra peptide synthesizer with a $10 \mathrm{~mL}$ open-type vial was conducted as follows: coupling with amino acids except for His(Trt) or $\operatorname{Arg}(\mathrm{Pbf})$ : Fmoc-protected amino acid, Oxyma pure, and DIPCI (4.0 equivalents each) in DMF (0.5 M), 5 min, $75^{\circ} \mathrm{C}$ under microwave irradiation; coupling with His(Trt) or $\operatorname{Arg}(\mathrm{Pbf})$ : Fmoc-protected amino acid, Oxyma pure and DIPCI (4.0 equivalents each) in DMF (0.5 M), 60 min, room temperature (rt); Fmoc removal: $20 \%(v / v)$ piperidine in DMF, $3 \mathrm{~min}, 50{ }^{\circ} \mathrm{C}$ under microwave irradiation or $3 \mathrm{~min}+10 \mathrm{~min}$, $\mathrm{rt})$. The reaction temperature was monitored by an IR sensor.

The manual synthesis was conducted as follows: coupling: Fmoc-protected amino acid, Oxyma pure, and DIPCI (4.0 equivalents each) in DMF (0.3 M), $60 \mathrm{~min}, \mathrm{rt}$; Fmoc removal: 20\% $(v / v)$ piperidine in DMF, $10 \mathrm{~min}, \mathrm{rt}$.

\section{Preparation of hydrazine-incorporated resin}

Hydrazine-incorporated resin was prepared using previously reported methods ${ }^{\mathrm{s}}$. Trityl OHChemMatrix resin was swollen in dry $\mathrm{CH}_{2} \mathrm{Cl}_{2}$ and treated with thionyl chloride (10 equiv) at $\mathrm{rt}$ for $2 \mathrm{~h}$. After being washed with dry $\mathrm{CH}_{2} \mathrm{Cl}_{2}$, the resulting resin was swollen in dry $\mathrm{CH}_{2} \mathrm{Cl}_{2}$. To the resin a solution of 9-fluorenylmethyl carbazate (4.0 equiv) and DIPEA (10 equiv) in dry DMF was added dropwise at $0{ }^{\circ} \mathrm{C}$. The reaction mixture was shaken at $\mathrm{rt}$ overnight, then $\mathrm{MeOH}$ was added. After 10 min, the resin was filtered and successively washed with DMF, water, DMF, $\mathrm{MeOH}$ and $\mathrm{Et}_{2} \mathrm{O}$. The loading was confirmed by quantification of the Fmoc group $(0.25-0.40 \mathrm{mmol} / \mathrm{g})$. 


\section{Synthesis of model peptide hydrazides}

Model peptide Ac-LYRAN-Xaa- $\mathrm{NHNH}_{2}$ 1a-1h was elongated on the hydrazine-incorporated resin synthesized by the automated synthesis and the resulting resin was treated with TFA-TIS- $\mathrm{H}_{2} \mathrm{O}$ (95:2.5:2.5 (v/v), $50 \mu \mathrm{L} / 1 \mathrm{mg}$ resin) at $\mathrm{rt}$ for $2 \mathrm{~h}$. The resin in the reaction mixture was filtrated off. To the resulting filtrate was added cold $\mathrm{Et}_{2} \mathrm{O}$ to give a precipitate. After successively washed with $\mathrm{Et}_{2} \mathrm{O}$, the crude peptides were purified by preparative HPLC. Analytical HPLC conditions: a YMC-Triart C8 analytical column with a linear gradient of solvent B in solvent A, 10\% to $60 \%$ over $30 \mathrm{~min}$.

$\mathrm{Xaa}=$ Ala (1a)

Retention time $=12.8 \mathrm{~min}, \mathrm{HRMS}$ (ESI-Q-TOF) $\mathrm{m} / z$ : $[\mathrm{M}+\mathrm{H}]^{+}$Calcd for $\mathrm{C}_{33} \mathrm{H}_{55} \mathrm{~N}_{12} \mathrm{O}_{9}$ 763.4209; Found 763.4270. Preparative HPLC conditions: YMC-Triart C8 semi-preparative column with a linear gradient of solvent B in solvent A, $10 \%$ to $30 \%$ over $30 \mathrm{~min}$ (4.8 $\mathrm{mg}$ from $163 \mathrm{mg}$ of peptidyl resin $(10 \%))$.

(A) Crude material of $\mathbf{1 a}$

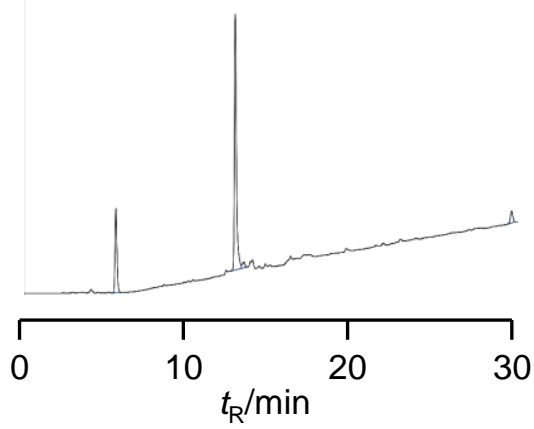

(B) Purified 1a

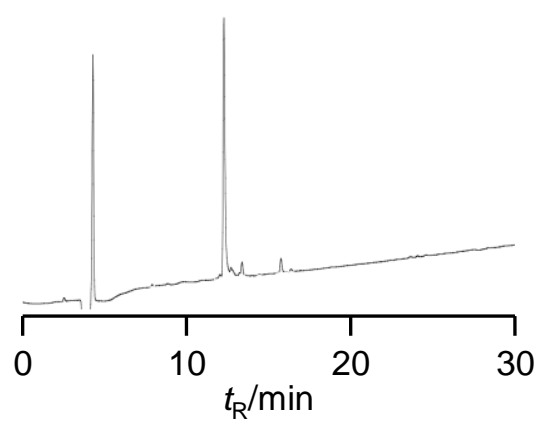

Figure S1. HPLC profile of peptide hydrazide 1a. (A) crude material of 1a and (B) purified 1a. 
$\mathrm{Xaa}=\operatorname{Val}(\mathbf{1 b})$

Retention time $=13.8 \mathrm{~min}, \mathrm{HRMS}\left(\mathrm{ESI}-\mathrm{Q}-\mathrm{TOF}\right.$ ) $\mathrm{m} / z:[\mathrm{M}+\mathrm{H}]^{+}$Calcd for $\mathrm{C}_{35} \mathrm{H}_{59} \mathrm{~N}_{12} \mathrm{O}_{9}$ 791.4522; Found 791.4590. Preparative HPLC conditions: YMC-Triart C8 semi-preparative column with a linear gradient of solvent B in solvent A, 20\% to $40 \%$ over $30 \mathrm{~min}$ (7.4 mg from $165 \mathrm{mg}$ of peptidyl resin $(14 \%))$.

(A) Crude material of $\mathbf{1 b}$

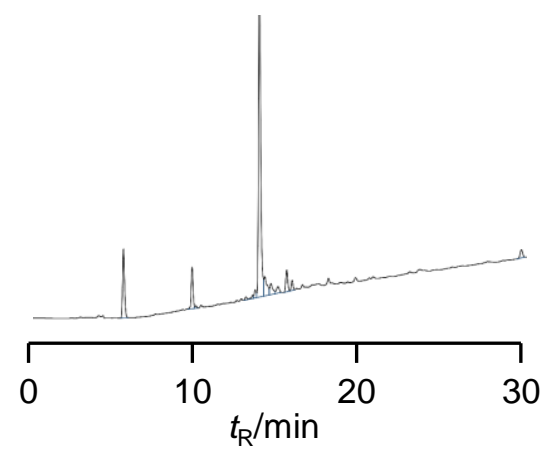

(B) Purified 1b

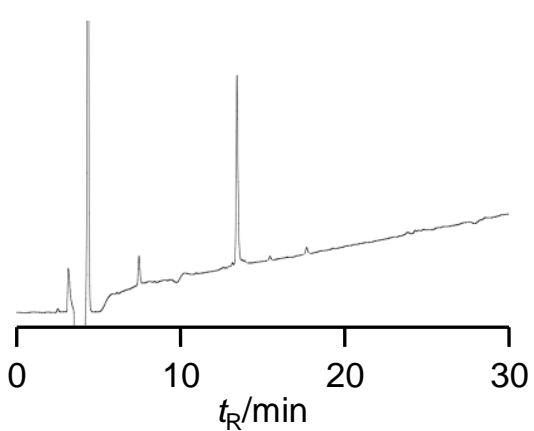

Figure S2. HPLC profile of peptide hydrazide $\mathbf{1 b}$. (A) crude material of $\mathbf{1 b}$ and (B) purified $\mathbf{1 b}$.

$\mathrm{Xaa}=$ Phe (1c)

Retention time $=16.2 \mathrm{~min}, \mathrm{HRMS}$ (ESI-Q-TOF) $\mathrm{m} / z$ : $[\mathrm{M}+\mathrm{H}]^{+}$Calcd for $\mathrm{C}_{39} \mathrm{H}_{59} \mathrm{~N}_{12} \mathrm{O}_{9}$ 839.4522; Found 839.4596. Preparative HPLC conditions: YMC-Triart C8 semi-preparative column with a linear gradient of solvent B in solvent A, 20\% to $40 \%$ over $30 \mathrm{~min}$ (3.4 mg from $113 \mathrm{mg}$ of peptidyl resin $(6 \%))$.

(A) Crude material of $\mathbf{1 c}$

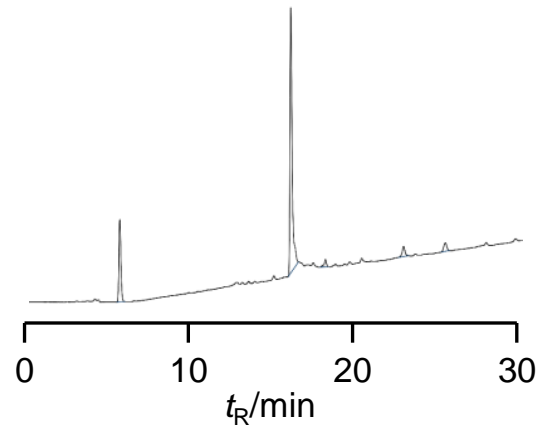

(B) Purified 1c

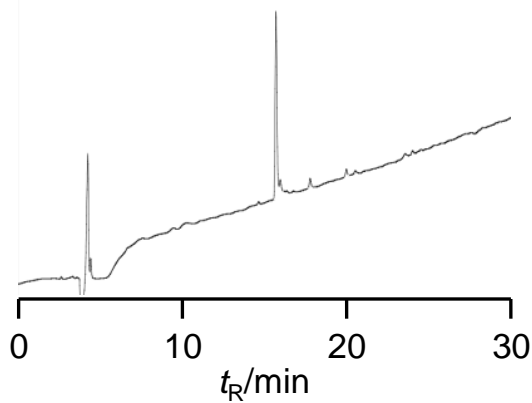

Figure S3. HPLC profile of peptide hydrazide 1c. (A) crude material of 1c and (B) purified 1c. 
$\mathrm{Xaa}=\operatorname{Ser}(\mathbf{1 d})$

Retention time $=12.2 \mathrm{~min}$, HRMS (ESI-Q-TOF) $m / z:[\mathrm{M}+\mathrm{H}]^{+}$Calcd for $\mathrm{C}_{33} \mathrm{H}_{55} \mathrm{~N}_{12} \mathrm{O}_{10}$ 779.4159; Found 779.4209. Preparative HPLC conditions: YMC-Triart C8 semi-preparative column with a linear gradient of solvent B in solvent A, 10\% to $30 \%$ over $30 \mathrm{~min}$ ( $7.0 \mathrm{mg}$ from $170 \mathrm{mg}$ of peptidyl resin $(14 \%))$.

(A) Crude material of $\mathbf{1 d}$

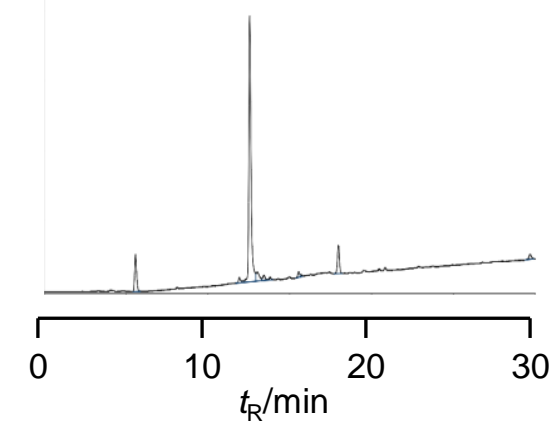

(B) Purified 1d

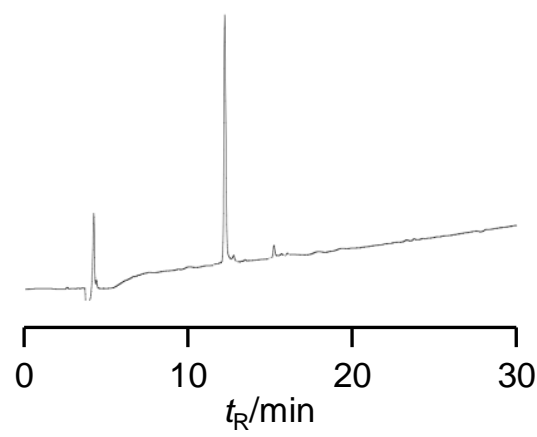

Figure S4. HPLC profile of peptide hydrazide 1d. (A) crude material of $\mathbf{1 d}$ and (B) purified $\mathbf{1 d}$.

$\mathrm{Xaa}=\operatorname{Thr}(\mathbf{1 e})$

Retention time $=12.5 \mathrm{~min}$, HRMS (ESI-Q-TOF) $\mathrm{m} / z$ : $[\mathrm{M}+\mathrm{H}]^{+}$Calcd for $\mathrm{C}_{34} \mathrm{H}_{57} \mathrm{~N}_{12} \mathrm{O}_{10} 793.4315$; Found 793.4390. Preparative HPLC conditions: YMC-Triart C8 semi-preparative column with a linear gradient of solvent B in solvent A, 15\% to $30 \%$ over $30 \mathrm{~min}$ (17.3 mg from $407 \mathrm{mg}$ of peptidyl resin $(34 \%))$.
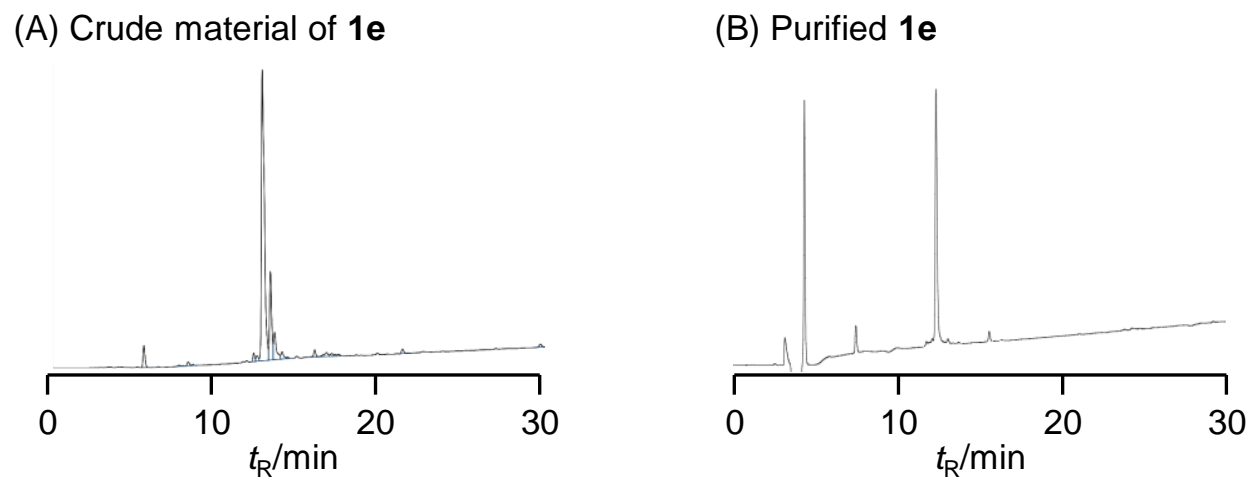

Figure S5. HPLC profile of peptide hydrazide 1e. (A) crude material of 1e and (B) purified 1e. 
$\mathrm{Xaa}=$ His $(\mathbf{1 f})$

Retention time $=12.4 \mathrm{~min}, \mathrm{HRMS}\left(\mathrm{ESI}-\mathrm{Q}-\mathrm{TOF}\right.$ ) $\mathrm{m} / z:[\mathrm{M}+\mathrm{H}]^{+}$Calcd for $\mathrm{C}_{36} \mathrm{H}_{57} \mathrm{~N}_{14} \mathrm{O} 9$ 829.4427; Found 829.4422. Preparative HPLC conditions: YMC-Triart C8 semi-preparative column with a linear gradient of solvent B in solvent A, 15\% to $25 \%$ over $30 \mathrm{~min}$ (23.6 mg from $255 \mathrm{mg}$ of peptidyl resin $(40 \%))$.

(A) Crude material of $\mathbf{1 f}$

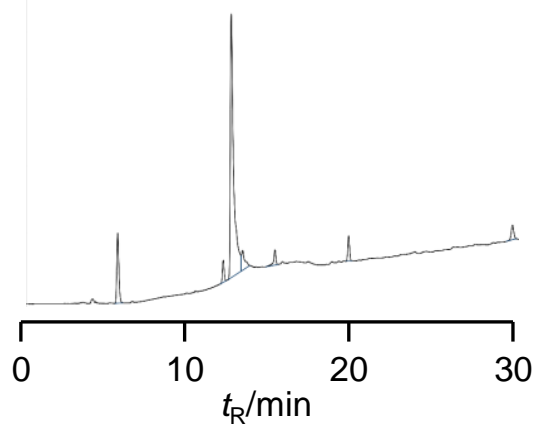

(B) Purified 1f

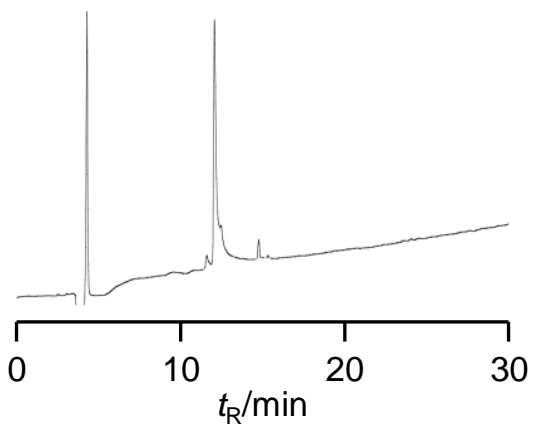

Figure S6. HPLC profile of peptide hydrazide 1f. (A) crude material of $\mathbf{1 f}$ and (B) purified $\mathbf{1 f}$.

Xaa $=$ Lys $(\mathbf{1 g})$

Retention time $=10.9$ min, HRMS (ESI-Q-TOF) $m / z:[\mathrm{M}+\mathrm{H}]^{+}$Calcd for $\mathrm{C}_{36} \mathrm{H}_{62} \mathrm{~N}_{13} \mathrm{O}_{9}$ 820.4788; Found 820.4776. Preparative HPLC conditions: YMC-Triart C8 semi-preparative column with a linear gradient of solvent B in solvent A, $15 \%$ to $25 \%$ over $60 \mathrm{~min}$ (9.5 mg from $112 \mathrm{mg}$ of peptidyl resin $(44 \%))$.

(A) Crude material of $\mathbf{1 g}$

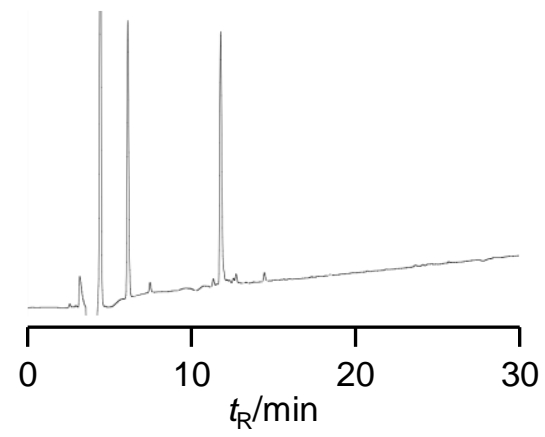

(B) Purified 1g

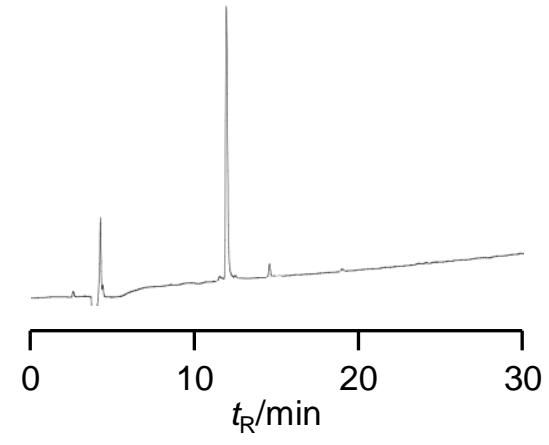

Figure S7. HPLC profile of peptide hydrazide 1g. (A) crude material of $1 \mathbf{g}$ and (B) purified $\mathbf{1 g}$. 
$\mathrm{Xaa}=\operatorname{Arg}(\mathbf{1 h})$

Retention time $=11.3 \mathrm{~min}, \mathrm{HRMS}\left(\mathrm{ESI}-\mathrm{Q}-\mathrm{TOF}\right.$ ) $\mathrm{m} / z$ : $[\mathrm{M}+\mathrm{H}]^{+}$Calcd for $\mathrm{C}_{36} \mathrm{H}_{62} \mathrm{~N}_{15} \mathrm{O}_{9}$ 848.4849; Found 848.4838. Preparative HPLC conditions: YMC-Triart C8 semi-preparative column with a linear gradient of solvent B in solvent A, 15\% to 25\% over $60 \mathrm{~min}$ (5.8 $\mathrm{mg}$ from $104 \mathrm{mg}$ of peptidyl resin $(33 \%))$.

(A) Crude material of $\mathbf{1 h}$

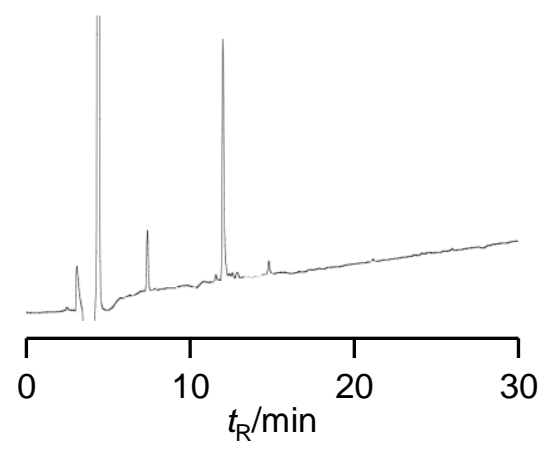

(B) Purified 1h

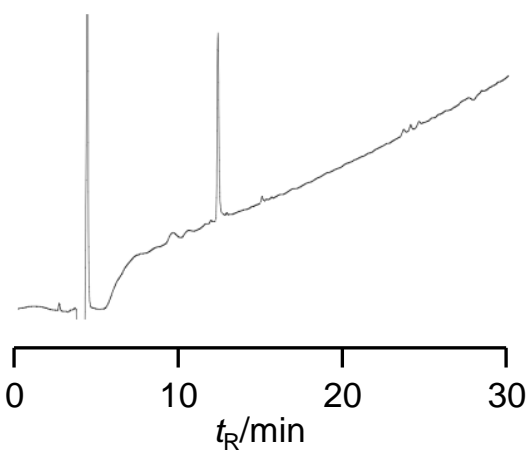

Figure S8. HPLC profile of peptide hydrazide $\mathbf{1 h}$. (A) crude material of $\mathbf{1 h}$ and (B) purified $\mathbf{1 h}$.

\section{Reductive alkylation followed by $\mathrm{Cu}$-mediated oxidative hydrolysis of peptide hydrazides \\ Synthesis of 4-formylbenzamide}

4-Formylbenzamide (2b) was synthesized as previously reported. ${ }^{\mathrm{S} 2}$ 4-Formylbenzoic acid $(753 \mathrm{mg}$, $5.0 \mathrm{mmol})$ was dissolved in $\mathrm{CH}_{2} \mathrm{Cl}_{2}(20 \mathrm{~mL})$ and then $N$-methylmorpholine $(0.55 \mathrm{~mL}, 5.0 \mathrm{mmol})$ was slowly added. The reaction mixture was cooled to $0^{\circ} \mathrm{C}$, and isobutyl chloroformate $(0.65 \mathrm{~mL}, 5.0 \mathrm{mmol})$ was slowly added. After being stirred at $0{ }^{\circ} \mathrm{C}$ for $30 \mathrm{~min}, 25 \% \mathrm{NH}_{3}$ aq. $(500 \mu \mathrm{L})$ was added and then the mixture was stirred at $0{ }^{\circ} \mathrm{C}$ for an additional $1 \mathrm{~h}$. Then to the reaction mixture was added $25 \%$ citric acid aq. The organic phase was successively washed with saturated $\mathrm{NaHCO}_{3}$ aq. and brine, and then dried over $\mathrm{Na}_{2} \mathrm{SO}_{4}$. After filtration followed by concentration under reduced pressure, 4formylbenzamide was obtained as a white solid (315 mg, 48\%). The ${ }^{1} \mathrm{H}$ NMR spectrum was identical to the reported spectrum ${ }^{\mathrm{S} 2}$.

\section{Reductive N-alkylation of the peptide hydrazide followed by Cu-mediated oxidative hydrolysis}

Model peptide hydrazide $1 \mathbf{a}(0.10 \mu \mathrm{mol})$ was reacted with aldehyde $\mathbf{2 a}$ or $\mathbf{2 b}$ ( 1.5 equiv) in HFIP (100 $\mu \mathrm{L})$ or $50 \%(v / v) \mathrm{AcOH}-\mathrm{HFIP}(100 \mu \mathrm{L})$ at $37^{\circ} \mathrm{C}$. After $1 \mathrm{~h}$ reaction, pic- $\mathrm{BH}_{3}(20$ equiv) was added and the mixture was incubated at $37^{\circ} \mathrm{C}$ for $1 \mathrm{~h}$. The resulting solution was concentrated by blowing air and then washed with $\mathrm{Et}_{2} \mathrm{O}$. The formed precipitate was dissolved in in $20 \%(v / v) \mathrm{CH}_{3} \mathrm{CN}-\mathrm{H}_{2} \mathrm{O}(50 \mu \mathrm{L})$ and the solution was analysed by HPLC. Analytical HPLC conditions: a Cosmosil $5 \mathrm{C}_{18}$-AR-II analytical column with the linear gradient of solvent B in solvent A, $15 \%$ to $50 \%$ over $30 \mathrm{~min}$. 


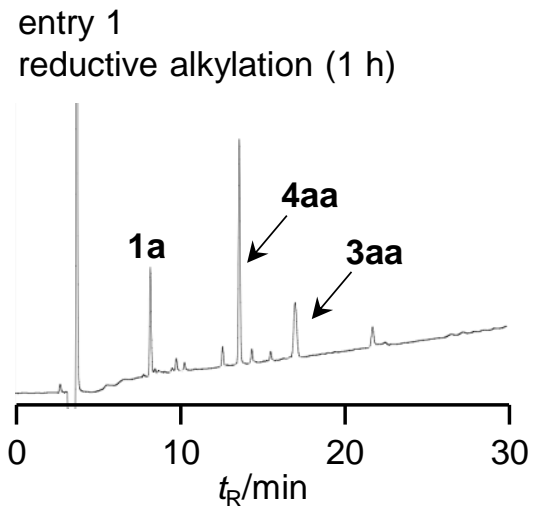

entry 3

reductive alkylation $(1 \mathrm{~h})$

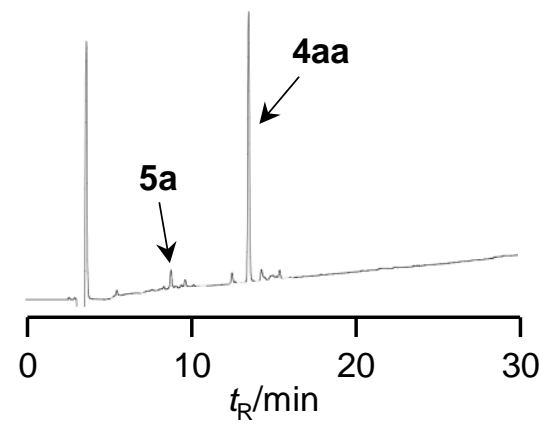

\section{entry 5}

reductive alkylation $(1 \mathrm{~h})$

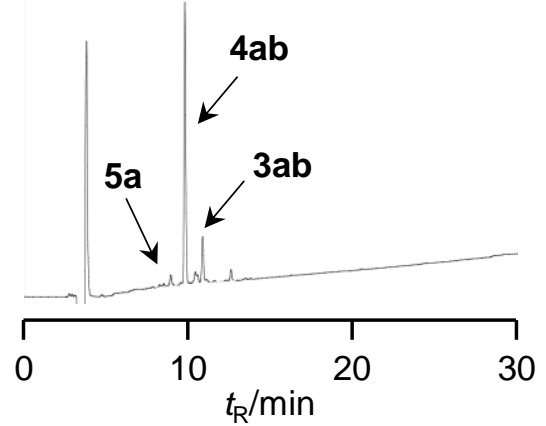

entry 2

reductive alkylation $(24 \mathrm{~h})$

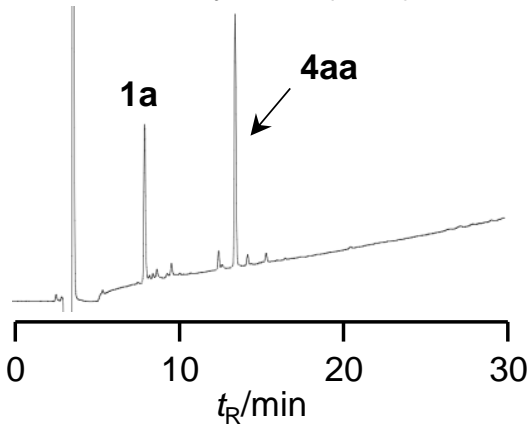

entry 4

reductive alkylation (10 $\mathrm{min})$

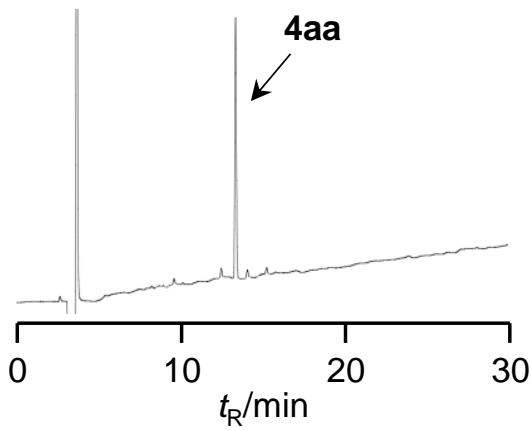

Figure S9. HPLC analyses of reductive alkylation between the model peptide 1a and aldehyde 2. 


\section{Examination of $\mathrm{Cu}$-mediated oxidative hydrolysis of $\mathrm{N}$-alkyl hydrazide peptide (4aa)}

The N-alkyl hydrazide peptide (4aa) generated as described above was dissolved in $20 \%(v / v) \mathrm{CH}_{3} \mathrm{CN}$ $\mathrm{H}_{2} \mathrm{O}(50 \mu \mathrm{L})$ containing $\mathrm{CuSO}_{4} \cdot 5 \mathrm{H}_{2} \mathrm{O}\left(20\right.$ equiv). The hydrolysis was performed at $37^{\circ} \mathrm{C}$ for $1 \mathrm{~h}$. After

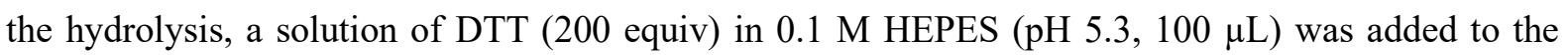
reaction mixture and the mixture was incubated for additional $15 \mathrm{~min}$ at $37{ }^{\circ} \mathrm{C}$. The formed precipitate was removed by centrifugation and the reaction progress was monitored by HPLC. Analytical HPLC conditions: a Cosmosil 5 $\mathrm{C}_{18}$-AR-II analytical column with the linear gradient of solvent $\mathrm{B}$ in solvent $\mathrm{A}$, $15 \%$ to $50 \%$ over $30 \mathrm{~min}$. The asterisk in the HPLC charts indicates non-peptidic compounds derived from $\mathrm{CuSO}_{4}$ and DTT.

Peptide acid 6a: Retention time $=9.8 \mathrm{~min}, \mathrm{HRMS}\left(\right.$ ESI-Q-TOF) $\mathrm{m} / \mathrm{z}$ : $[\mathrm{M}+\mathrm{H}]^{+}$Calcd for $\mathrm{C}_{33} \mathrm{H}_{53} \mathrm{~N}_{10} \mathrm{O}_{10}$ 749.3941; Found 749.3832.
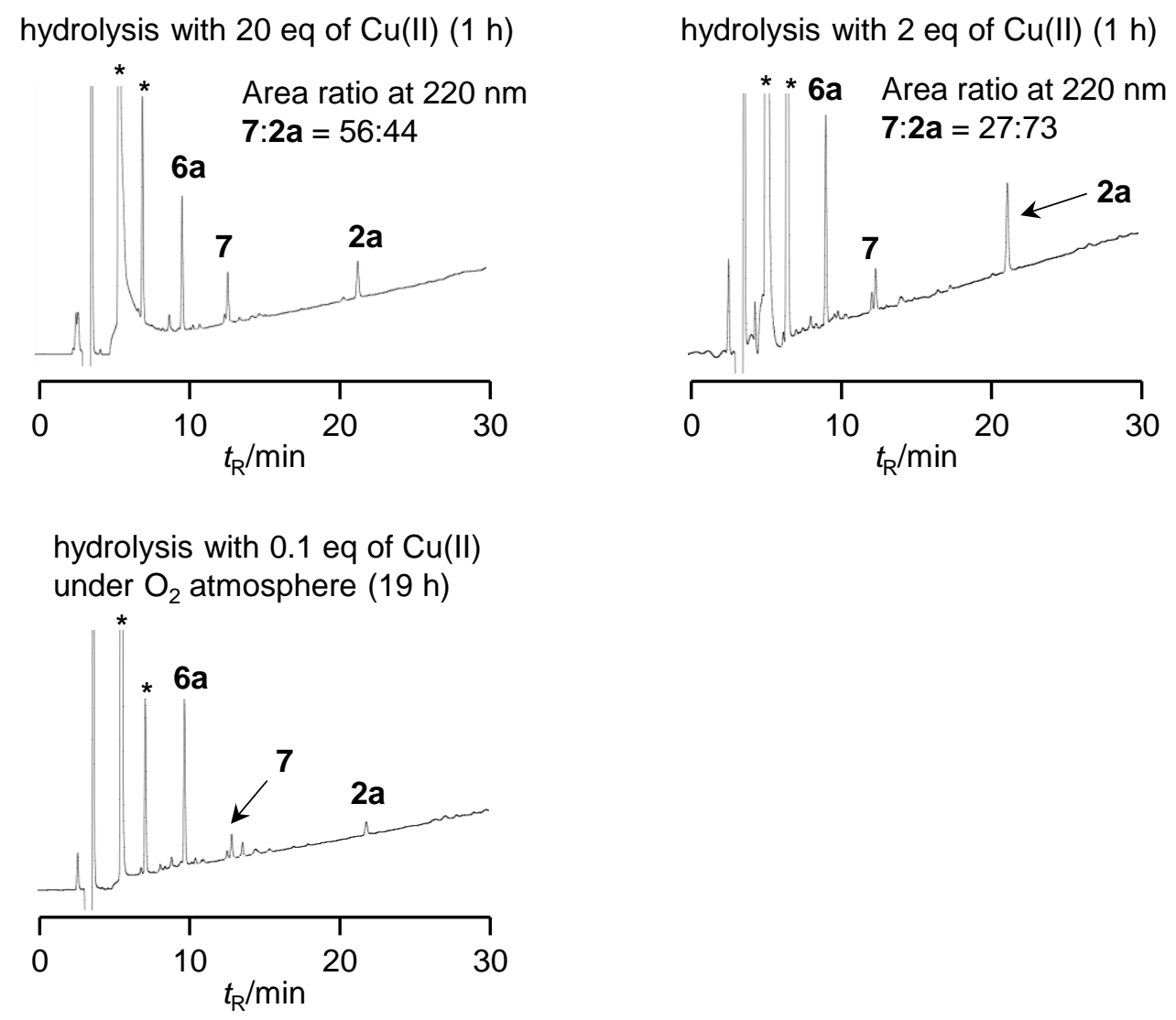

Figure S10. HPLC monitoring of Cu-mediated oxidative hydrolysis of N-alkyl hydrazide $4 \mathbf{a a}$. 
Stability of 4-methoxybenzyl alcohol under $\mathrm{Cu}$-mediated oxidation condition<smiles>COc1ccc(CO)cc1</smiles>

7

$\mathrm{Oh}$

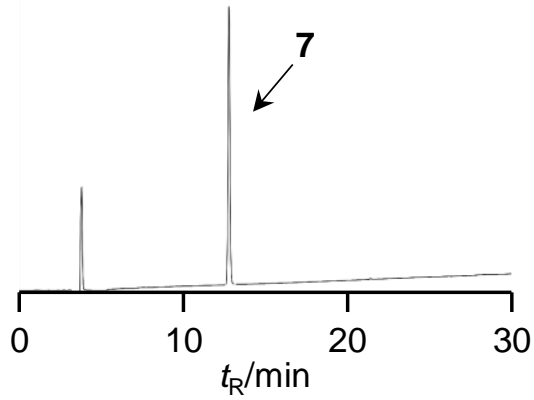

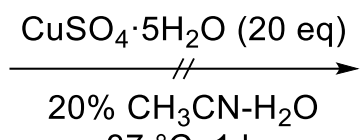

$37^{\circ} \mathrm{C}, 1 \mathrm{~h}$

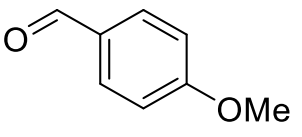

$2 a$

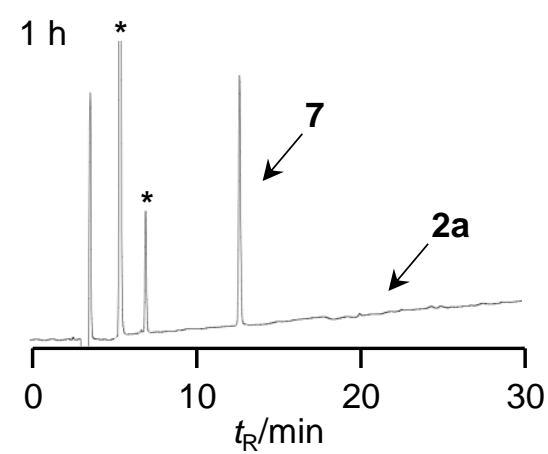

Figure S11. Reaction of 4-methoxybenzyl alcohol $(0.012 \mu \mathrm{L}, 0.1 \mu \mathrm{mol})$ under Cu-mediated oxidative hydrolysis condition $\left(\mathrm{CuSO}_{4} \cdot 5 \mathrm{H}_{2} \mathrm{O}\left(0.5 \mathrm{mg}, 2 \mu \mathrm{mol}, 20\right.\right.$ equiv) in $\left.20 \% \mathrm{CH}_{3} \mathrm{CN}-\mathrm{H}_{2} \mathrm{O}(100 \mu \mathrm{L})\right)$. HPLC analytical conditions: a Cosmosil $5 \mathrm{C}_{18}$-AR-II analytical column with the linear gradient of solvent $\mathrm{B}$ in solvent A, $15 \%$ to $50 \%$ over $30 \mathrm{~min}$. Asterisk in the HPLC charts indicates non-peptidic compounds derived from $\mathrm{CuSO}_{4}$ and DTT. 


\section{Scope of the C-terminal amino acids}

Peptide hydrazides $\mathbf{1 b}-\mathbf{h}$ (Ac-LYRAN-Xaa- $\mathrm{NHNH}_{2}$ ), which were synthesized as described above, were subjected to the reductive alkylation followed by $\mathrm{Cu}$-mediated oxidative hydrolysis to yield peptide acids $\mathbf{6 b}-\mathbf{6 h}$ using the same procedure as in the reaction with the hydrazide 1a. Analytical HPLC conditions: a Cosmosil 5C $\mathrm{C}_{18}$-AR-II analytical column with a linear gradient of solvent $\mathrm{B}$ in solvent A, $15 \%$ to $50 \%$ over $30 \mathrm{~min}$. Asterisk in the HPLC charts indicates non-peptidic compounds derived from $\mathrm{CuSO}_{4} \cdot 5 \mathrm{H}_{2} \mathrm{O}$ and DTT.

$\mathrm{Xaa}=\operatorname{Val}(\mathbf{6 b})$

Retention time $=12.0$ min, HRMS (ESI-Q-TOF) $m / z:[\mathrm{M}+\mathrm{H}]^{+}$Calcd for $\mathrm{C}_{35} \mathrm{H}_{57} \mathrm{~N}_{10} \mathrm{O}_{10} 777.4254$;

Found 777.4110.

reductive alkylation $(1 \mathrm{~h})$

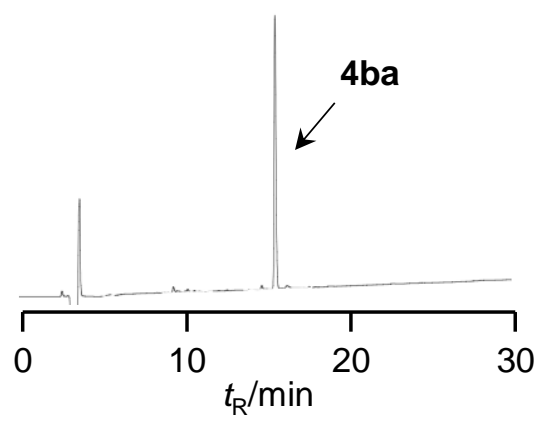

hydrolysis $(1 \mathrm{~h})$

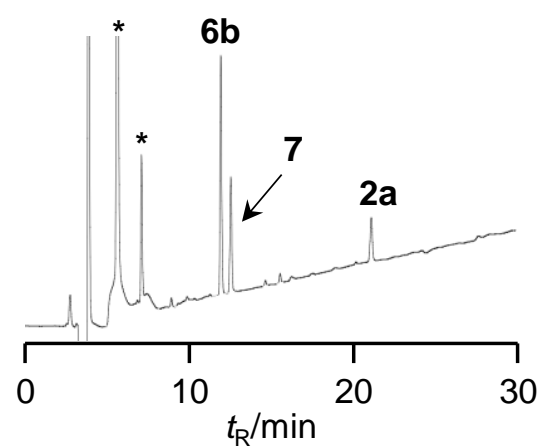

Figure S12. HPLC profiles of reductive alkylation followed by hydrolysis using hydrazide $\mathbf{1 b}$.

$\mathrm{Xaa}=$ Phe $(6 \mathbf{c})$

Retention time $=15.7 \mathrm{~min}$, HRMS (ESI-Q-TOF) $m / z:[\mathrm{M}+\mathrm{H}]^{+}$Calcd for $\mathrm{C}_{39} \mathrm{H}_{57} \mathrm{~N}_{10} \mathrm{O}_{10} 825.4254$;

Found 825.4175 .
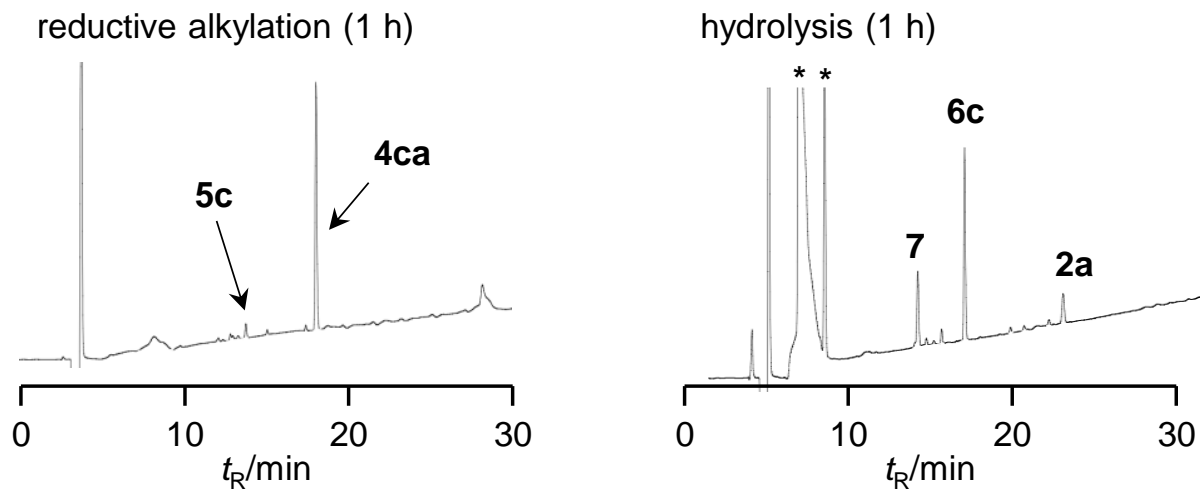

Figure S13. HPLC profiles of reductive alkylation followed by hydrolysis using hydrazide 1c. 
Xaa $=\operatorname{Ser}(\mathbf{6 d})$

Retention time $=8.7 \mathrm{~min}, \mathrm{HRMS}$ (ESI-Q-TOF) $\mathrm{m} / z$ : $[\mathrm{M}+\mathrm{H}]^{+}$Calcd for $\mathrm{C}_{33} \mathrm{H}_{53} \mathrm{~N}_{10} \mathrm{O}_{11}$ 765.3890; Found 765.3779 .
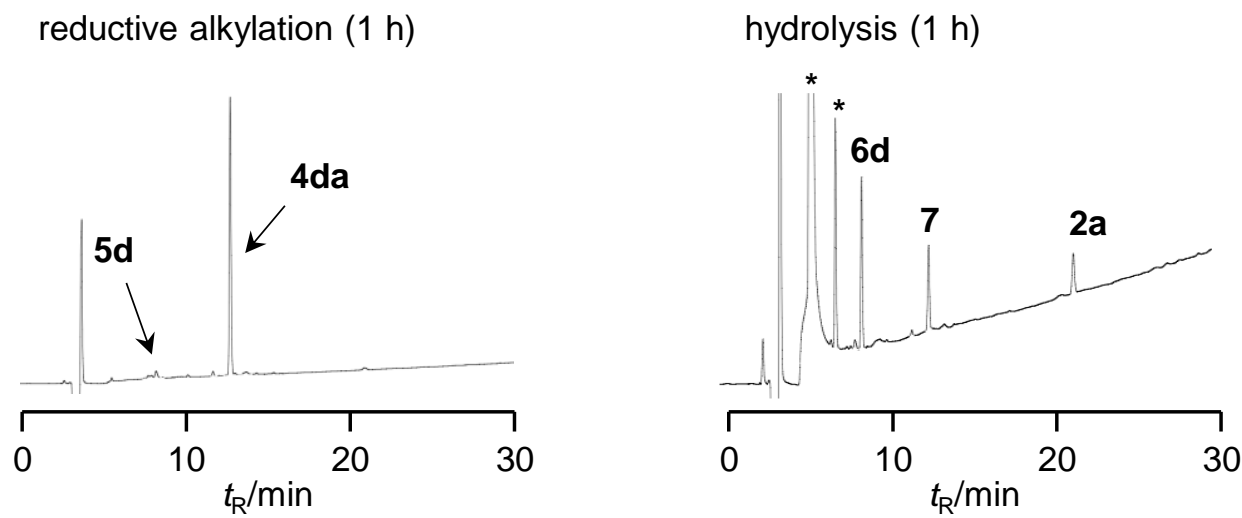

Figure S14. HPLC profiles of reductive alkylation followed by hydrolysis using hydrazide 1d.

$\mathrm{Xaa}=\operatorname{Thr}(\mathbf{6 e})$

Retention time $=9.4 \mathrm{~min}, \mathrm{HRMS}(\mathrm{ESI}-\mathrm{Q}-\mathrm{TOF}) \mathrm{m} / z$ : $[\mathrm{M}+\mathrm{H}]^{+}$Calcd for $\mathrm{C}_{34} \mathrm{H}_{55} \mathrm{~N}_{10} \mathrm{O}_{11}$ 779.4046; Found 779.4002 .
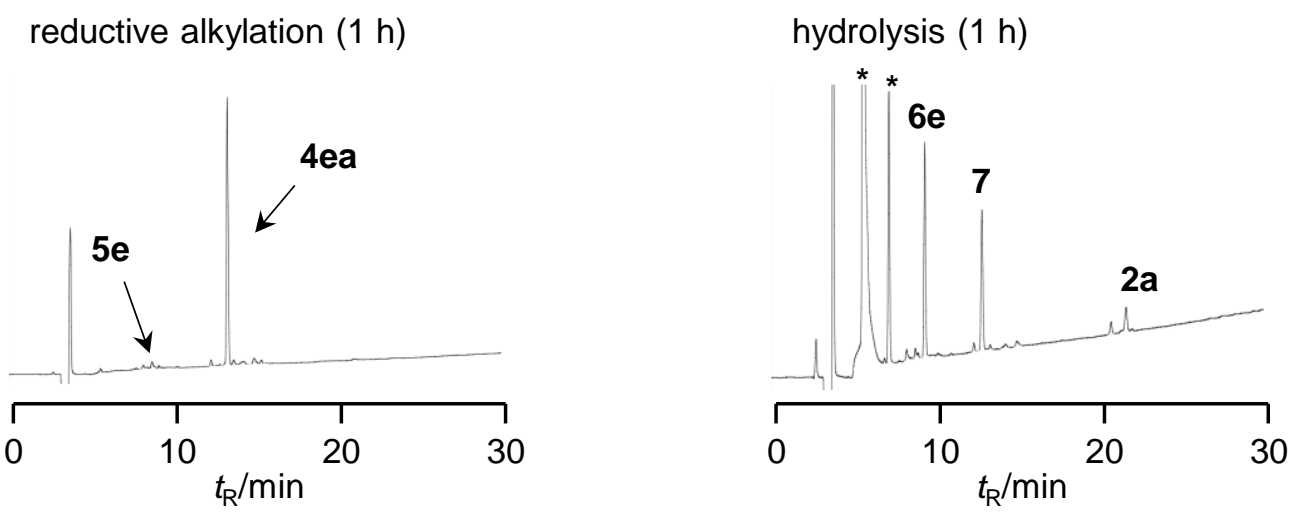

Figure S15. HPLC profiles of reductive alkylation followed by hydrolysis using hydrazide 1e. 
$\mathrm{Xaa}=$ His $(\mathbf{6} \mathbf{f})$

Retention time $=7.9 \mathrm{~min}, \mathrm{HRMS}$ (ESI-Q-TOF) $\mathrm{m} / z$ : $[\mathrm{M}+\mathrm{H}]^{+}$Calcd for $\mathrm{C}_{36} \mathrm{H}_{55} \mathrm{~N}_{12} \mathrm{O}_{10}$ 815.4159; Found 815.4119.

reductive alkylation ( $1 \mathrm{~h}$ )

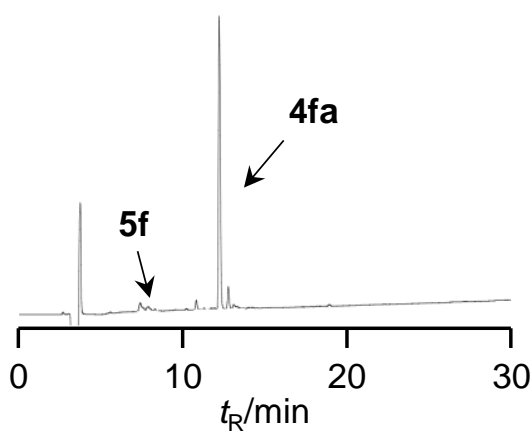

hydrolysis (1 h)

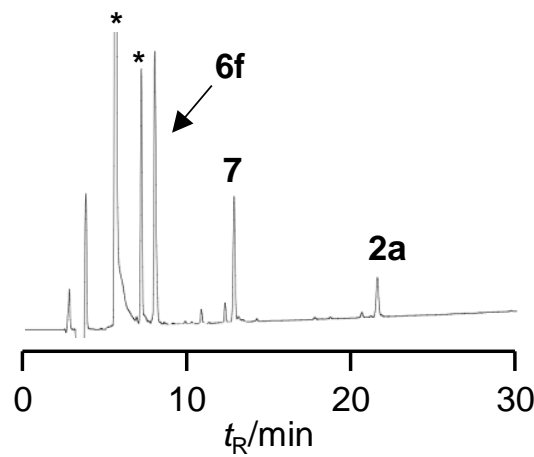

Figure S16. HPLC profiles of reductive alkylation followed by hydrolysis using hydrazide 1f.

$\mathrm{Xaa}=$ Lys $(\mathbf{6 g})$

Retention time $=7.9$ min, HRMS (ESI-Q-TOF) $m / z$ : $[\mathrm{M}+\mathrm{H}]^{+}$Calcd for $\mathrm{C}_{36} \mathrm{H}_{60} \mathrm{~N}_{11} \mathrm{O}_{10}$ 806.4519; Found 806.4498 .
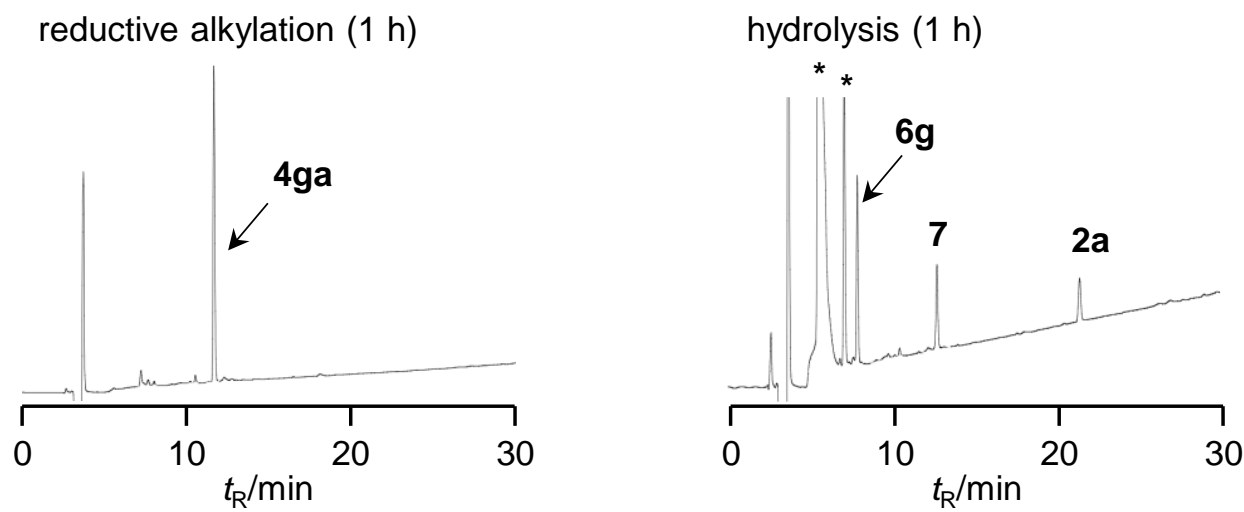

Figure S17. HPLC profiles of reductive alkylation followed by hydrolysis using hydrazide (1g). 
$\mathrm{Xaa}=\operatorname{Arg}(\mathbf{6 h})$

Retention time $=9.5 \mathrm{~min}, \mathrm{HRMS}$ (ESI-Q-TOF) $\mathrm{m} / z$ : $[\mathrm{M}+\mathrm{H}]^{+}$Calcd for $\mathrm{C}_{36} \mathrm{H}_{60} \mathrm{~N}_{13} \mathrm{O}_{10}$ 834.4581; Found 834.4489.
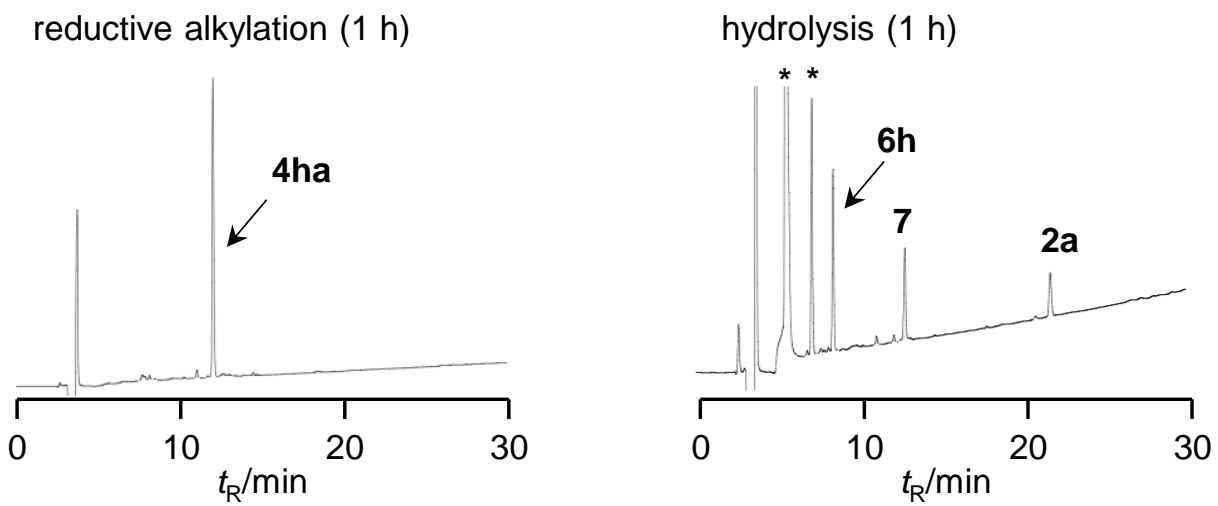

Figure S18. HPLC profiles of reductive alkylation followed by hydrolysis using hydrazide $\mathbf{1 h}$.

\section{Check of epimerization of C-terminal amino acids during the reactions}

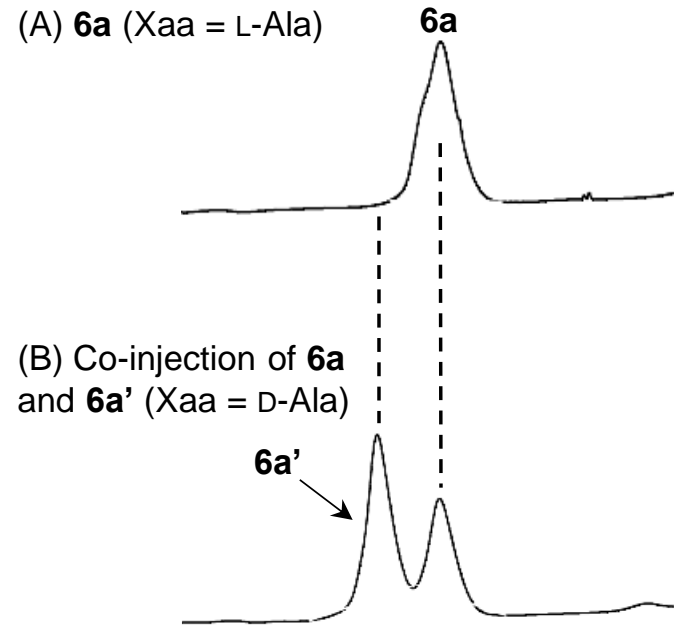

(C) $6 \mathbf{b}(\mathrm{Xaa}=\mathrm{L}-\mathrm{Val})$

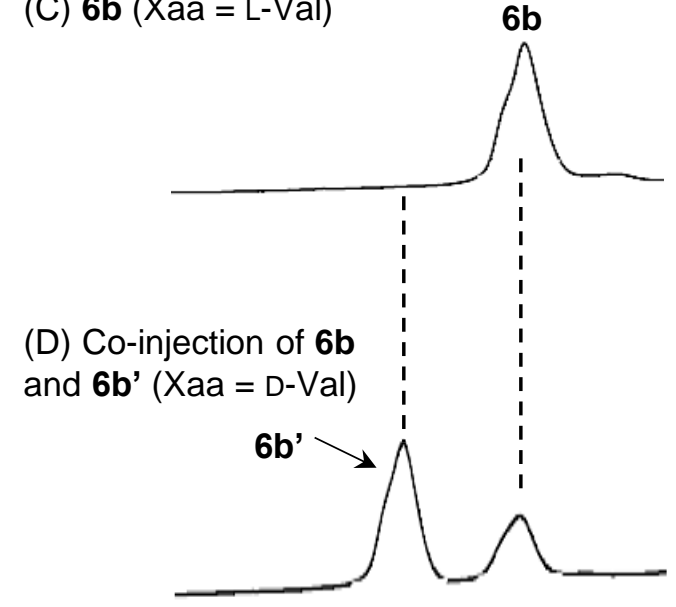

Figure S19. HPLC examination of epimerization of C-terminal amino acids during reductive alkylation followed by $\mathrm{Cu}$-mediated oxidative hydrolysis of the hydrazides. Only a critical retention time region of the HPLC charts is enlarged. D-Xaa containing diastereomer peptides 6a' and 6b' were synthesized by standard manual Fmoc SPPS protocols using Fmoc-D-Xaa-OH on HMPB ChemMatrix resin. Analytical HPLC conditions: a Cosmosil 2.5Cholester analytical column with a linear gradient of solvent in solvent A, $7 \%$ to $10 \%$ over 30 min $(\mathbf{6 a}$ : Retention time $=20.1$ min. 6a': Retention time $=$ $18.8 \mathrm{~min})$ for $\mathrm{Xaa}=$ Ala, $10 \%$ to $13 \%$ over $30 \mathrm{~min}(\mathbf{6 b}:$ Retention time $=24.6 \mathrm{~min} . \mathbf{6 b}$ ': Retention time $=22.2 \mathrm{~min}$ ) for $\mathrm{Xaa}=$ Val. 


\section{Stability of oxidation-sensitive amino acids to $\mathrm{Cu}$-mediated oxidative hydrolysis}

Peptide (H-WCLYRAM-NH ${ }_{2}, 0.1 \mathrm{mg}, 0.1 \mu \mathrm{mol}$ ) prepared by manual synthesis was dissolved in $20 \%$ $(v / v) \mathrm{CH}_{3} \mathrm{CN}-\mathrm{H}_{2} \mathrm{O}(100 \mu \mathrm{L})$ containing $\mathrm{CuSO}_{4} \cdot 5 \mathrm{H}_{2} \mathrm{O}(0.5 \mathrm{mg}, 2 \mu \mathrm{mol}, 20$ equiv). The reaction mixture was incubated at $37^{\circ} \mathrm{C}$, and the reaction was monitored by HPLC. Analytical HPLC conditions: a YMCTriart C18 analytical column with the linear gradient of solvent B in solvent A, 20\% to $50 \%$ over 30 $\min$.

Retention time $=13.8 \mathrm{~min}, \mathrm{HRMS}(\mathrm{ESI}-\mathrm{Q}-\mathrm{TOF}) \mathrm{m} / z$ : $[\mathrm{M}+2 \mathrm{H}]^{2+}$ Calcd for $\mathrm{C}_{86} \mathrm{H}_{128} \mathrm{~N}_{24} \mathrm{O}_{16} \mathrm{~S}_{4} 940.4406$; Found 940.4430 .

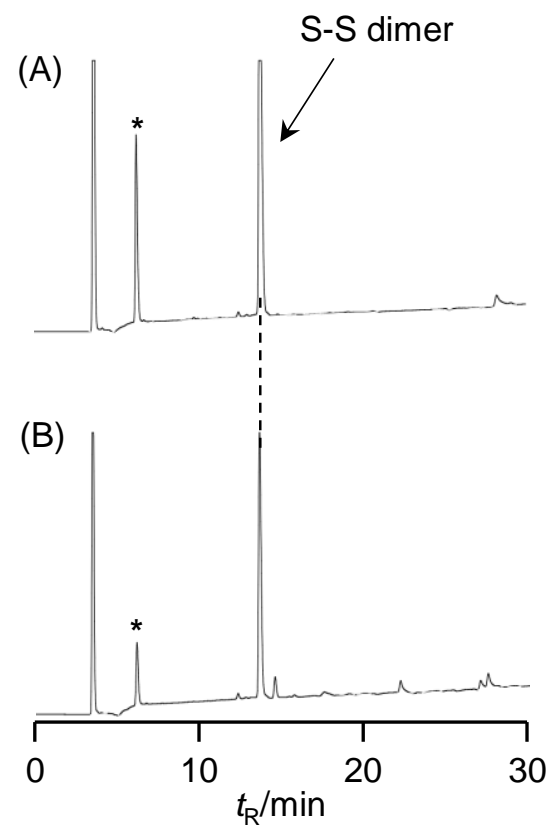

(C)

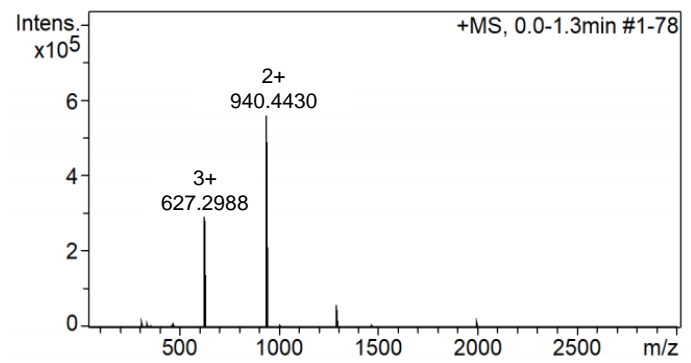

Figure S20. HPLC monitoring of stability check of oxidation-sensitive amino acids. (A) Incubation in the presence of $\mathrm{CuSO}_{4}(t=<5 \mathrm{~min})$. (B) Incubation in the presence of $\mathrm{CuSO}_{4}(t=5 \mathrm{~h})$. (C) mass spectrum of the disulfide dimer of H- WCLYRAM- $\mathrm{NH}_{2}$. Asterisk in the HPLC charts indicates nonpeptidic compounds derived from $\mathrm{CuSO}_{4}$. 


\section{Synthesis of HIV-1 protease}

\section{Syntheses of thioester 10 and 11}

For the preparation of peptide thioesters $\mathbf{1 0}$ and 11, the peptides were synthesized as peptide hydrazides and subsequently converted to the corresponding thioesters. ${ }^{\mathrm{S3}}$ On the hydrazine incorporated resin $(0.30$ $\mathrm{mmol} / \mathrm{g}$ ), the peptides were elongated using a manual protocol to give protected peptidyl resins. According to the previous synthesis, $\mathrm{Met}^{36,46}$ and $\mathrm{Cys}^{67}$ were replaced to norleucine (Nle) and 2aminobutyric acid (Abu), respectively. ${ }^{\mathrm{S} 4}$ The resulting resins were treated with TFA-TIS- $\mathrm{H}_{2} \mathrm{O}-m$-cresolthioanisole (80:2.5:2.5:5:10, $(v / v), 50 \mu \mathrm{L} / 1 \mathrm{mg}$ resin) at rt. After $2 \mathrm{~h}, 10 \%(w / w) \mathrm{NaNO}_{2}$ aq $(1 \mu \mathrm{L} / 1 \mathrm{mg}$ resin) was added to the mixture at $-10{ }^{\circ} \mathrm{C}$ and the solution was incubated at the same temperature for $30 \mathrm{~min}$. To the reaction mixture was added cold $\mathrm{Et}_{2} \mathrm{O}$ giving a precipitate. The formed precipitate was collected by centrifugation and thoroughly washed with $\mathrm{Et}_{2} \mathrm{O}$ to afford crude peptide azides. The crude product was dissolved into 5\% $(w / w)$ MESNa in buffer $(6 \mathrm{M} \mathrm{Gn} \cdot \mathrm{HCl}, 0.2 \mathrm{M}$ Na phosphate, $\mathrm{pH} 7.3,10$ $\mu \mathrm{L} / 1 \mathrm{mg}$ resin). After $30 \mathrm{~min}$ at $\mathrm{rt}$, the solution was acidified to $\mathrm{pH} 2-3$ by the addition of TFA and purified by preparative HPLC. Analytical HPLC conditions: Cosmosil 5C $\mathrm{C}_{8}$-AR-300 analytical column with a linear gradient of solvent B in solvent A, $10 \%$ to $60 \%$ over 30 min.

Peptide thioester (HIV-1 protease segment $\left.\left(\mathrm{Thz}^{28}-\mathrm{Lys}^{70}\right)\right) \mathbf{1 0}$

Retention time $=19.5 \mathrm{~min}$, HRMS (ESI-Q-TOF) $m / z$ : $[\mathrm{M}+3 \mathrm{H}]^{3+}$ Calcd for $\mathrm{C}_{222} \mathrm{H}_{359} \mathrm{~N}_{58} \mathrm{O}_{62} \mathrm{~S}_{3}$ 1641.8623; Found 1642.1837. Preparative HPLC conditions: Cosmosil 5C 8 -AR-300 preparative column with a linear gradient of solvent B in solvent A over $60 \mathrm{~min}: 25 \%$ to $35 \%$ (86 mg from $488 \mathrm{mg}$ of protected resin $(31 \%))$.

(A) crude material of 10

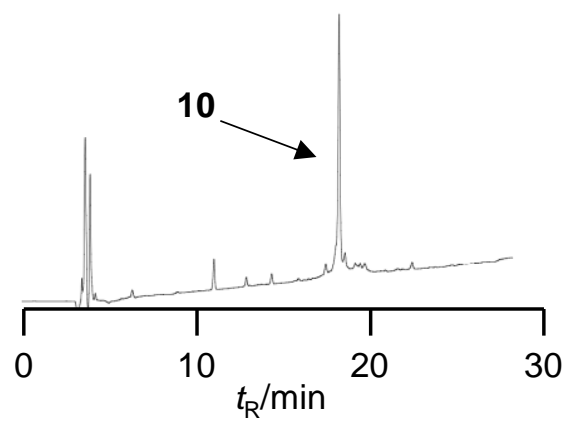

(B) purified 10

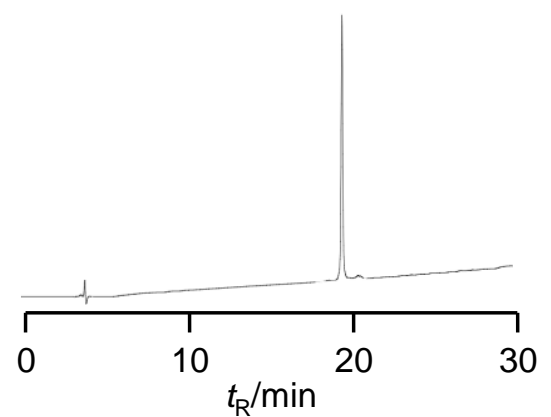

Figure S21. HPLC profile of peptide thioester 10. (A) crude material of $\mathbf{1 0}$ and (B) purified $\mathbf{1 0 .}$ 
Peptide thioester (HIV-1 protease segment $\left.\left(\operatorname{Pro}^{1}-\mathrm{Gly}^{27}\right)\right) \mathbf{1 1}$

Retention time $=19.5 \mathrm{~min}$, HRMS (ESI-Q-TOF) $m / z$ : $[\mathrm{M}+3 \mathrm{H}]^{3+}$ Calcd for $\mathrm{C}_{140} \mathrm{H}_{241} \mathrm{~N}_{38} \mathrm{O}_{39} \mathrm{~S}_{2}$ 1047.5823; Found 1047.5784. Preparative HPLC conditions: Cosmosil 5C 8 -AR-300 preparative column with a linear gradient of solvent B in solvent A over $60 \mathrm{~min}$ : 25\% to 35\% (85 mg from $409 \mathrm{mg}$ of protected resin $(29 \%))$.

(A) crude material of $\mathbf{1 1}$

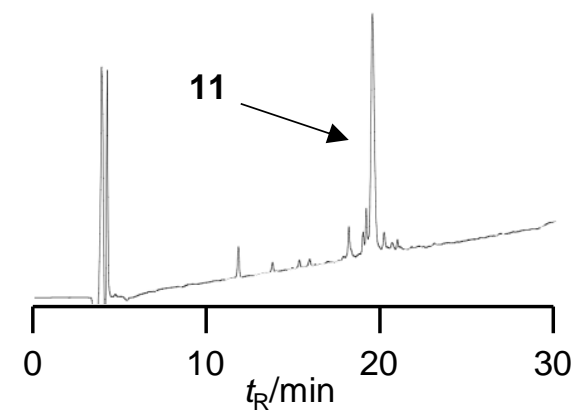

(B) purified 11

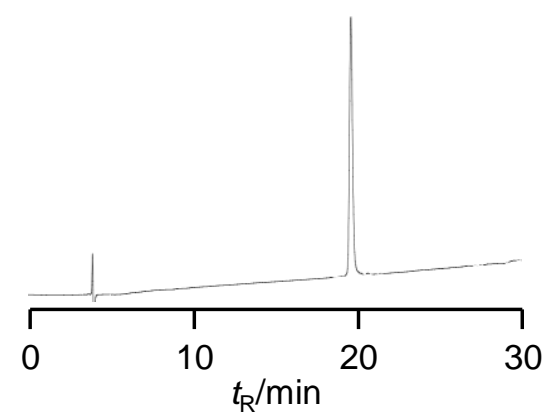

Figure S22. HPLC profile of peptide thioester 11. (A) crude material of $\mathbf{1 1}$ and (B) purified $\mathbf{1 1 .}$

\section{Synthesis of solubilizing tag 12}

The Lys 10-mer was elongated on a Rink Amide ChemMatrix resin (429 mg, $0.20 \mathrm{mmol}, 0.47 \mathrm{mmol} / \mathrm{g}$ ) using automated Fmoc SPPS procedure as described in general methods. The resulting resin was treated with TFA- $\mathrm{H}_{2} \mathrm{O}(95: 5(\mathrm{v} / \mathrm{v}), 50 \mu \mathrm{L} / 1 \mathrm{mg}$ resin) at $\mathrm{rt}$ for $2 \mathrm{~h}$. The resin in the reaction mixture was filtrated off and then the filtrate was concentrated by blowing air. The crude peptides were precipitated by the addition of cooled $\mathrm{Et}_{2} \mathrm{O}$. The formed precipitate was washed with $\mathrm{Et}_{2} \mathrm{O}$ successively. The crude peptide was purified by preparative HPLC.

\section{Solubilizing tag 12}

Analytical HPLC conditions: Cosmosil 5C $\mathrm{C}_{8}$-AR-300 analytical column with a liner gradient of solvent $\mathrm{B}$ in solvent A, $5 \%$ to $35 \%$ over $30 \mathrm{~min}$, retention time $=11.5 \mathrm{~min}$, HRMS (ESI-Q-TOF) $\mathrm{m} / \mathrm{z}$ : $[\mathrm{M}+$ $2 \mathrm{H}]^{2+}$ Calcd for $\mathrm{C}_{69} \mathrm{H}_{133} \mathrm{~N}_{21} \mathrm{O}_{13}$ 732.0191; Found 731.0070.

Preparative HPLC conditions: Cosmosil 5 $\mathrm{C}_{8}-\mathrm{AR}-300$ preparative column with a linear gradient of solvent B in solvent A over $60 \mathrm{~min}$ : 5\% to 20\% (91 mg from $703 \mathrm{mg}$ of protected resin (19\%)).

(A) crude material of $\mathbf{1 2}$

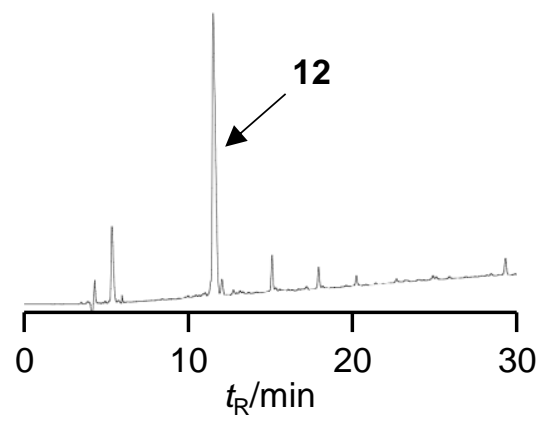

(B) purified 12

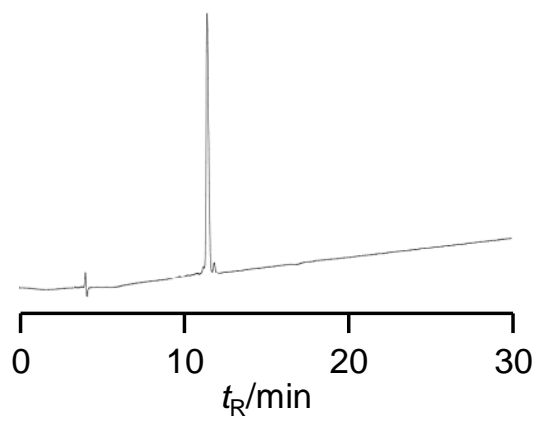


Figure S23. HPLC profile of solubilizing tag 12. (A) crude material of 12 and (B) purified 12.

\section{Synthesis of tag-introduced peptide 13}

Peptide 9 was elongated on a hydrazine-incorporated resin $(154.4 \mathrm{mg}, 0.05 \mathrm{mmol}, 0.296 \mathrm{mmol} / \mathrm{g})$ using automated Fmoc SPPS procedure as described in general methods, and Fmoc-Leu-

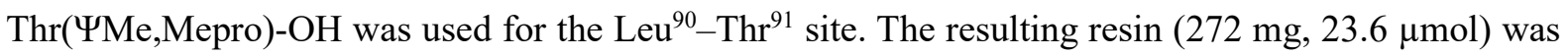
treated with TFA-TIS- $\mathrm{H}_{2} \mathrm{O}(95: 2.5: 2.5(v / v), 50 \mu \mathrm{L} / 1 \mathrm{mg}$ resin) at $\mathrm{rt}$ for $2 \mathrm{~h}$. After filtration of the resin in the reaction mixture, the filtrate was removed by blowing air and the addition of cooled $\mathrm{Et}_{2} \mathrm{O}$ to the residue afforded a precipitation. The formed precipitate was washed thoroughly with $\mathrm{Et}_{2} \mathrm{O}$. The crude material of peptide hydrazide 9 was dissolved in 50\% AcOH-HFIP $(11.8 \mathrm{~mL})$ and used without further purification for the reductive alkylation to introduce a solubilizing tag.

To the solution of the crude material of $9(23.6 \mu \mathrm{mol}, 2 \mathrm{mM}, 11.8 \mathrm{~mL})$ was added the solubilizing tag 12 (92 mg, $35.4 \mu \mathrm{mol}, 1.5$ equiv) and the mixture was incubated at $37^{\circ} \mathrm{C}$. After $3 \mathrm{~h}$ reaction, pic- $\mathrm{BH}_{3}$ (51 mg, $38.9 \mu \mathrm{mol}, 20$ equiv) was added and the resulting mixture was incubated for additional $10 \mathrm{~min}$ at $37^{\circ} \mathrm{C}$. After the addition of TFA $(200 \mu \mathrm{L})$ to the solution, the solvent was removed by blowing air, affording the crude peptide of 13. The residue was dissolved in $\mathrm{H}_{2} \mathrm{O}-\mathrm{CH}_{3} \mathrm{CN}(3: 1(v / v), 5 \mathrm{~mL})$ and purified by preparative HPLC (Cosmosil 5 $\mathrm{C}_{8}$-AR-300 preparative column a linear gradient of solvent B in solvent over $60 \mathrm{~min}$ : $34 \%$ to $44 \%$ ) to give the purified peptide 13 ( $47.7 \mathrm{mg}, 8.2 \mu \mathrm{mol}, 35 \%$ isolated yield). Analytical HPLC conditions: Cosmosil 5C 8 -AR-300 analytical column with a liner gradient of solvent $\mathrm{B}$ in solvent $\mathrm{A}, 10 \%$ to $60 \%$ over $30 \mathrm{~min}$.

\section{Peptide hydrazide 9}

Retention time $=24.2 \mathrm{~min}, \mathrm{HRMS}\left(\mathrm{ESI}-\mathrm{Q}-\mathrm{TOF}\right.$ ) $m / z$ : $[\mathrm{M}+3 \mathrm{H}]^{3+} \mathrm{Calcd}$ for $\mathrm{C}_{135} \mathrm{H}_{233} \mathrm{~N}_{38} \mathrm{O}_{37} \mathrm{~S} 1003.5741$; Found 1003.5718.

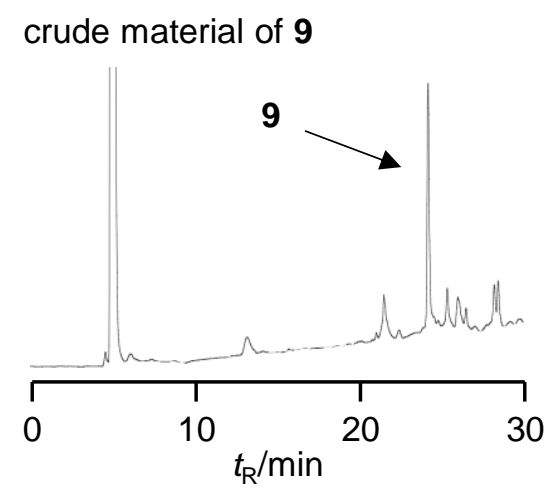

Figure S24. HPLC profile of crude material of peptide hydrazide 9. 
Tag-introduced peptide $\mathbf{1 3}$

Retention time $=23.1 \mathrm{~min}, \mathrm{HRMS}\left(\mathrm{ESI}-\mathrm{Q}-\mathrm{TOF}\right.$ ) $\mathrm{m} / z:[\mathrm{M}+4 \mathrm{H}]^{4+}$ Calcd for $\mathrm{C}_{204} \mathrm{H}_{363} \mathrm{~N}_{59} \mathrm{O}_{49} \mathrm{~S} 1113.9356$; Found 1113.9357.
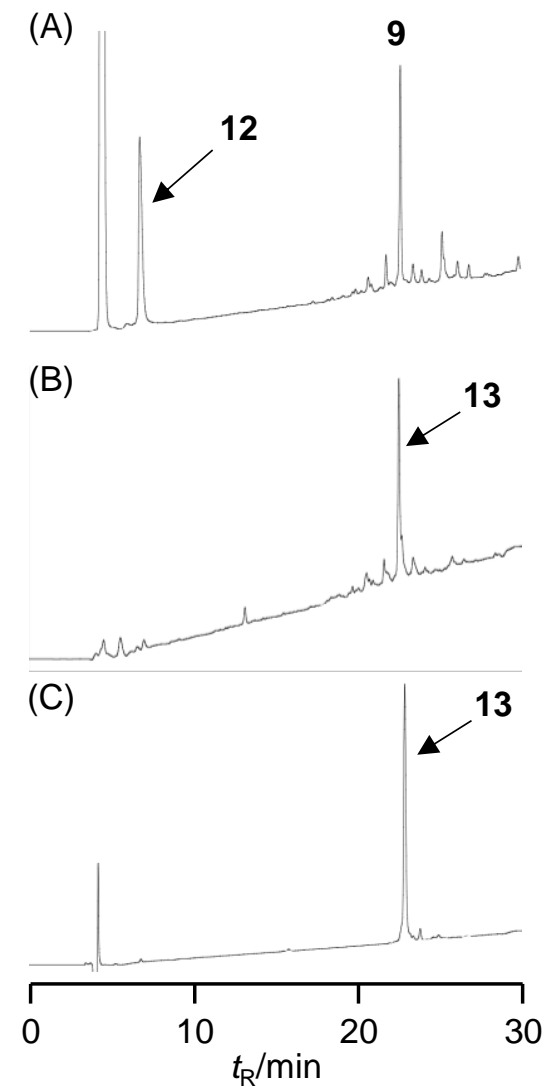

Figure S25. HPLC monitoring of introduction of solubilizing tag. (A) Condensation ( $t=<5 \mathrm{~min}$ ). (B) Reductive $N$-alkylation ( $t=10 \mathrm{~min}$ ). (C) Purified peptide 13. 


\section{One-pot synthesis of Fr1-Fr2-Fr3-tag 14}

The N-Cys peptide 13 (47.7 mg, $8.2 \mu$ mol, 1.0 equiv) and peptide thioester $\mathbf{1 0}$ (56.8 mg, $9.8 \mu \mathrm{mol}, 1.2$ equiv) were dissolved in $8.2 \mathrm{~mL}$ of ligation buffer ( $6 \mathrm{M} \mathrm{Gn} \cdot \mathrm{HCl}, 0.2 \mathrm{M}$ Na phosphate, $100 \mathrm{mM}$ MPAA, $50 \mathrm{mM}$ TCEP$\cdot \mathrm{HCl}, \mathrm{pH} 7.1$ ), and the solution was incubated at $37^{\circ} \mathrm{C}$. The reaction, monitored by HPLC was completed within $3 \mathrm{~h}$. To the reaction mixture was added $\mathrm{CH}_{3} \mathrm{ONH}_{2} \cdot \mathrm{HCl}(134 \mathrm{mg}$, final concentration $0.2 \mathrm{M}$ ) and incubated at $37^{\circ} \mathrm{C}$ for additional $12 \mathrm{~h}$. After confirming the completion of the Thz deprotection by HPLC analysis, $\mathrm{pH}$ of the reaction mixture was adjusted to $\sim 7$ by the addition of 1 $\mathrm{M} \mathrm{NaOH}$ aq (approximately $990 \mu \mathrm{L}$ ). Then peptide thioester 11 (73.9 mg, $20.5 \mu \mathrm{mol}, 2.5$ equiv) was added to the reaction mixture. The second NCL was completed within $10 \mathrm{~h}$ and the crude peptide was purified by preparative HPLC (Cosmosil 5 $\mathrm{C}_{8}$-AR-300 preparative column with a linear gradient of solvent B in solvent A, $34 \%$ to $44 \%$ over $60 \mathrm{~min}$ ) to give the purified peptide 14 (39.4 $\mathrm{mg}, 2.68 \mu \mathrm{mol}$, $33 \%$ isolated yield).

Analytical HPLC conditions: Cosmosil 5C 8 -AR-300 analytical column with a linear gradient of solvent B in solvent A, $20 \%$ to $50 \%$ over $30 \mathrm{~min}$, retention time $=24.6 \mathrm{~min}$, HRMS (ESI-Q-TOF) $\mathrm{m} / \mathrm{z}$ : $[\mathrm{M}+$ $6 \mathrm{H}]^{6+}$ Calcd for $\mathrm{C}_{561} \mathrm{H}_{947} \mathrm{~N}_{155} \mathrm{O}_{144} \mathrm{~S}_{2} 2037.3492$; Found 2037.6452.
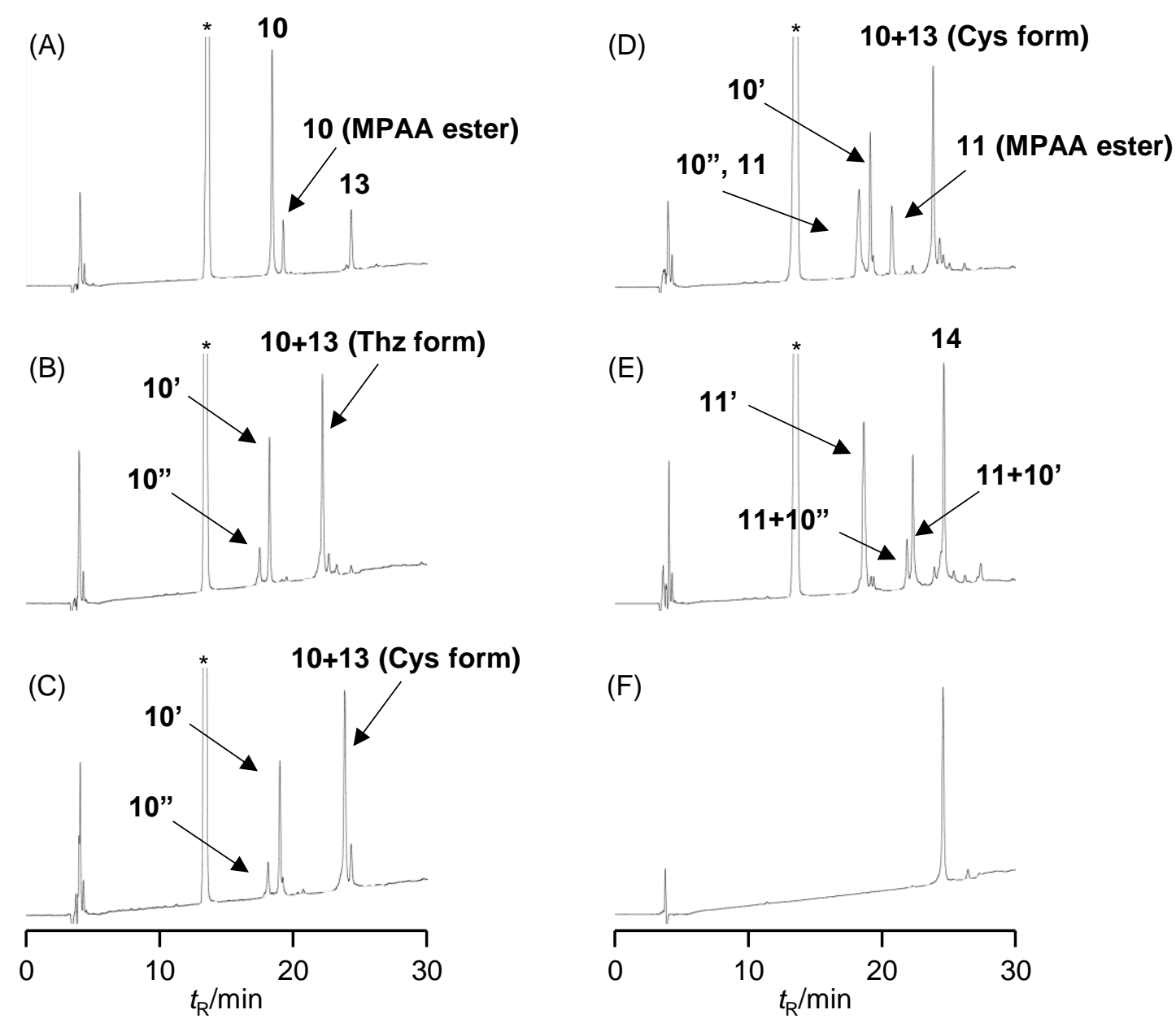

Figure S26. HPLC monitoring of NCL between 10, 11, and 13. (A) $1 \mathrm{st} \mathrm{NCL}(t=<5 \mathrm{~min})$. (B) $1 \mathrm{st} \mathrm{NCL}$ ( $t=3 \mathrm{~h}$ ). (C) Thz deprotection ( $t=12 \mathrm{~h}$ ). (D) 2nd NCL ( $t=<5 \mathrm{~min})$. (E) 2nd NCL ( $t=10 \mathrm{~h}$ ). (F) Peptide $\mathbf{1 4}$ after purification. *MPAA. 


\section{Desulfurization}

Peptide 14 (7.4 mg, $0.50 \mu \mathrm{mol})$ was dissolved in desulfurization buffer (6 M Gn·HCl, $0.1 \mathrm{M}$ HEPES, $500 \mathrm{mM}$ TCEP $\cdot \mathrm{HCl}, 200 \mathrm{mM}$ MESNa, $\mathrm{pH} 7.5,7.18 \mathrm{~mL})$, and to the solution was added VA-044 (18.1 $\mathrm{mg}, 50 \mu \mathrm{mol}, 100$ equiv) as a solid. Then the mixture was incubated at $37{ }^{\circ} \mathrm{C}$. The reaction was monitored by HPLC and two Cys residues were converted to the Ala residue within $13 \mathrm{~h}$. The crude peptide was purified by preparative HPLC (Cosmosil 5C 8 -AR-300 preparative column with a linear gradient of solvent B in solvent A, 34\% to $44 \%$ over $60 \mathrm{~min})$ to give the purified peptide $15(5.2 \mathrm{mg}$, $0.35 \mu \mathrm{mol}, 70 \%$ isolated yield).

Analytical HPLC conditions: Cosmosil 5C 8 -AR-300 analytical column with a linear gradient of solvent B in solvent A, $20 \%$ to $50 \%$ over $30 \mathrm{~min}$, retention time $=24.6 \mathrm{~min}$, HRMS (ESI-Q-TOF) $\mathrm{m} / \mathrm{z}$ : [M + $6 \mathrm{H}]^{6+}$ Calcd for $\mathrm{C}_{561} \mathrm{H}_{947} \mathrm{~N}_{155} \mathrm{O}_{144}$ 2026.6919; Found 2027.0560.
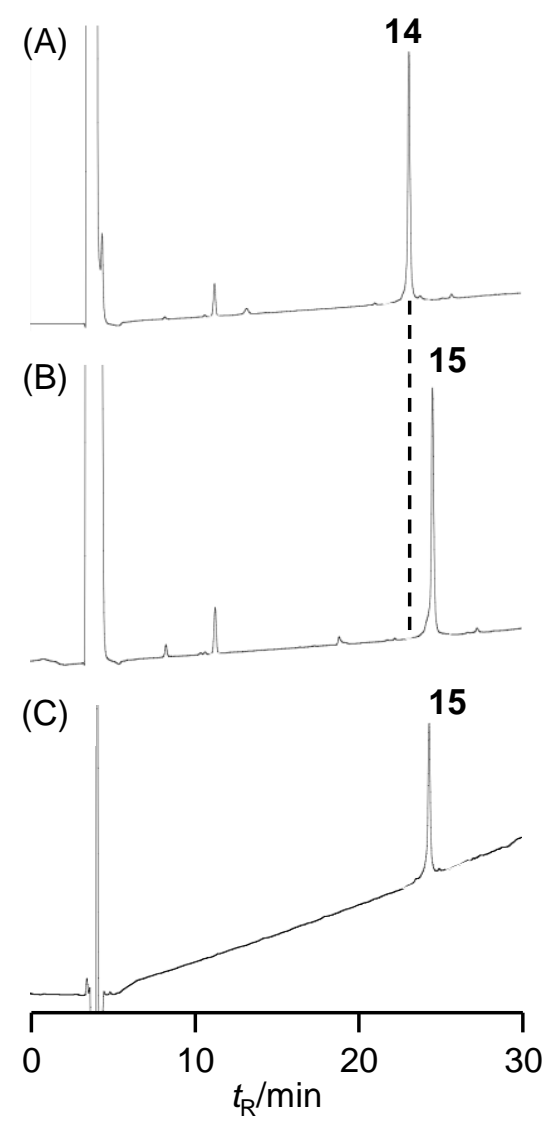

Figure S27. HPLC monitoring of desulfurization. (A) Desulfurization ( $t=<5 \mathrm{~min}$ ). (B) Desulfurization $(t=13$ h). (C) Peptide 15 after purification. 


\section{Removal of solubilizing tag followed by folding}

Peptide 15 (1.0 mg, $0.068 \mu \mathrm{mol})$ was dissolved in $20 \% \mathrm{CH}_{3} \mathrm{CN}-\mathrm{H}_{2} \mathrm{O}(100 \mu \mathrm{L})$ containing $\mathrm{CuSO}_{4} \cdot 5 \mathrm{H}_{2} \mathrm{O}$ ( $0.34 \mathrm{mg}, 1.4 \mu \mathrm{mol}, 20$ equiv), and the solution was incubated at $37^{\circ} \mathrm{C}$. The reaction was monitored by HPLC and essentially completed within $1 \mathrm{~h}$. Then the entire sequence of HIV-1 protease $\mathbf{1 6}$ was folded by a three-step dialysis procedure against sodium acetate buffer ( $\mathrm{pH}$ 5.6) by use a $3500 \mathrm{MW}$ cutoff membrane as previously described. ${ }^{\mathrm{S} 4}$ In the first step, the reaction mixture of $\mathrm{Cu}$-mediated oxidative hydrolysis without any purifications was dialyzed in $200 \mathrm{~mL}$ of $50 \mathrm{mM}$ sodium acetate buffer (pH 5.6) for $3 \mathrm{~h}$ at rt. The second step was against $200 \mathrm{~mL}$ of $25 \mathrm{mM}$ sodium acetate buffer ( $\mathrm{pH} \mathrm{5.6)} \mathrm{for} 2 \mathrm{~h}$ at rt. The third step was against $200 \mathrm{~mL}$ of $10 \mathrm{mM}$ sodium acetate buffer (pH 5.6) overnight at $4{ }^{\circ} \mathrm{C}$. The final concentration of the folded HIV-protease was determined by UV absorbance at $280 \mathrm{~nm}$ with a calculated dimer extinction coefficient $\left(25,120 \mathrm{M}^{-1} \mathrm{~cm}^{-1}, 51.7 \mu \mathrm{M}, 525 \mu \mathrm{L}, 80 \%\right)$.

Analytical HPLC conditions: Cosmosil 5C $\mathrm{C}_{8}$-AR-300 analytical column with a linear gradient of solvent B in solvent A, 20\% to $50 \%$ over $30 \mathrm{~min}$, retention time $=27.3 \mathrm{~min}$, HRMS (ESI-Q-TOF) $\mathrm{m} / \mathrm{z}$ : $\mathrm{M}+$ $\mathrm{H}]^{+}$Calcd for $\mathrm{C}_{492} \mathrm{H}_{811} \mathrm{~N}_{132} \mathrm{O}_{133}$ (average isotopes) 10703.6905; Found 10704.2895.

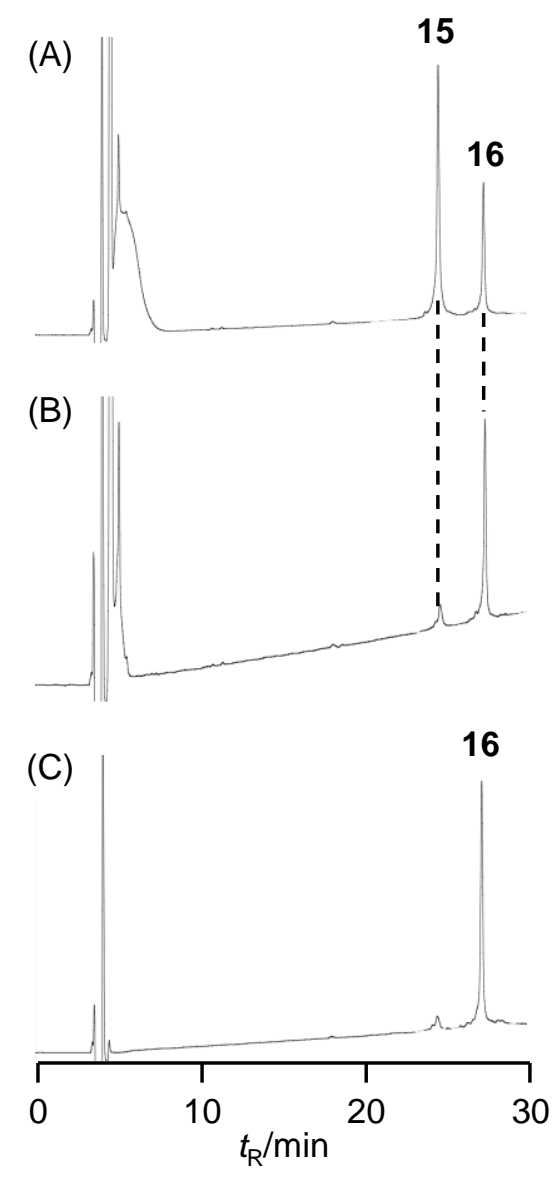

Figure S28. HPLC monitoring of removal of solubilizing tag followed by folding. (A) Removal of solubilizing tag $(t=<5 \mathrm{~min})$. (B) Removal of solubilizing tag $(t=1 \mathrm{~h})$. (C) After a three-step dialysis. 


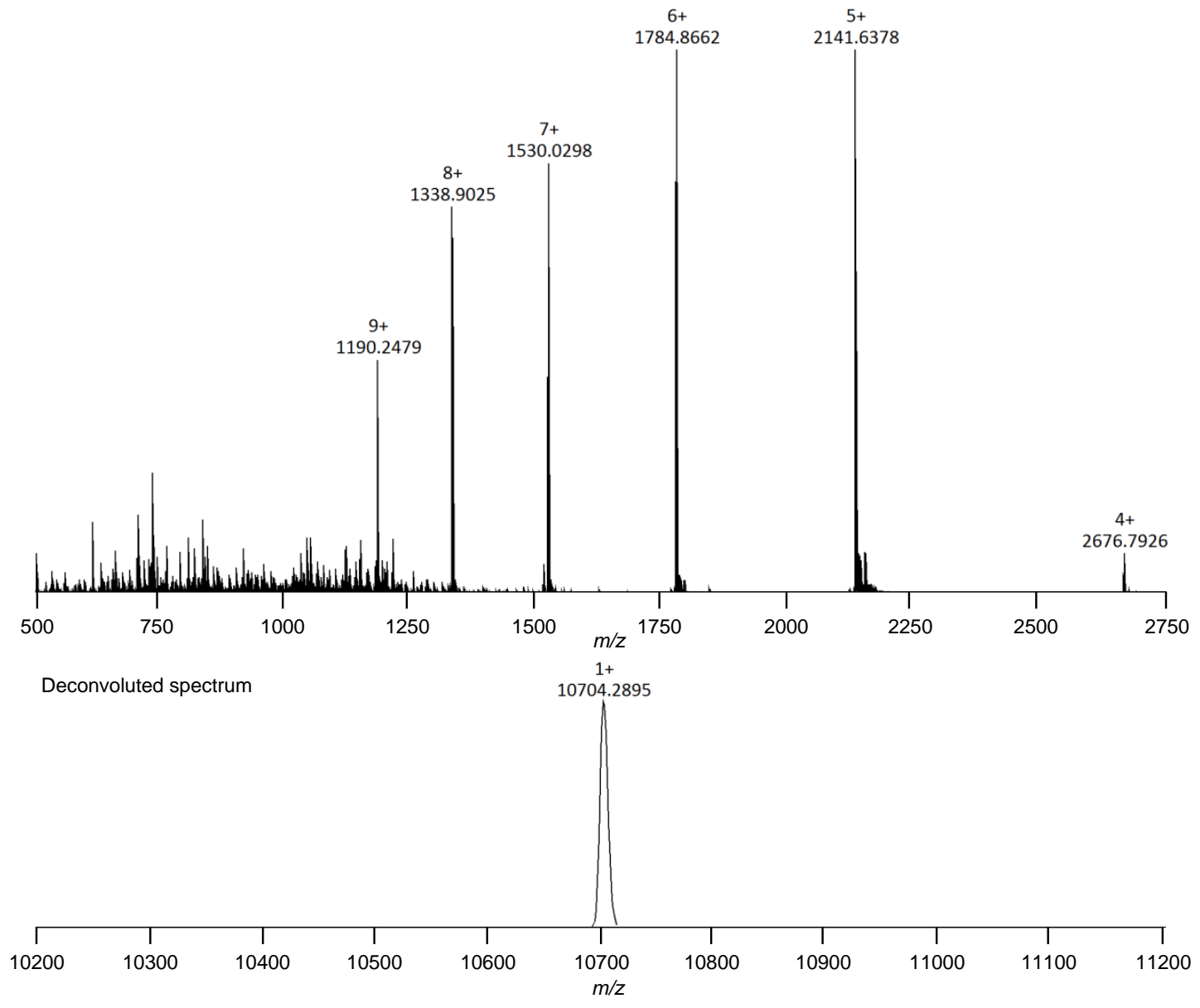

Figure S29. Mass spectrum of synthesized HIV-1 protease. 


\section{Quantitation of $\mathrm{Cu}$ after dialysis}

The Concentration of $\mathrm{Cu}$ in the solution of the synthesized HIV-1 protease after dialysis was examined using ICP-OES. The protein solution $(400 \mu \mathrm{L})$ was diluted to $4.00 \mathrm{~mL}$ by $5 \%$ nitric acid aq, and the concentration of $\mathrm{Cu}$ was determined $0.11 \mathrm{ppm}$. Thus, the $\mathrm{Cu}$ concentration in the protein sample was calculated as $1.1 \mathrm{ppm}$.

\section{Assay for protease activity of synthesized HIV-1 protease Synthesis of substrate peptide S1 (H-GHKARVLAEAMSQVTNSATIMMQRGNP- RNQRK-OH)}

For the preparation of substrate peptide S1, an HMPB ChemMatrix resin $(0.44 \mathrm{mmol} / \mathrm{g}, 0.137 \mathrm{~g}, 0.05$ $\mathrm{mmol}$ ) was used. On this resin, the peptide was elongated using a manual protocol to give a protected peptidyl resin. The resulting resin was treated with TFA-TIS- $\mathrm{H}_{2} \mathrm{O}(95: 2.5: 2.5,(v / v), 50 \mu \mathrm{L} / 1 \mathrm{mg}$ resin) at $\mathrm{rt}$ for $2 \mathrm{~h}$. Then the resin in the reaction mixture was filtrated off. To the resulting filtrate was added cooled $\mathrm{Et}_{2} \mathrm{O}$ to give a precipitate. The formed precipitate was collected by centrifugation and thoroughly washed with $\mathrm{Et}_{2} \mathrm{O}$ to afford crude peptide. The peptide was purified by preparative HPLC (Cosmosil $5 \mathrm{C}_{8}$-AR-300 preparative column with a linear gradient of solvent B in solvent A over 60 min: $30 \%$ to 40\% (6.3 mg from $107 \mathrm{mg}$ of protected resin, 15\% isolated yield)).

Analytical HPLC conditions: Cosmosil 5C $\mathrm{C}_{8}$-AR-300 analytical column with a linear gradient of solvent $\mathrm{B}$ in solvent A, $10 \%$ to $60 \%$ over $30 \mathrm{~min}$, retention time $=17.7 \mathrm{~min}$, HRMS (ESI-Q-TOF) $\mathrm{m} / \mathrm{z}$ : $[\mathrm{M}+$ $3 \mathrm{H}]^{3+}$ Calcd for $\mathrm{C}_{146} \mathrm{H}_{257} \mathrm{~N}_{54} \mathrm{O}_{45} \mathrm{~S}_{3}$ 1195.0578 Found 1194.9366.
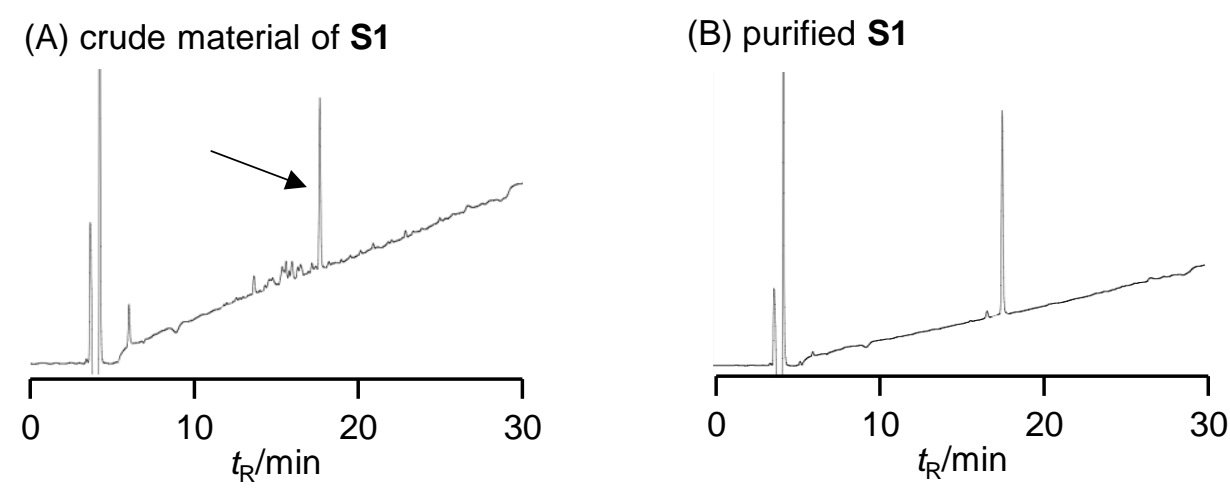

Figure S30. HPLC profile of peptide S1. (A) crude material of S1 and (B) purified S1.

\section{Evaluation of protease activity of synthesized protein}

The substrate peptide $\mathbf{S 1}$ (1.3 mg) was dissolved in $50 \mathrm{mM}$ acetate buffer ( $\mathrm{pH} 5.6,577 \mu \mathrm{L}, 0.5 \mathrm{mM}$ ). To the buffer containing $\mathbf{S 1}(30 \mu \mathrm{L})$ were added $5 \mu \mathrm{L}$ of a solution of the synthesized HIV-1 protease $(26 \mu \mathrm{M})$ and $1.5 \mu \mathrm{L}$ of a solution of ritonavir in DMSO $(3.4 \mathrm{mM})$. The resulting mixture was incubated at $37^{\circ} \mathrm{C}$ for $10 \mathrm{~h}$ and then analyzed directly by ESI-Q-TOF MS. 


\begin{tabular}{|c|c|c|c|c|c|}
\hline $\begin{array}{c}\text { GHKARVL }- \\
\mathbf{S 1 - a}\end{array}$ & $\begin{array}{l}\text { SQVTN } \\
\text { S1-b }\end{array}$ & $\begin{array}{l}\text { GNPRNQRK } \\
\text { S1-c }\end{array}$ & $\begin{array}{c}\text { Substrate } \\
\text { S1 }\end{array}$ & $\begin{array}{l}\text { Synthesized } \\
\text { enzyme }\end{array}$ & $\begin{array}{l}\text { Inhibitor } \\
\text { (ritonavir) }\end{array}$ \\
\hline
\end{tabular}

(A)

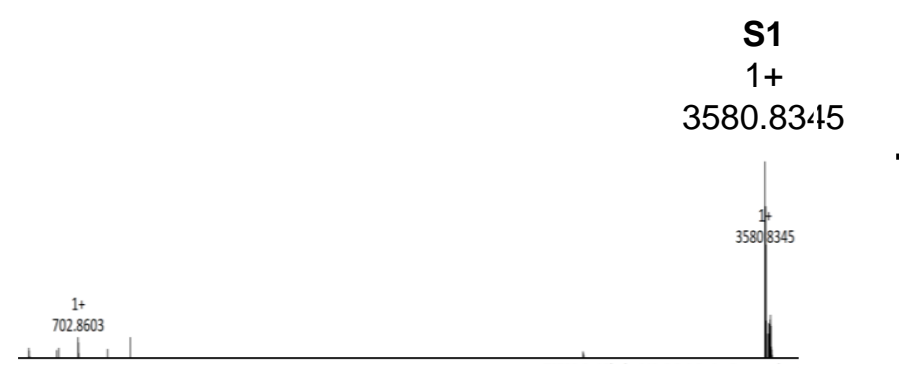

(B)

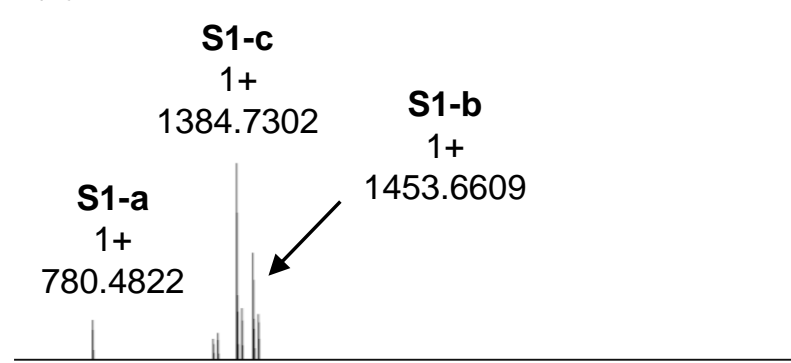

(C)

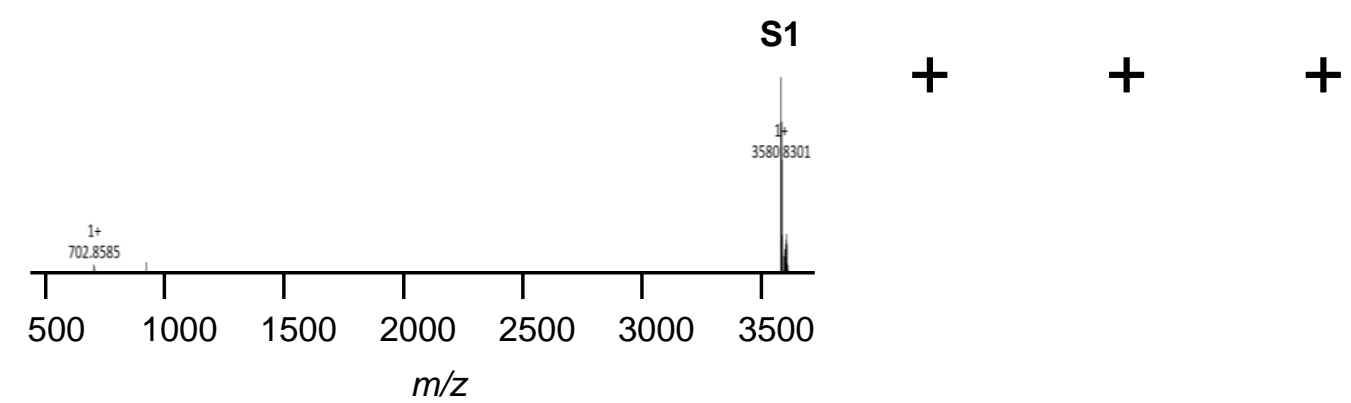

Figure S31. Evaluation of protease activity of the synthesized HIV-1 protease. (A) Mass spectrum of substrate peptide S1. (B) Mass spectrum of S1 with the synthesized protease. (C) Mass spectrum of S1 with the synthesized protease and ritonavir as a protease inhibitor. S1-a, S1-b, and S1-c indicates peptide fragments generated by the protease.

\section{References for Supporting Information}

S1 (a) Harre, M.; Nickisch, K.; Tilstam, U. React. Funct. Polym. 1999, 41, 111. (b) Y.-C. Huang, Y.C.; C.-C. Chen, C.-C.; S.-J. Li, S.-J.; Gao, S.; Shi, J.; Y.-M. Li, Y.-M. Tetrahedron 2014, 70, 2951.

S2 Urban, F. J.; Jasys, V. J. Org. Proc. Dev. 2004, 8, 169.

S3 Sato, K.; Tanaka, S.; Yamamoto, K.; Tashiro, Y.; Narumi, T.; Mase, N. Chem. Commun. 2018, 54, 9127.

S4 Johnson, E. C. B.; Malito, E.; Shen, Y.; Rich, D.; Tang, W.-J.; Kent, S. B. H. J. Am. Chem. Soc. 2007, 129, 11480 . 


\section{Mass spectra of synthesized peptides}

Ac-LYRANA-NHNH ${ }_{2}$ (1a)

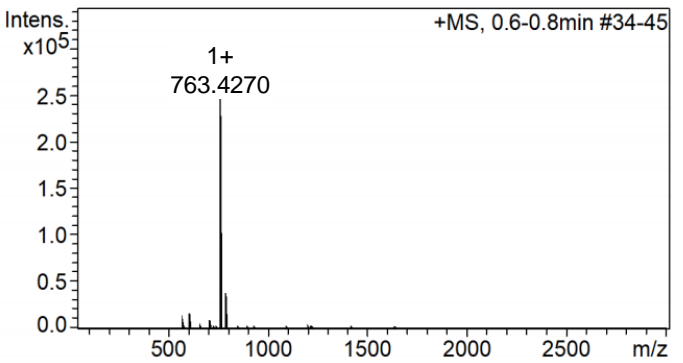

Ac-LYRANF-NHNH ${ }_{2}$ (1c)

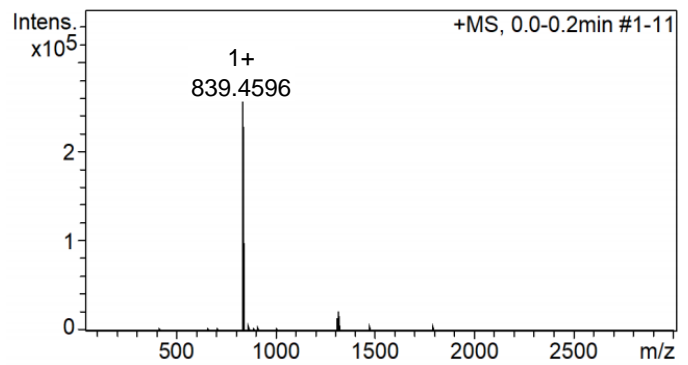

Ac-LYRANT-NHNH ${ }_{2}$ (1e)

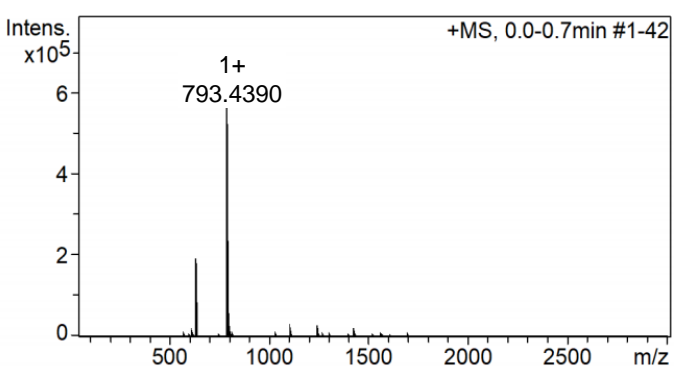

Ac-LYRANK-NHNH ${ }_{2}$ (1g)

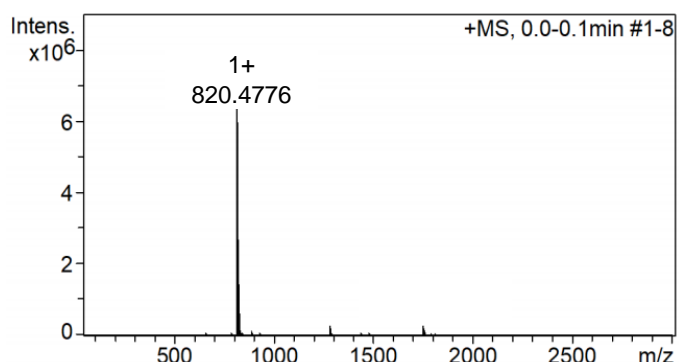

Ac-LYRANV-NHNH ${ }_{2}$ (1b)

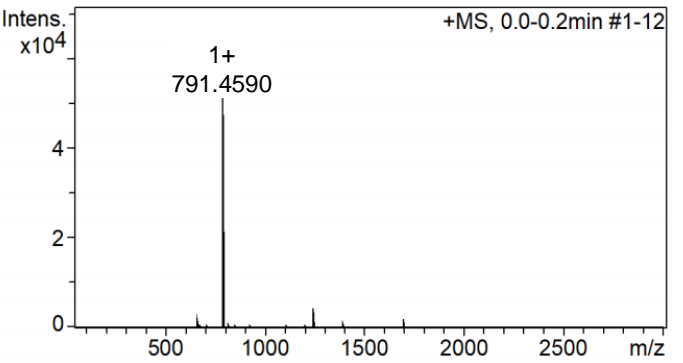

Ac-LYRANS-NHNH ${ }_{2}$ (1d)

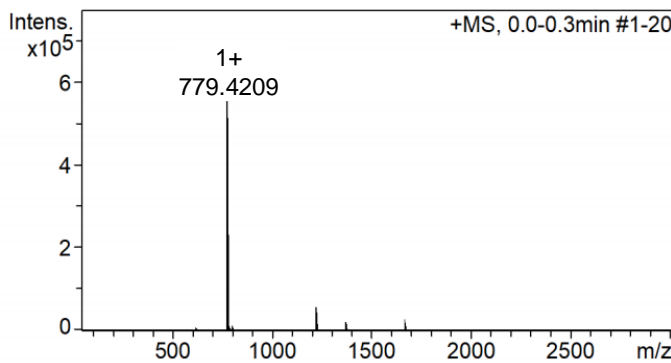

Ac-LYRANH-NHNH ${ }_{2}$ (1f)

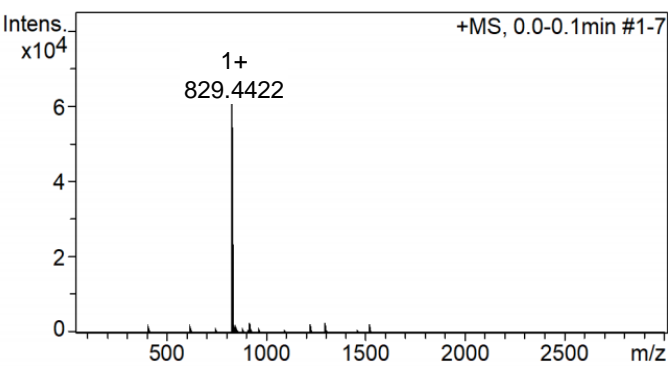

Ac-LYRANR-NHNH ${ }_{2}$ (1h)

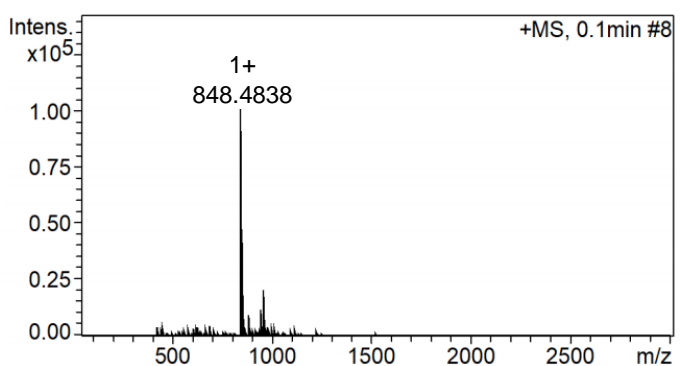


Ac-LYRANA-NHNH-CH ${ }_{2} \mathrm{Ar}$ (4aa)

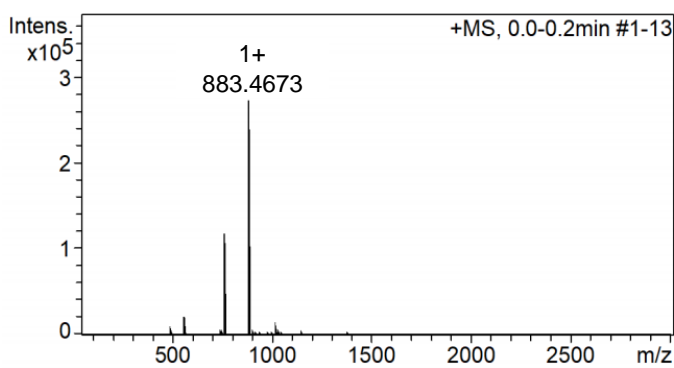

Ac-LYRANF-NHNH-CH${ }_{2} \mathrm{Ar}$ (4ca)

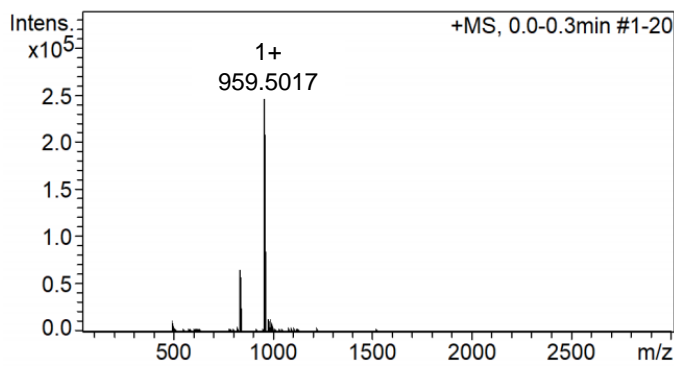

Ac-LYRANT-NHNH-CH${ }_{2} \mathrm{Ar}$ (4ea)

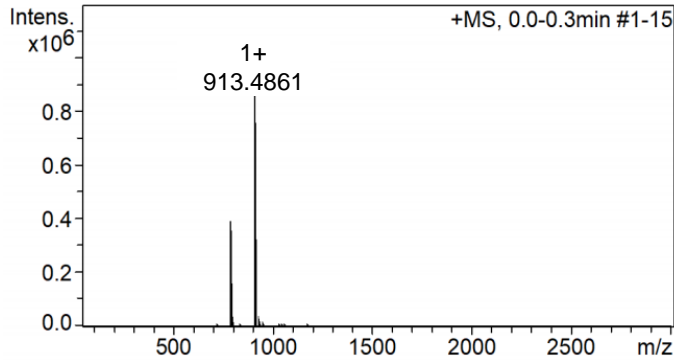

Ac-LYRANK-NHNH-CH ${ }_{2} \mathrm{Ar}$ (4ga)

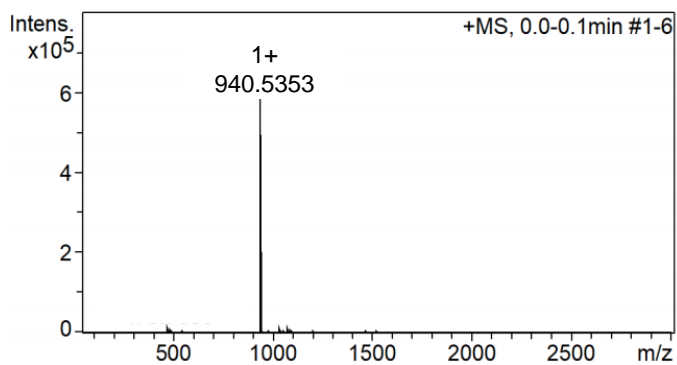

Ac-LYRANA-NHNH-CH $\mathrm{CH}_{2} \mathrm{Ar}$ (4ab)

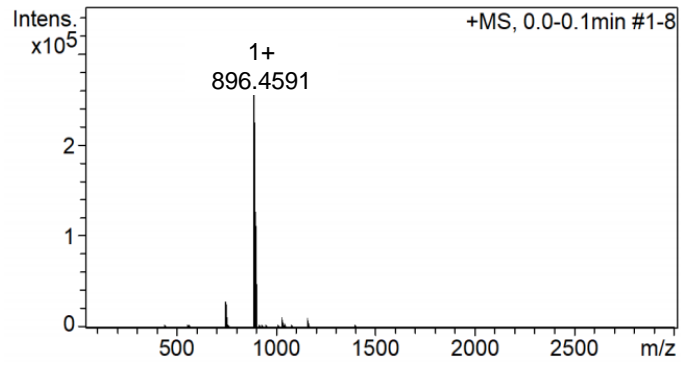

Ac-LYRANV-NHNH-CH $\mathrm{CH}_{2} \mathrm{Ar}$ (4ba)

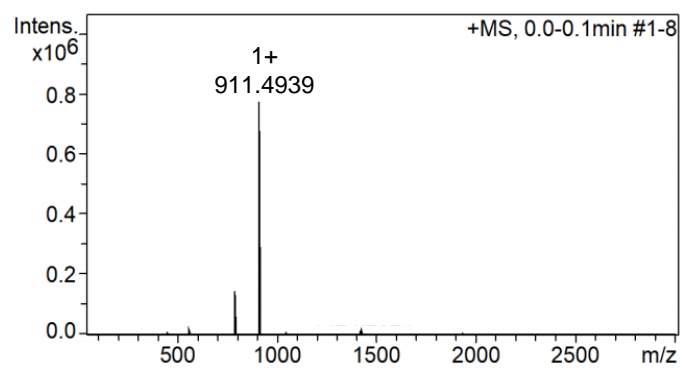

Ac-LYRANS-NHNH-CH

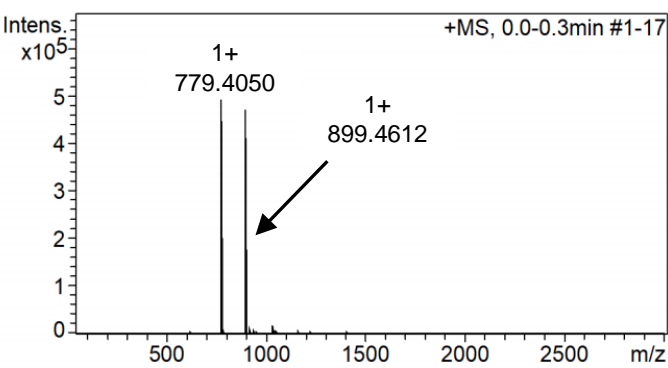

Ac-LYRANH-NHNH-CH ${ }_{2} \mathrm{Ar}$ (4fa)

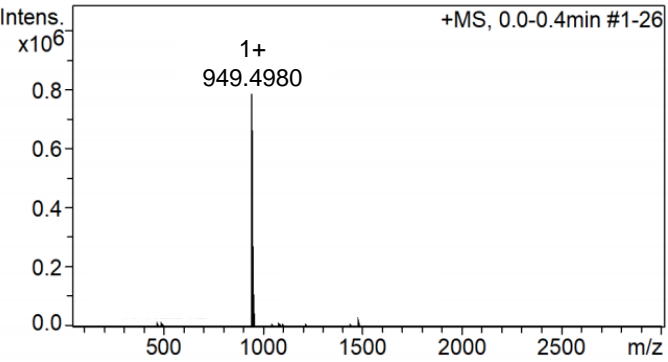

Ac-LYRANR-NHNH-CH $\mathrm{Ar}_{2}$ (4ha)

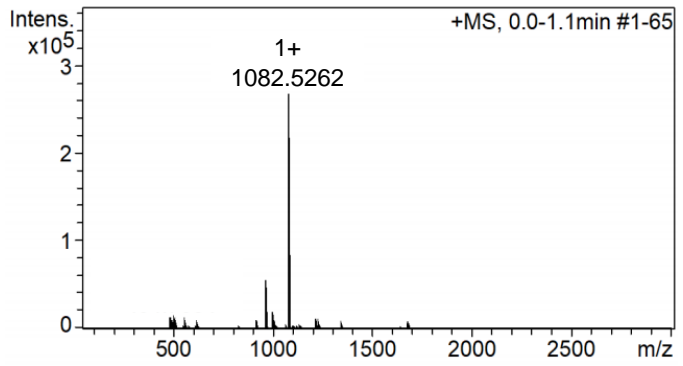


Ac-LYRANA-NH ${ }_{2}(\mathbf{5 a})$

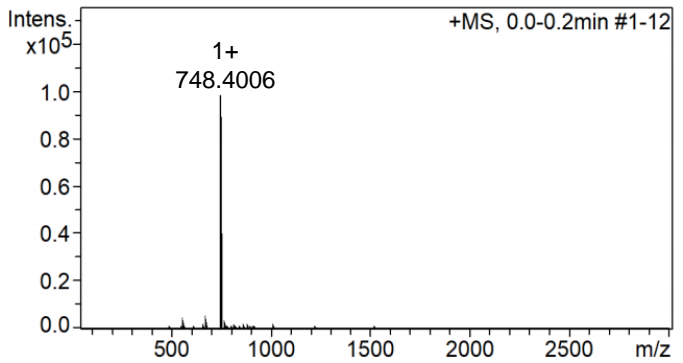

Ac-LYRANS- $\mathrm{NH}_{2}(\mathbf{5 d})$

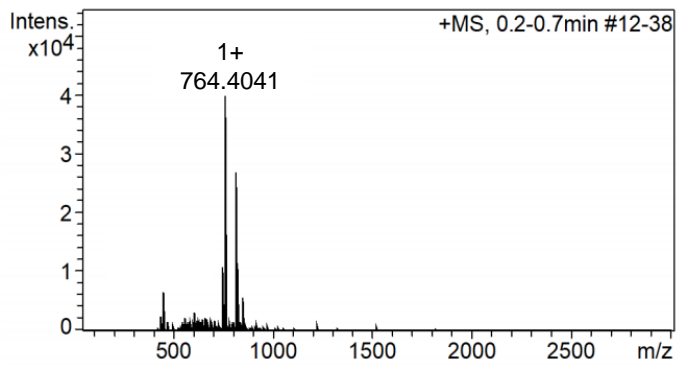

Ac-LYRANF-NH $\mathrm{N}_{2}(\mathbf{5 c})$

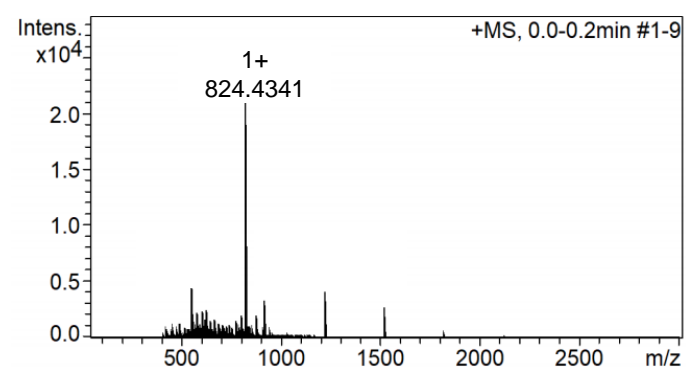

Ac-LYRANT-NH ${ }_{2}(\mathbf{5 e})$

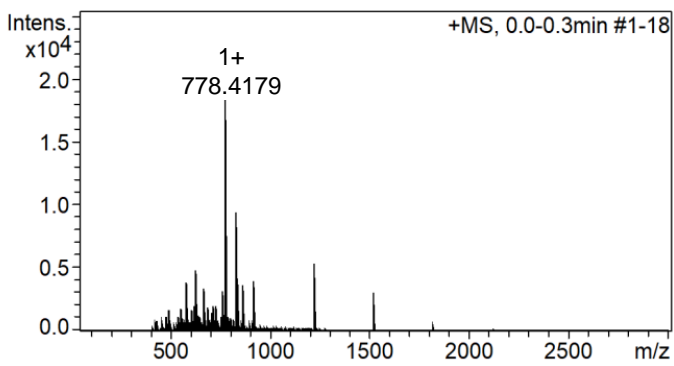

Ac-LYRANH-NH ${ }_{2}$ (5f)

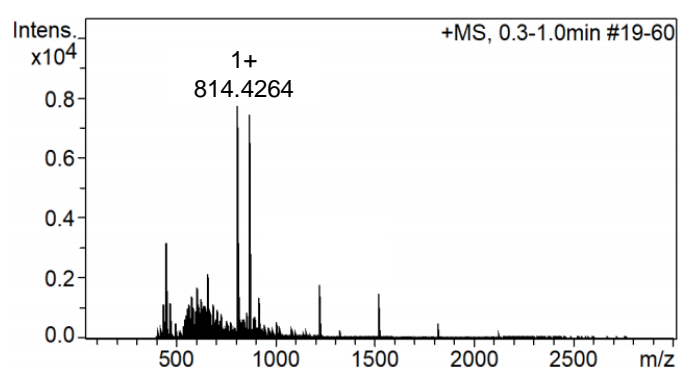


Ac-LYRANA-OH (6a)

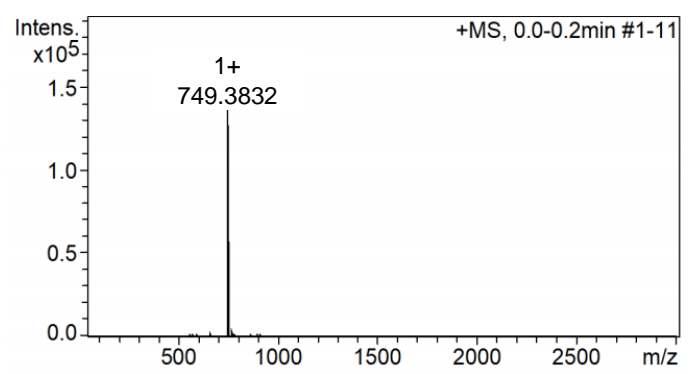

Ac-LYRANF-OH (6c)

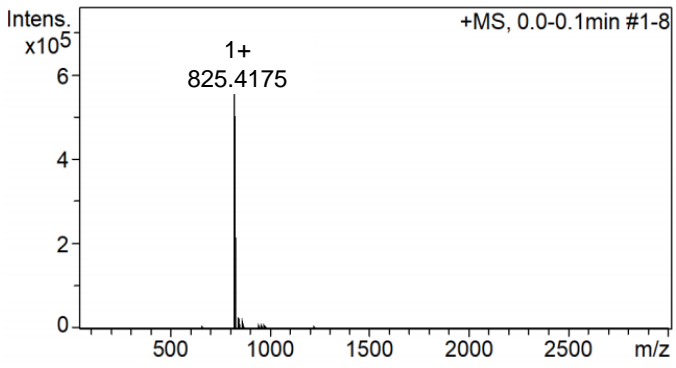

Ac-LYRANT-OH (6e)

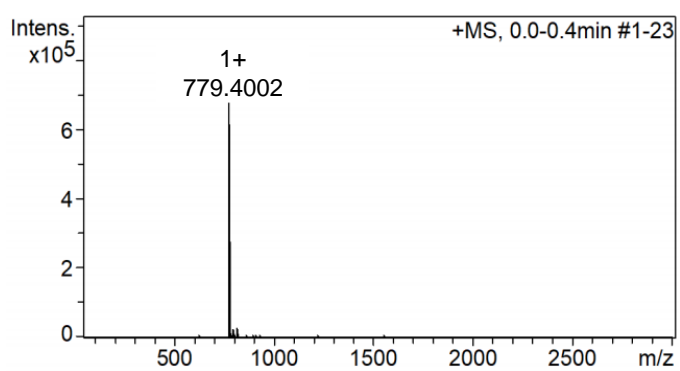

Ac-LYRANK-OH (6g)

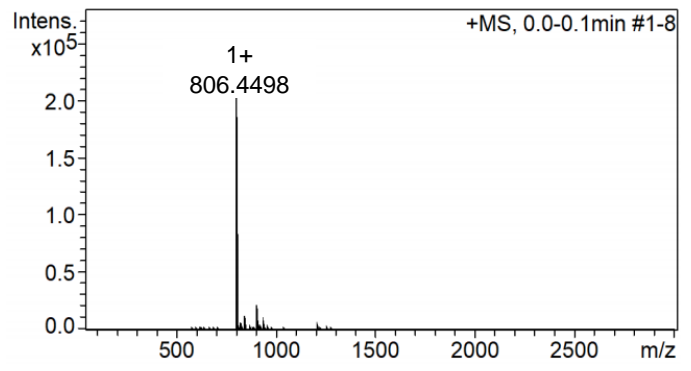

Ac-LYRANA ${ }^{\mathrm{d}-O H}$ (6a')

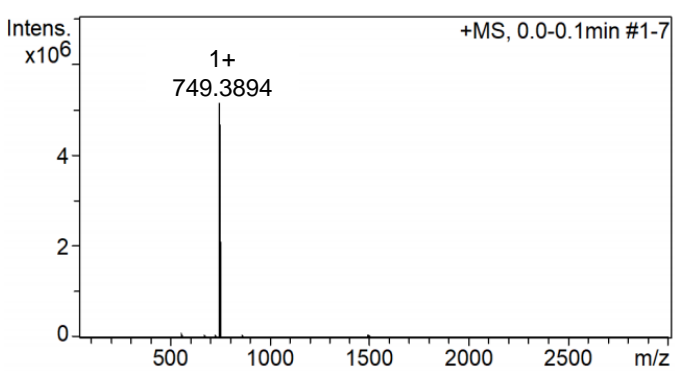

Ac-LYRANV-OH (6b)

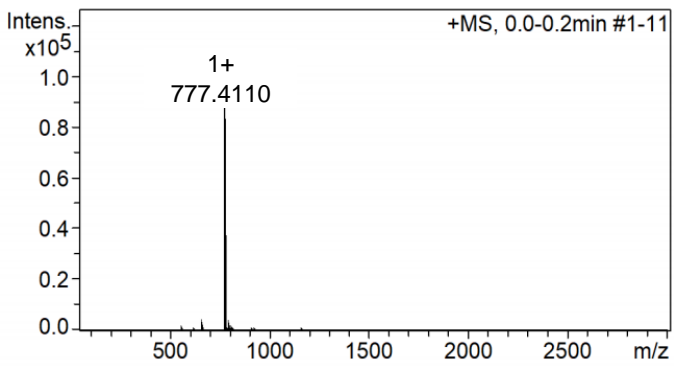

Ac-LYRANS-OH (6d)

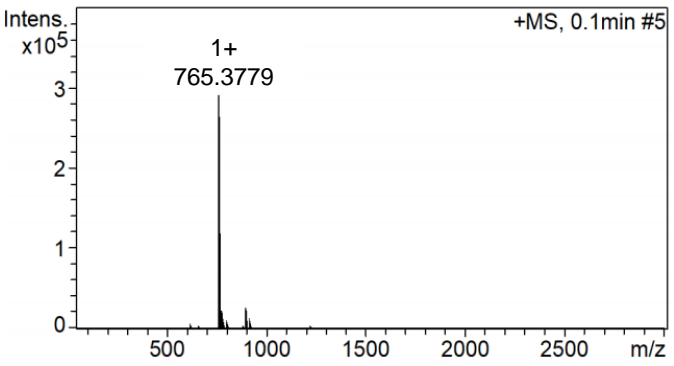

Ac-LYRANH-OH (6f)

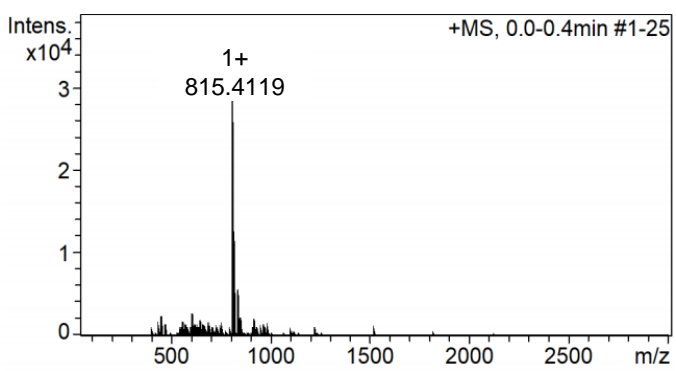

Ac-LYRANR-OH (6h)

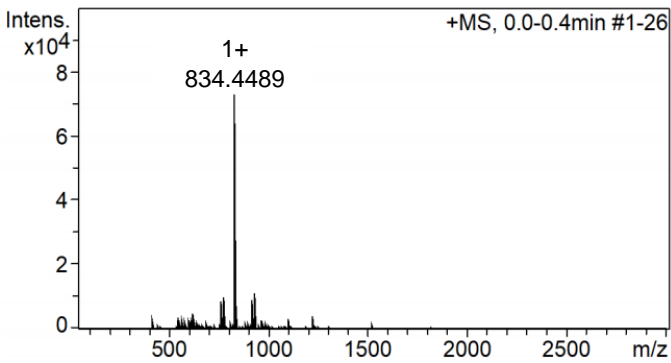

Ac-LYRANVd-OH (6b')

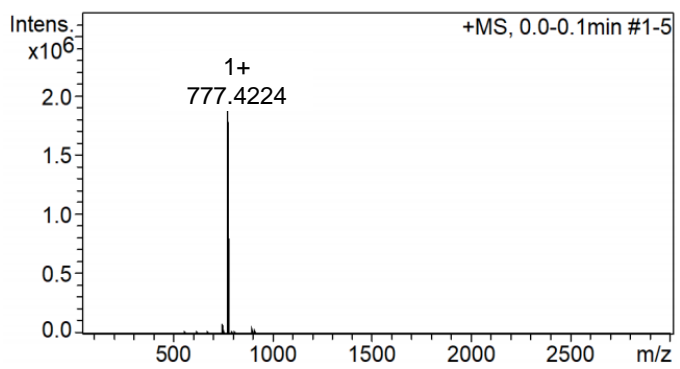


HIV-1 protease C-term. segment 9

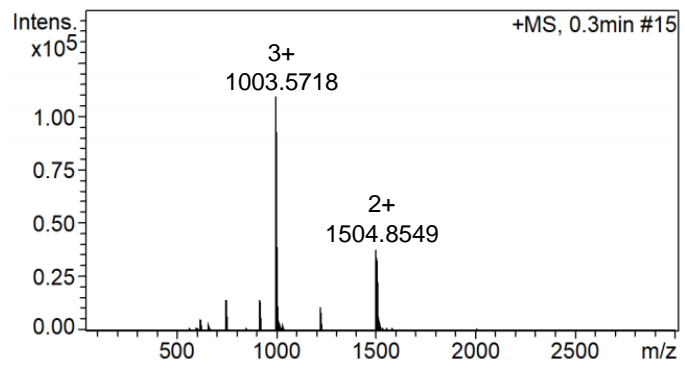

HIV-1 protease N-term. segment 11

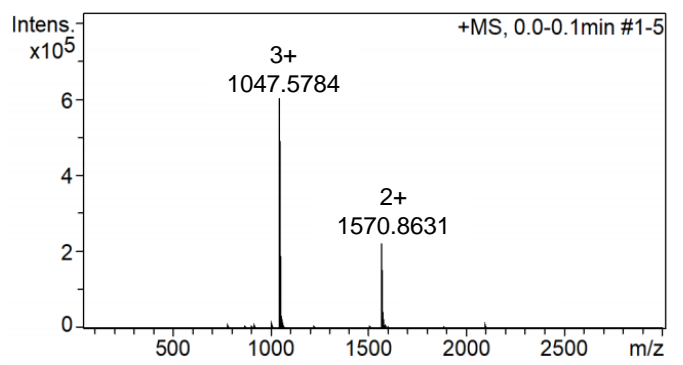

C-term. segment + solubilizing tag 13

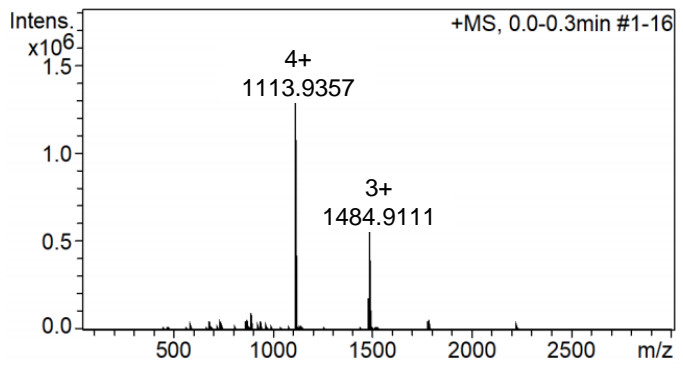

HIV-1 protease + solubilizing tag 15

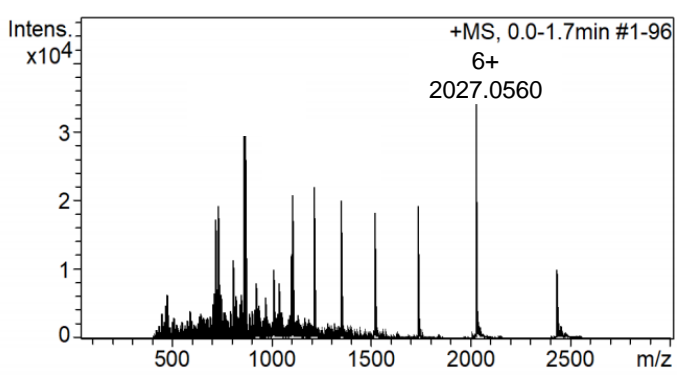

HIV-1 protease middle segment 10

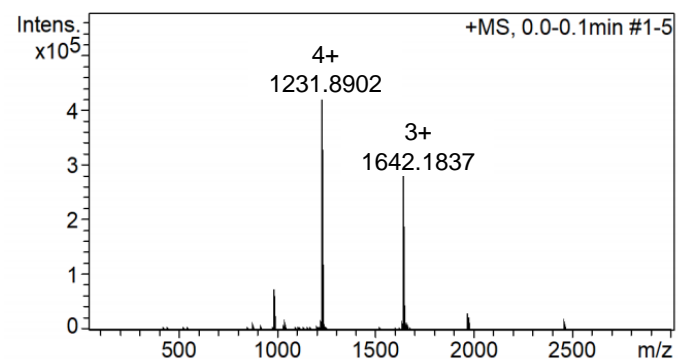

Solubilizing tag 12

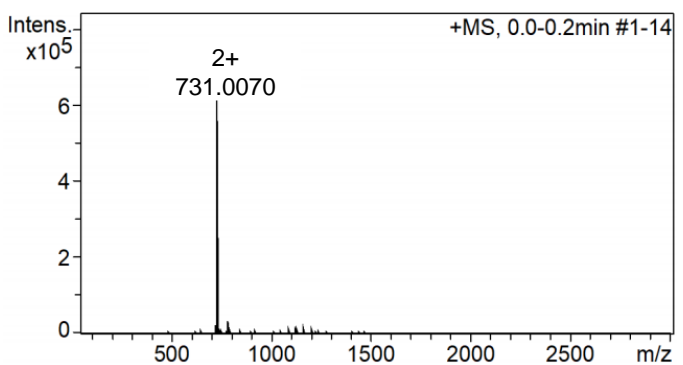

HIV-1 protease $(2 \mathrm{SH})+$ solubilizing tag 14

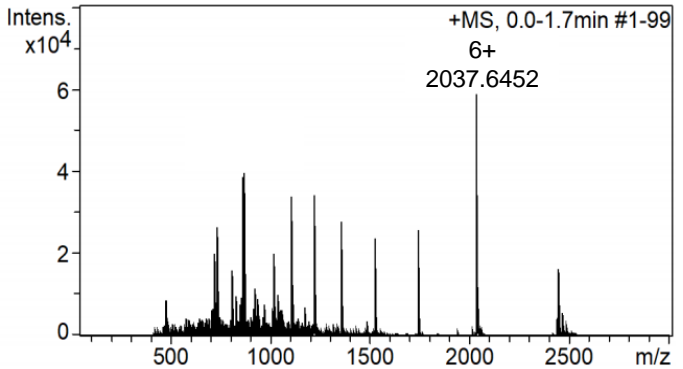

Substrate peptide $\mathbf{S 1}$

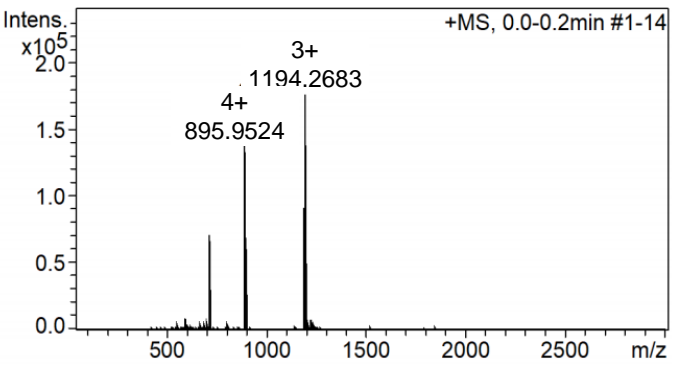


10 (MPAA ester)

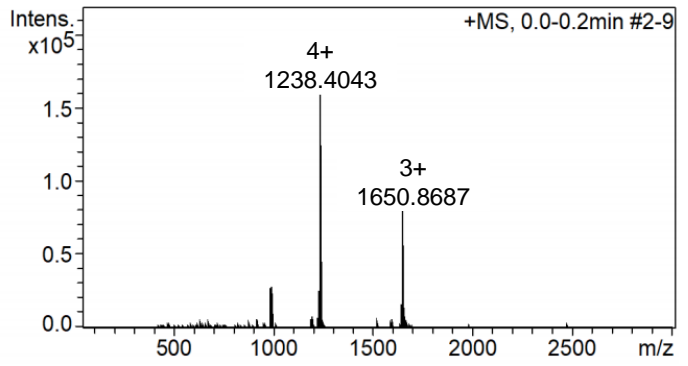

10"' (hydrolyzed)

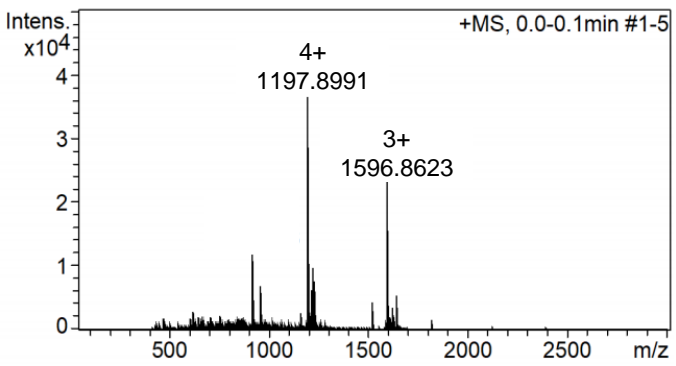

$10+13$ (Cys form)

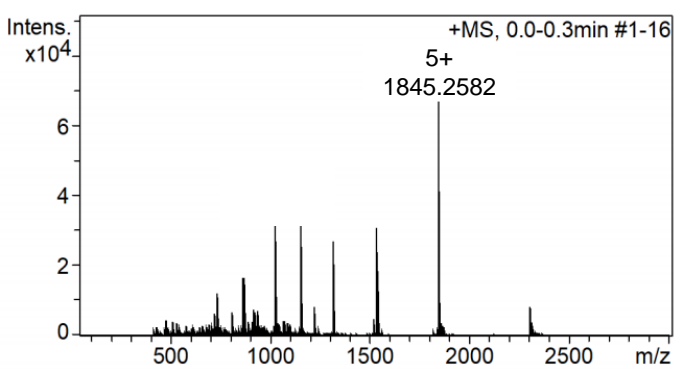

11' (methoxyamide)

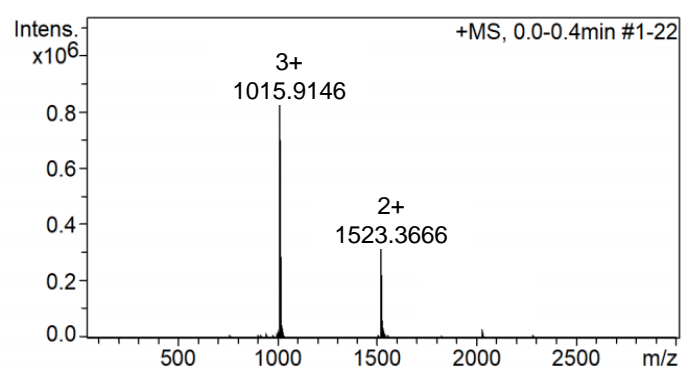

$11+10$ "' (carboxylic acid)

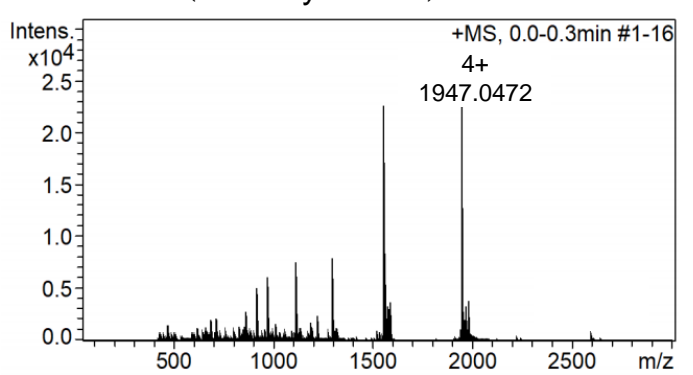

10' (lactam)

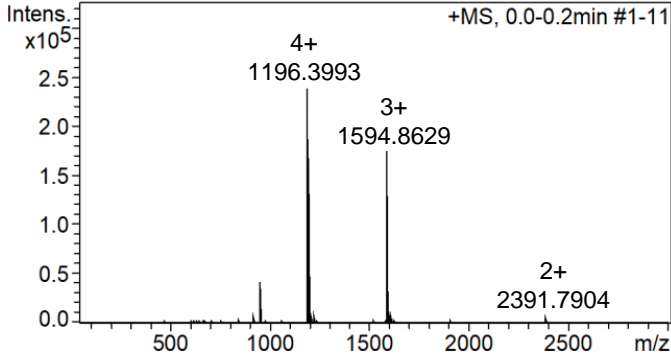

$10+13$ (Thz form)

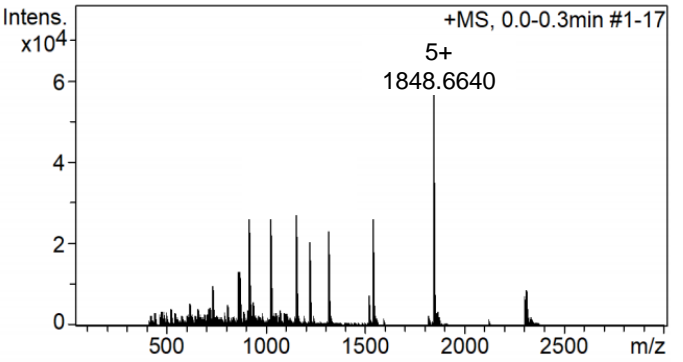

11 (MPAA ester)

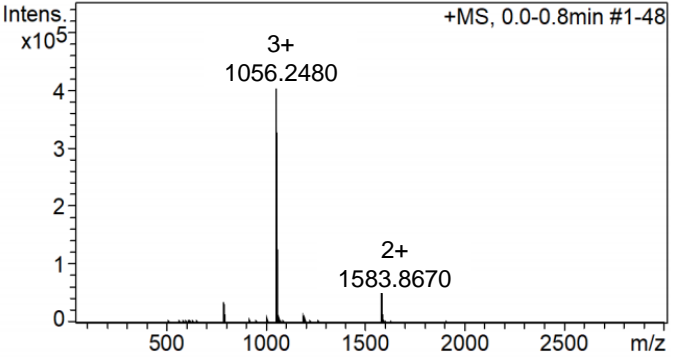

11 + 10' (lactam)

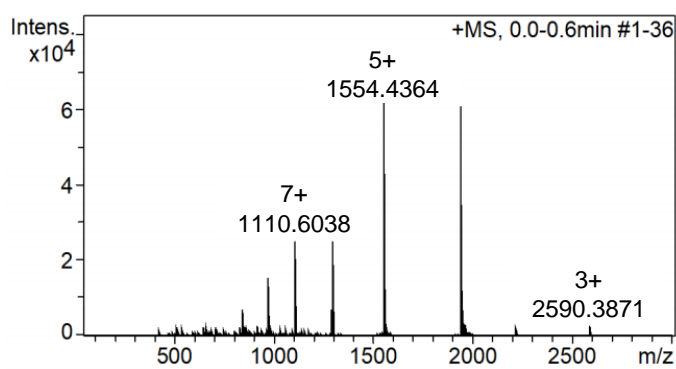




\section{Temperature-time profiles of microwave-assisted SPPS}

Ac-LYRANA-NHNH 2 (1a)

Cycle No: 1
A (Fmoc-Ala-OH $)$
20\%

20\% Piperidine , 2020-06-08 13-14

Onioff: 10/15. R. Room Temperature Thme

Reaction: Temp: Room Temperature Time (mm:ss): 10:00 Oscillating Mixer: On Interval Mixing

Onloff: 10115

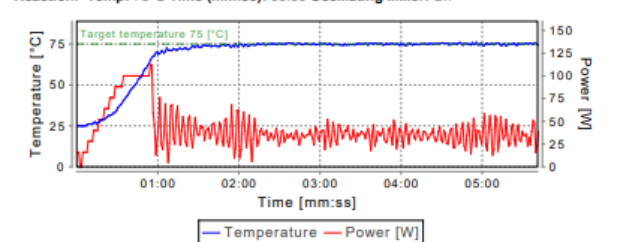

$20 \%$ Piperidine - Temperature - Power [W]

Reaction: Temp: Room Temperature Time (mm:ss): 03:00 Oscillating Mixer: On Interval Mixing

Onloft: 101/5
Raaction: Tremp: Room Temperature Time (mm:ss): 10:00 oscillating Mixer: On Interval Mixing
Onloff: 1015

Cycle No: 4

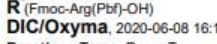

Peaction: Tremp: Room Thench

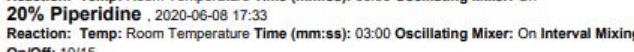

Onloft: 10/15
Reaction: Temp: Room Temperature Time (mm:ss): 10:00 Oscillating Mixer: On Interval Mixing
Onloff: 1015
Cycle No: 2
N(Fmoc-Asn (Thton)

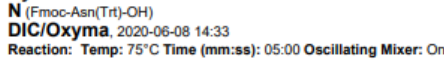

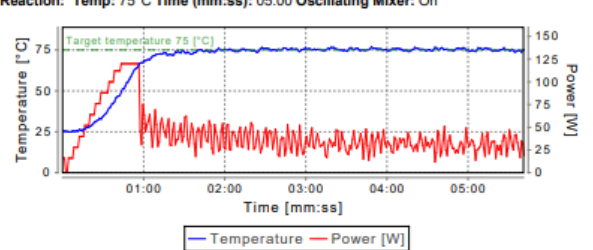

20\% Piperidine .2020-06-08 14:56

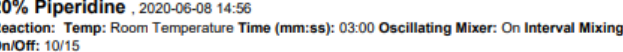

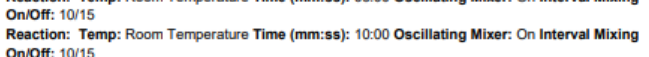

\section{Cycle No: 5}

DICIOXyma, 2020.06-08 18:02

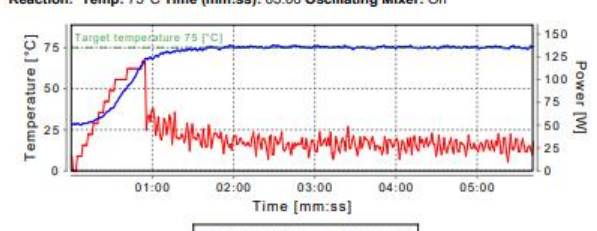

20\% Piperidine $\begin{aligned} & \text { 2020-06-08 } \\ & 18.25\end{aligned}$

20\% Piperidine, 2020-06-08 18.25
Reaction: Temp: Room Temperature Time (mm:ss): 03:00 oscillating Mixer: On Interval Mixing

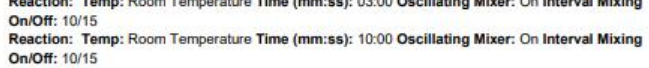

\section{Cycle No: 3
A(Fmoc-Ala-OH}

DIClOxyma, 2020-06.08 15:25:
Reaction: Temp: $75^{\circ}$ Time (mm:ss): 05:00 0scillating Mixer: On

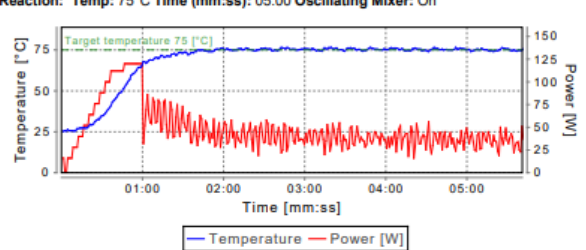

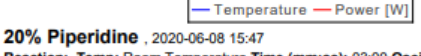

Reaction: Tremp: Room Temperature Time (mm:Ss). 03.00 oscillating Mixer: On Interval Mixing
Oncoff: 10/15 Reaction: Temp: Room Temperatatue Time (mm:ss): 10:00 Oscillating Mixer: On Interval Mixing

Cycle No: 6

DIC/Oxyma, 2020-06-08 18:54

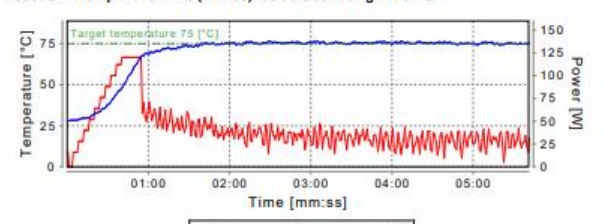

20\% Piperidine, $2020.06-080$ 19:18
18

Reaction: Temp: Room Temperature Time (mm:ss): 03:00 Oscillating Mixer: On Interval Mixing Onioff: 10/15 On/off: 1015
Capping Acetic anhydride, 2020-06-08 19:47 


\section{Ac-LYRANV-NHNH 2 (1b)}

\section{Cycle No: 1}

20\% Piperidine , 2020-06-09 12:43

(mm:ss): 03:00 Oscillating Mixer: On Interval Mixing

Reaction: Temp: Room Temperature Time (mm:ss): 10:00 Oscillating Mixer: On Interval Mixing

Onlof: 10115 2020-106-09 13:12

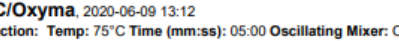

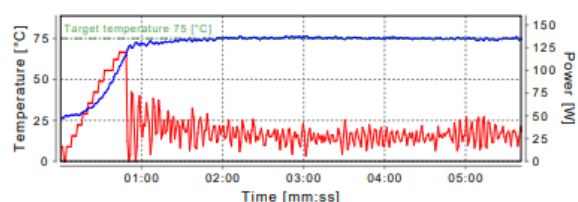

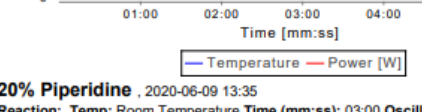

Reaction: Tomp: Room Temperatutur Time (mm:ss): 03:00 Oscillating Mixer: On Interval Mixing
Onloff: 10/15

Reaction: Tremp: Room Temperature Time (mm:ss): 10:00 Oscillating Mixer: On Interval Mixing
Onloft: 101515

$\underset{\text { Rycle No: } 4}{\text { Rifmoc-Arg (Pot)-OH }}$

DIClOxyma, 2020-06-09 15:

(2)

20\% Piperidine. 2020-06-019 17:04 (mm)
Reaction: Temp: Room Temperature Time (mm:ss): 03:00 0scillating Mixer: On Interval Mixing

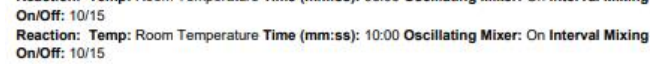

\section{Cycle No: 2}

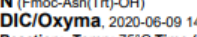

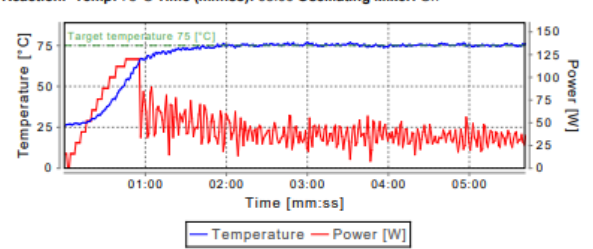

20\% Piperidine. 2020-06-09 14:26

Reaction: Temp: Room Temperature Time (mm:ss): 03:00 Oscillating Mixer. On Interval Miving OOl/ff: 10/15:
Reaction: Tremp: Room Temperature Time (mm:ss): 10:00 oscillating Mixer: On Interval Mixing
Onloff: 10/15

Cycle No: 5
Y(Fmoc-Tyrt(Bu)

DIC/OCxyma, 2020-06-09 17:32

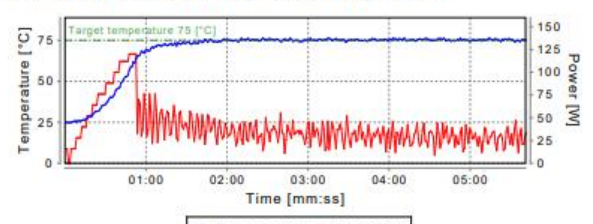
- Temperature - Power [W

20\% Piperidine, 2020-06-09 17:55
Reaction: Temp: Room Temperature Time (mm:ss): 03:00 Oscillating Mixer: On Interval Mixing

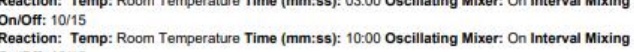

Cycle No: 3

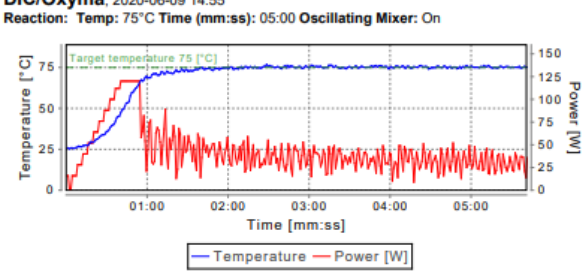

$20 \%$ Piperidine - Temperature - Power [W]

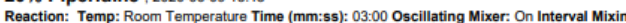

Onloff: 10/15
Reaction: Tremp: Room Temperature Time (mm:ss): 10:00 Oscillating Mixer: On Interval Mixing
Onloff: 10/15

\section{Cycle No: 6}

DIClOxyma, 2020-06-09 18.24

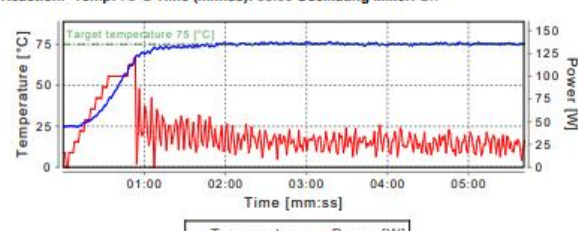

20\% Piperidine $2020-06-09$ 18:49

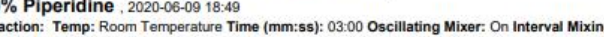
Reaction: Temp: Room Temperature Time (mm:ss): 10:00 Oscillating Mixer: On Interval Mixing

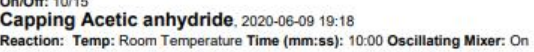




\section{Ac-LYRANF-NHNH 2 (1c)}

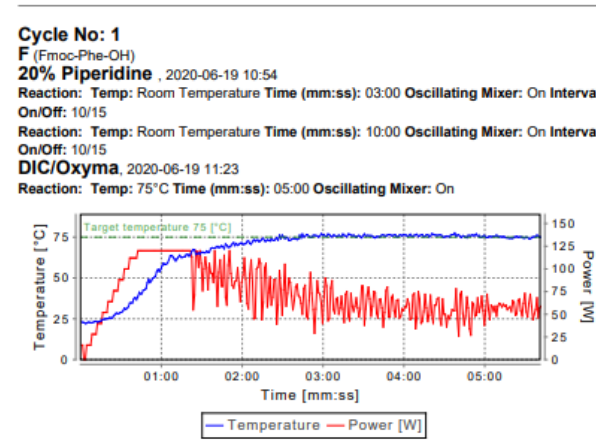

\section{-Temperature - Power [W]
20\%\% Piperidine, 2020-06-19 11:47}

Time (mm:ss): 03:00 Oscillating Mixer: On Interval Mixing

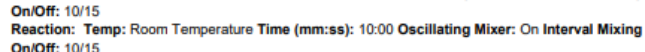

\section{Cycle No: 4
R (Fmoo:Arg(Pt)-}

DIC/Oxyma. 2020-06-19 14:

Time (mm:ss): 60:00 Oscillating Mixer: On

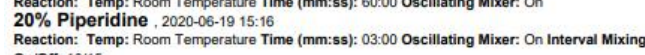

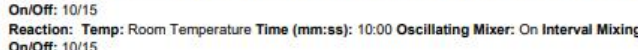

Cycle No: 2
N(Fmoco-Asn(Ttr)-OH)

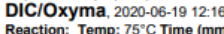

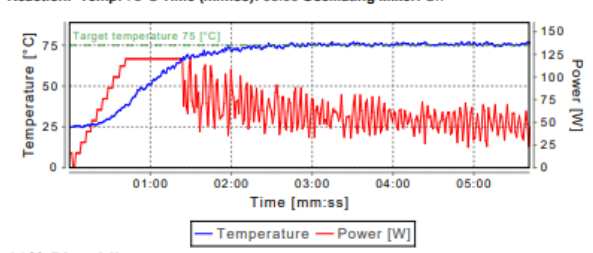

$20 \%$ Piperidine 2000091230

20\% Piperidine, 2020-06-19 12:39
Reaction: Temp: Room Temperature Time (mm:ss): 03:00 oscillating Mixer: On Interval Mixing Onloft: 1015
Reaction: Tremp: Room Temperature Time (mm:ss): 10:00 Oscillating Mixer: On Interval Mixing
Onloff: 10/15

Cycle No: 5
Y(Fmoc-Ty(tBu

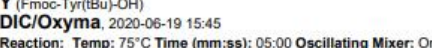

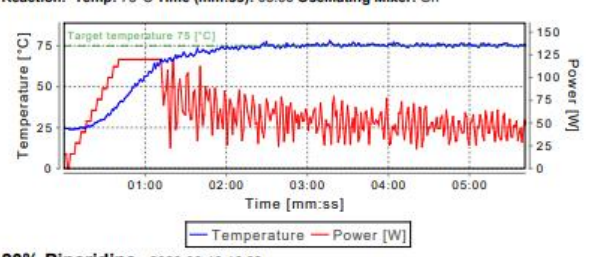

20\% Piperidine $2020.06-1960.09$

Reaction: Temp: Room Temperature Time (mm:ss): 03:00 Oscillating Mixer: On Interval Mixing
Onloff: 101515

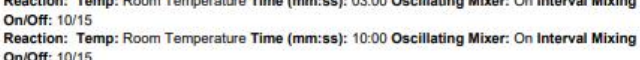

Cycle No: 3

DIC/Oxyma, 2020-06-19 13:00

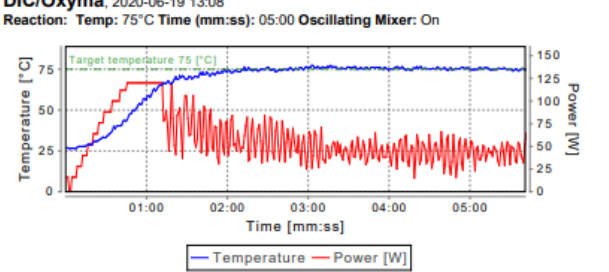

$20 \%$ Piperidine - Temperature - Power [W]

20\% Piperidine, 2020-06-19 13:31
Reaction: Temp: Room Temperature Time (mm:ss): 03:00 Oscillating Mixer: On Interval Mixing Onloft: 101/15 Reaction: Temp: Room Temperature Time (mm:ss): $10: 00$ Oscillating Mixer: On Interval Mixing
Onloff: 10115

\section{Cycle No: 6
Lifmoo-Leu-OH)}

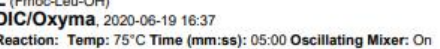

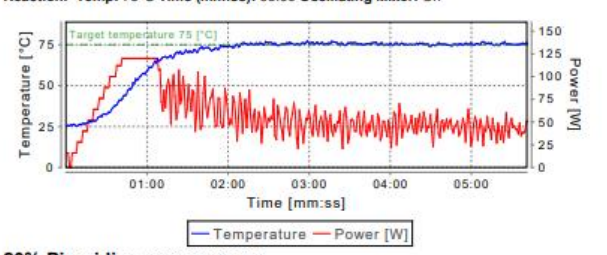

Mixer: On Interval Mixing Reaction: Temp: Room Temperature Time (mm:ss): 10:00 Oscillating Mixer: On Interval Mixing

Capping Acetic anhydride. 2020-06-19 1730

Reaction: Temp: Room Temperatutur Time (mm:ss): 10:00 Oscillating Mixer: On 


\section{Ac-LYRANS-NHNH 2 (1d)}

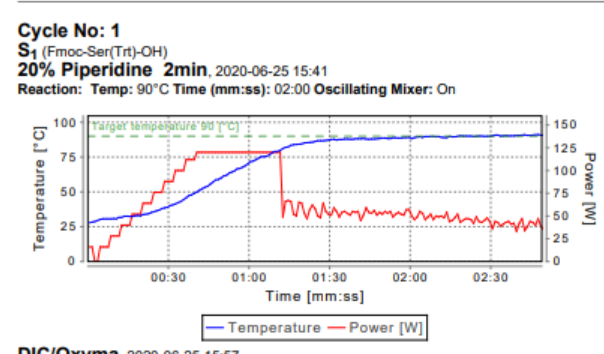

DIC/Oxyma, 2020-06-25 15:57 20.

Reaction: Temp: Room Temperature Time (mm:ss): 60:00 oscillating Mixer: On
20\% Piperidine 2 min, 2020-06-2517:14

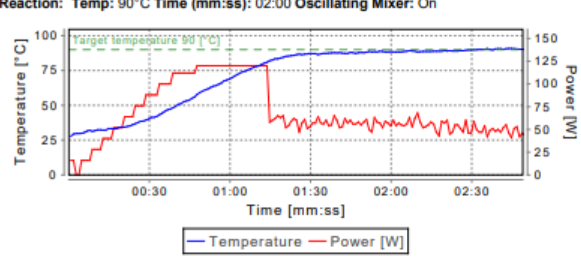

Cycle No: 4
R(FmococArg(Pto

DIClOxyyma, 2020-06-25 18:46

in (mm:ss): 60:00 oscillating Mixer:

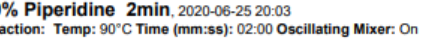

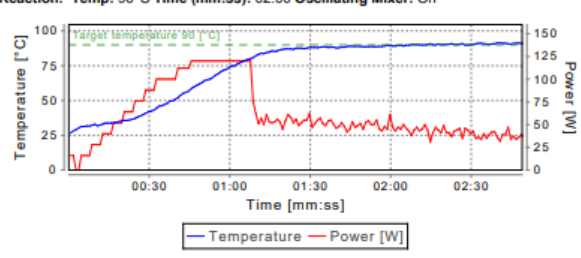

Cycle No: 2
N(Fmoc-Asn(Ttr)

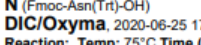

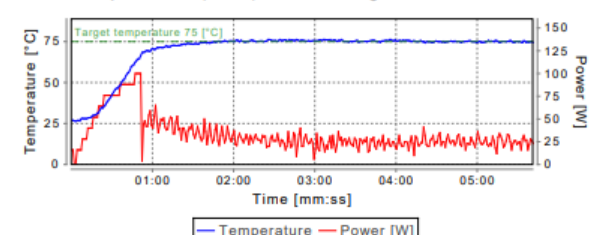

20\% Piperidine 2 min 2020 - Temperature - Power [W]

20\% Piperidine $2 \mathrm{~min}, 2020-06-2517.52$
Reaction: Temp: $90^{\circ} \mathrm{C}$ Time (mm: 5 ): 02:00 0scillating Mixer: O

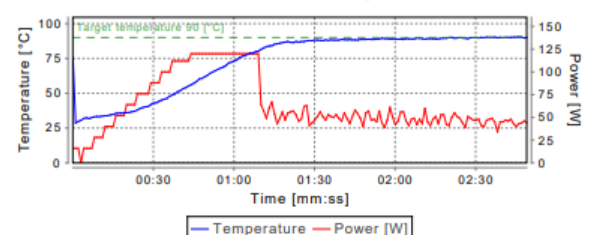

-Temperature - Power $[\mathrm{W}]$

\section{Cycle No: 5
Y(Fmoc-Tyr(tBu)}

DIC/Oxyma, 2020-06-25 20:19

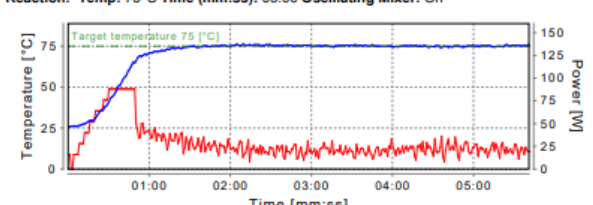

01:00 02:00 03:00

- Temperature - Power [W]

-Temperature - Power [W]
20\% Piperidine 2 min, 2020-06-25 20:41
Reaction: Temp: $90^{\circ} \mathrm{C}$ Time (mm:ss): 02:00 0scillating Mixer: On

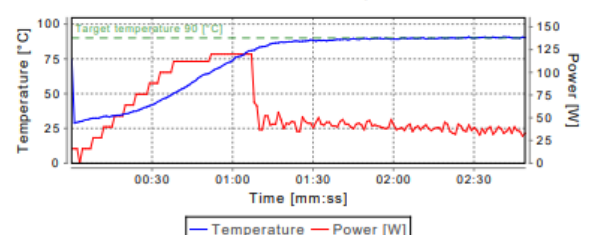

Cycle No: 3
A (Fmoc-Ala-OH)

DIC/Oxyma, 2020-06.25 18:08
Reaction: Temp: 75 C Time (mm:ss): 05:00 Oscillating Mixer: On

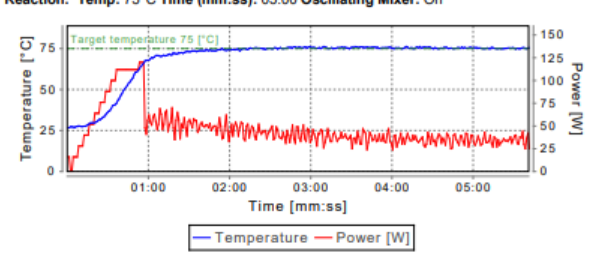

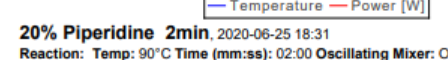

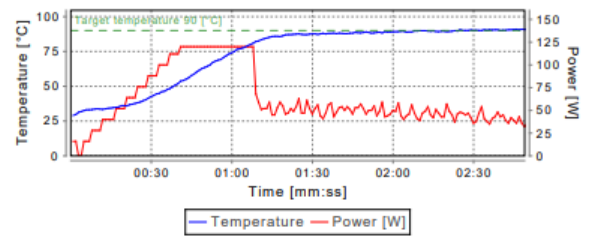

Cycle No: 6
(Fmoc-eo- $\mathrm{OH})$

DIC/OXyma, $2020.06-2520.57$
Reaction: Temp: $75^{\circ} \mathrm{C}$ Time (mm

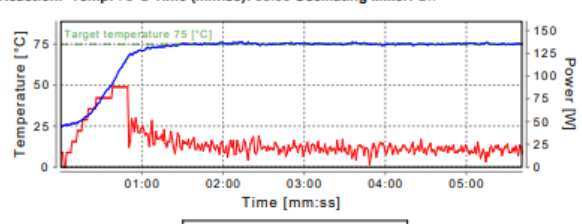

-Temperature - Power [W]

20\% Piperidine 2min, 2020 -06-2521:20
Reaction: Temp: $90^{\circ} \mathrm{C}$ Time (mm:ss): 02:00 Oscillating Mixer:

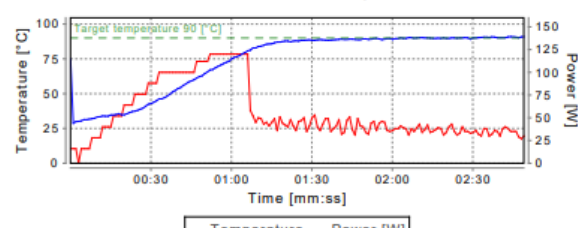

-Temperature - Power [W]

Capping Acetic anhydride, 2020-0.-25 21.35 


\section{Ac-LYRANT-NHNH 2 (1e)}

\section{Cycle No: 1}

20\% Piperidine 2 min, 2020.06-26 18:42
Reaction: Temp: $90^{\circ} \mathrm{C}$ Time (mm:ss): 02:00 Oscillating Mixer: On

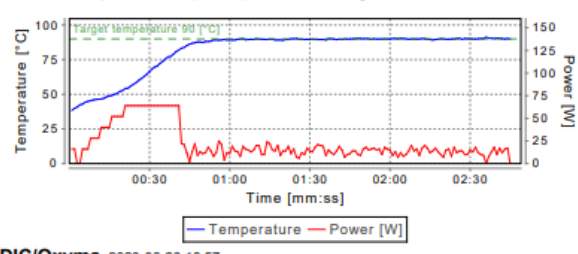

DIC/Oxyma, 2020.06-26 18:57

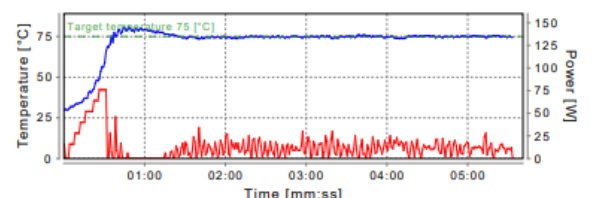$$
\text { Time [mm.ss] }
$$

$20 \%$ Piperidine 2 min. 2020-06-26 19:19

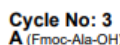

DICIOxyma, 2020-06-26 20:12

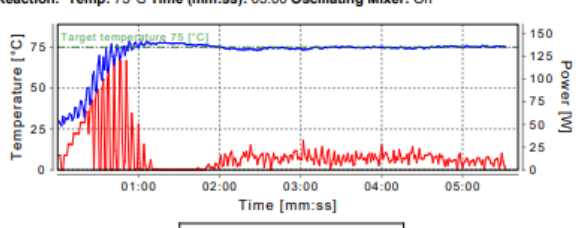

$20 \%$ Piperidine 2 min - Temperature - Power [W]

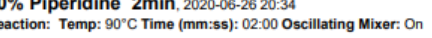

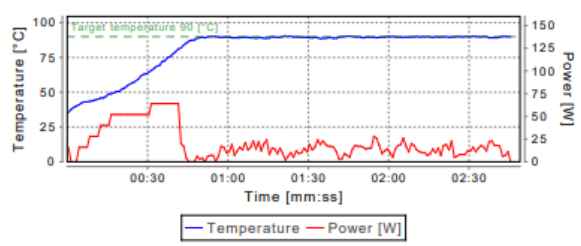

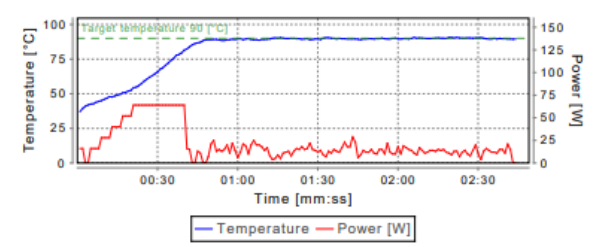

- Temperature - Power $[\mathrm{W}]$

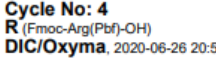

Reaction: Temp: Room Temperature Time (mm:ss): 60:00 Oscillating Mixer: O

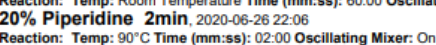

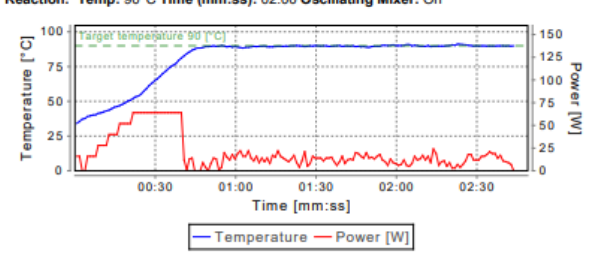

Cycle No: 2

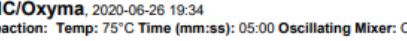

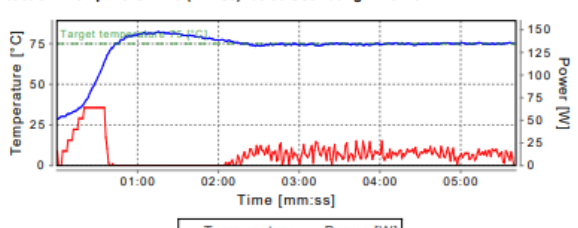

Time [mm:ss]

20\% Piperidine 2 min, 2020-06-26 19:57

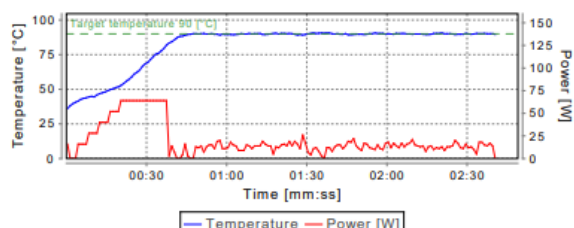

- Temperature - Power [W]

\section{Cycle No: 5
Yy(Fmoc-Tyrt(Bu)-OH)}

(O)xyma, 2020-06-26 22:20.

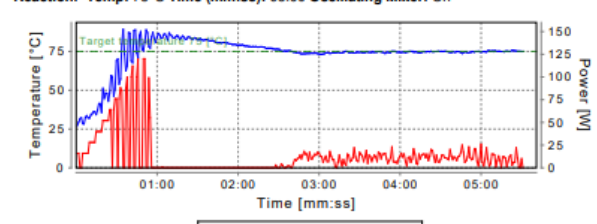

20\% Piperidine $2 \mathrm{~min}, 2020.06-26222: 44$
Reaction: Temp: $900^{\circ} \mathrm{C}$ Time (mm:ss) 02:00 Oscillating Mixer: On

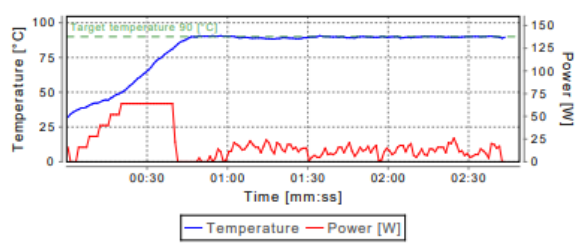


Cycle №: 6

DIC/Oxyma, 2020-06.26 22.59
Reaction: Temp: $75^{\circ}$ C Time (mm:ss): 05:00 Oscillating Mixer: On

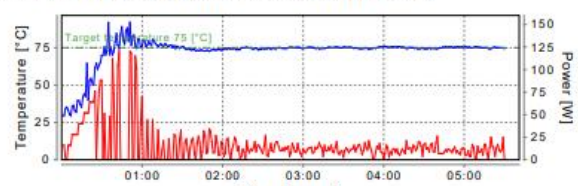

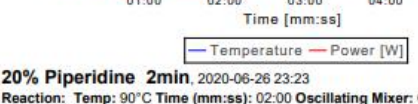

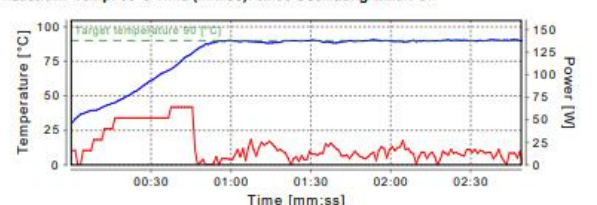

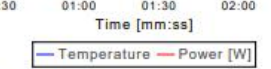

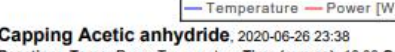

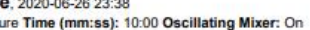




\section{Ac-LYRANH-NHNH 2 (1f)}

\section{Cycle No: 2}

DIC/OXxma, 2020-07-02 14:05
Reaction: Temp: $75^{\circ} \mathrm{C}$ Time (mm:ss): 05:00 Oscillating Mixer: On

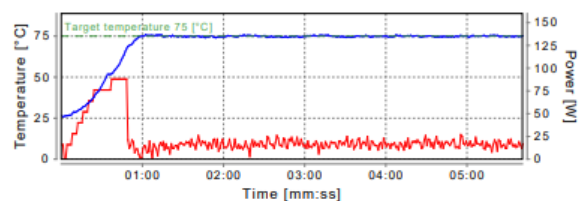

- Temperature - Power [W]

20\% Piperidine 2 min, 2020.07.02 14:27
Reaction: Temp: 90'C Time (mm:ss): 02:00 oscillating Mixer: O

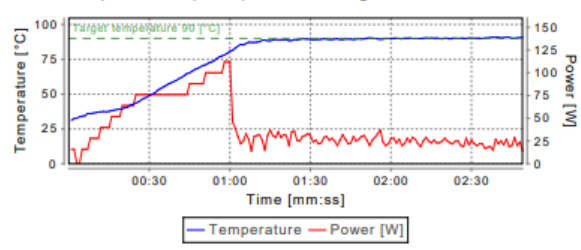

\section{Cycle No: 5
Y(Fmoc-Tyr(tBu}

DiC/Oxyma, 2020-07.

05.00 Oscillating Mixer: on

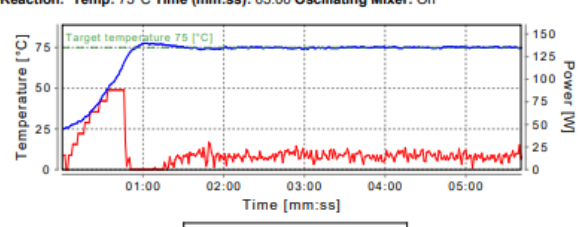

Temperature - Power [W]

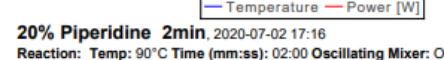

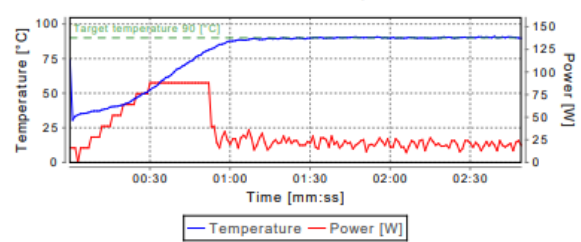

Cycle No: 3

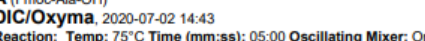

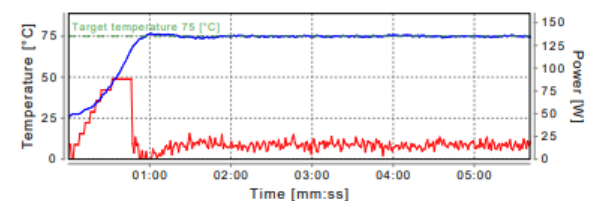

- Temperature - Power [W]

20\% Piperidine 2 min, $2020-07-02$ 15:05
Reaction: Temp: $90^{\circ} \mathrm{C}$ Time (mm:ss): 02:00 Oscillating Mixer: O

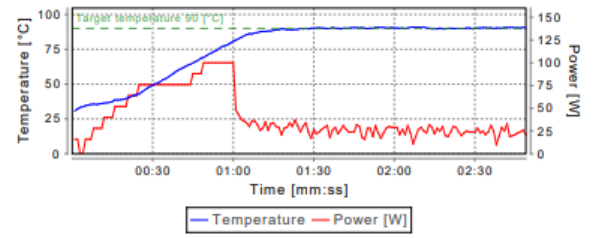

-Temperature - Power [W]

Cycle No: 6

DIC/Oxyma, 2020.07-02

:05:00 Oscillating Mixer: On

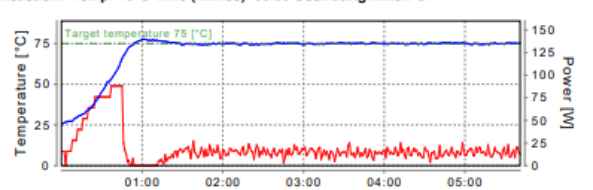

- Temperature - Power [W]

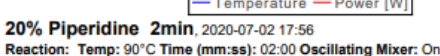

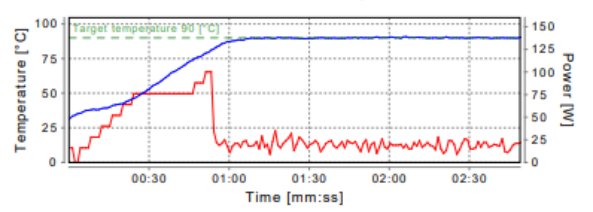

- Temperature - Power $[\mathrm{W}]$

Capping Acetic anhydride, 2020-07-02 18:11

\section{Cycle No: 4}

C/Oxyma, 2020-07-02 15:2,

perature Time (mm:ss): 60:00 Oscillating Mixer: On

$\begin{array}{ll} & \\ & \end{array}$

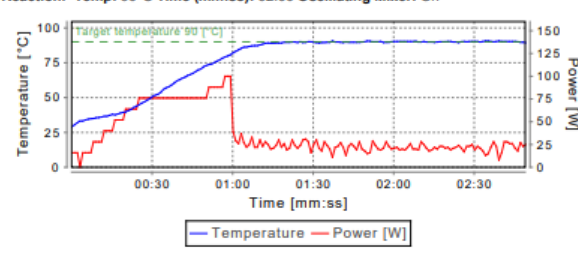




\section{Ac-LYRANK-NHNH 2 (1g)}

\section{Cycle No: 1}

Swelling DMF, 2020-12-05 16:19
Reaction: Temp: 70.C Time (mm:ss): 20:00 Oscillating Mixer: On

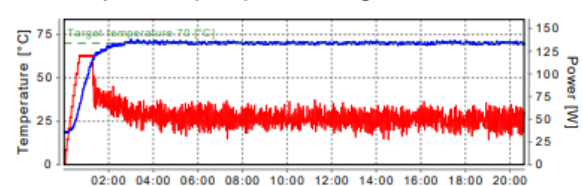

02:00 04:00 06:00 08:00 10:00 12:00 14:00 16:00 18:00 20:00

$$
\text { -Temperature - Power [W] }
$$

20\% Piperidine MW. 2020-12.05 16:42

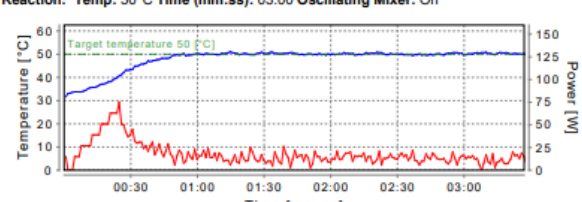

DIC/Oxyma, 2020-12-05 16:55
Reaction: Temp: $75^{\circ} \mathrm{C}$ Time (mm:ss): 05:00 Oscillating Mixer:

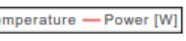

\section{Cycle No: 3
A (Fmoo-Ala-OH)}

Dil/ Xxyma, 2020-12-05 17:46
Reaction: Temp: $75^{\circ} \mathrm{C}$ Time (mm:ss): 05:00 Oscillating Mixer: On

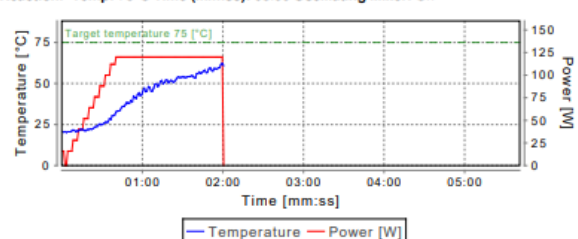

- Temperature - Power [W]

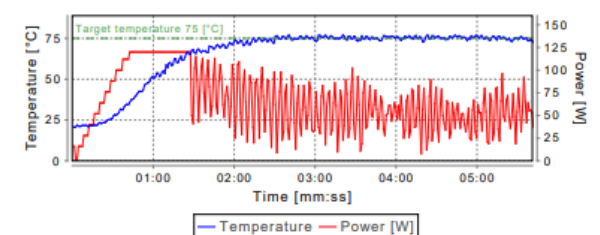

20\% Piperidine MW, 2020-12-05 17:07

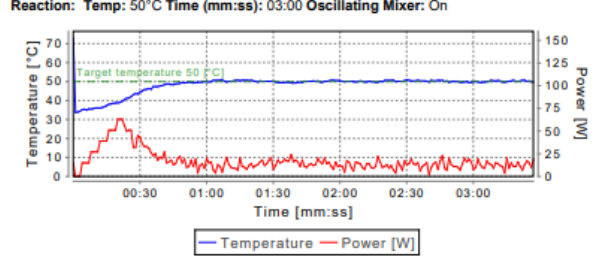

- Temperature - Power [W]
Cycle No: 2

DIClOxyma, 2020-12.05 17:20
Reaction: Temp: 75"C Time (mm:ss): 05:00 Oscillating Mixer: On

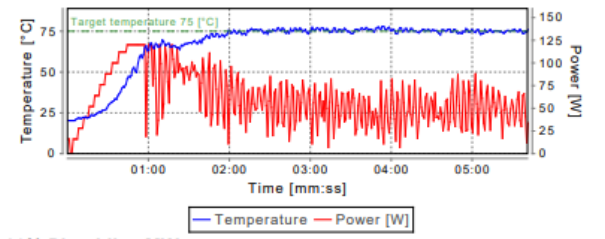

20\% Piperidine MW, 2020-12-05 17:33

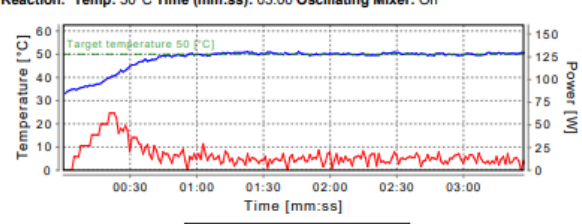

- Temperature - Power [ [W] 
Cycle No: 1
A(Fmoc-Ala-OH)
Dicions

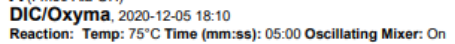

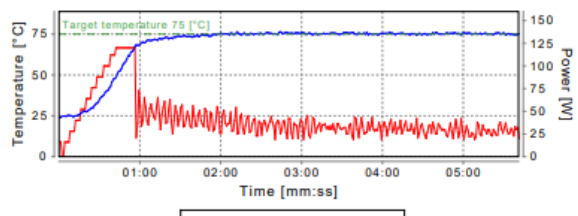

-Temperature - Power [W]

20\% Piperidine MW, 2020-12-05 18:21
Reaction: Temp: 50' CTime (mm:s5): 03:00 Oscillating Miver: On

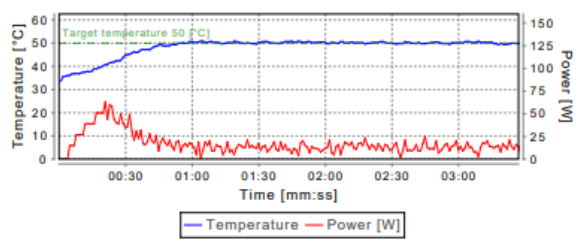

-Temperature - Power [W]

\section{Cycle No: 4}

DiC/Oxyma, 2020-12-05 20:18

s): $05: 00$ oscillating Mixer:

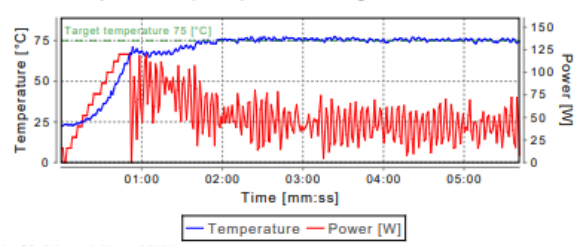

20\% Piperidine MW, 2020-12:05 20-29
Reaction: Temp: 50 50 C C Time (mm:ss): 03:00 Oscillating Mixer: 0

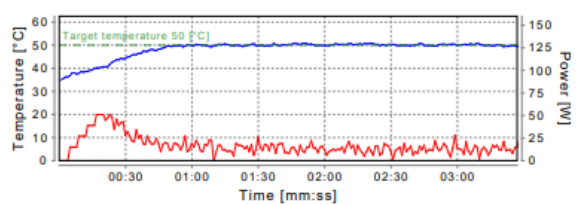

- Temperature - Power [ $[$ ]

Capping Acetic anhydride, $2020.12 .0520: 42$
Reaction: Temp: Room Temperature Time (mm:ss): 10:00 Oscillating Mixer: on

\section{Cycle No: 2
R (Fmoc-Arg(Pb)}

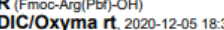

ss: 60.000 oscillating Mixer: on

20\% Piperidine MW. 2020-12-05 19:40
Reaction: Temp: 50C Time (mm:ss): 03:00 oscillating Mixer: On

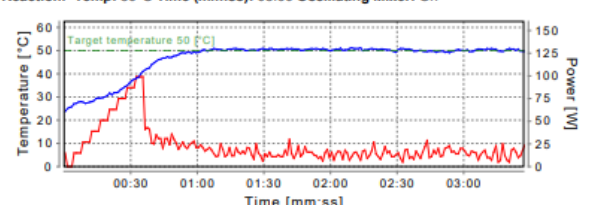

- Temperature - Power [W]
Cycle No: 3

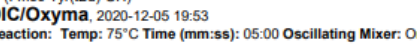

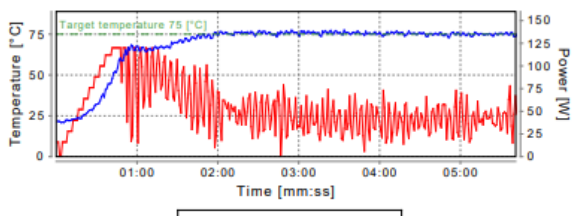

20\% Piperidine MW. $2020-12-05$ 20:05

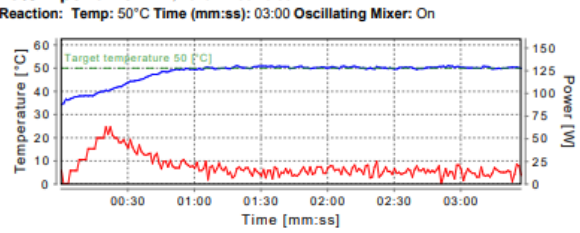

\begin{tabular}{c} 
Time [mm:ss] \\
\hline -Temperature - Power [W]
\end{tabular} 


\section{Ac-LYRANR-NHNH 2 (1h)}

\section{Cycle No: 1}

Swelling DMF.,2020.12-05 22:21
Reaction: Temp: 70, CTime (mm:ss): 20:00 oscillating Mixer: On

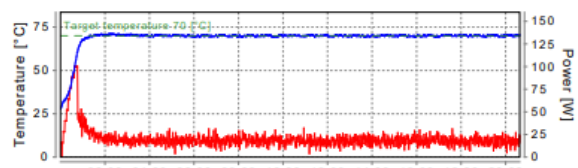

02:00 04:00 08:00 08.00

-Temperature - Power [W]

20\% Piperidine MW, 2020-12.05 22:43
Reaction: Temp: 50'C Time (mm:ss): 03:00 0scillating Mixer: On

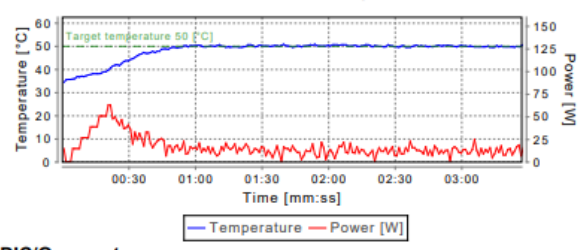

DIC/Oxyma rt. 2020-12-05 22:56

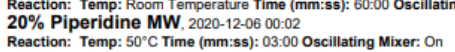

\section{Cycle No: 3
A (Fmoc-Ala-OH)}

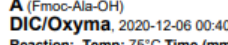

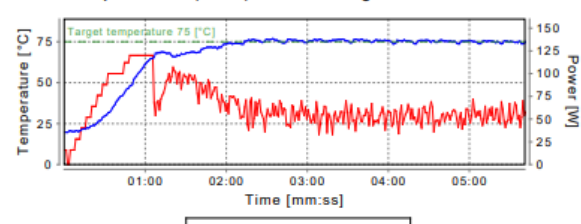

20\% Piperidine MW. 2020-12-06 00:52

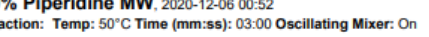

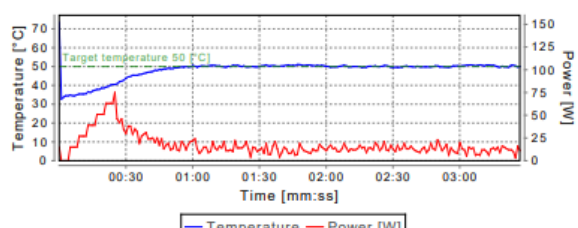

-Temperature - Power [W]

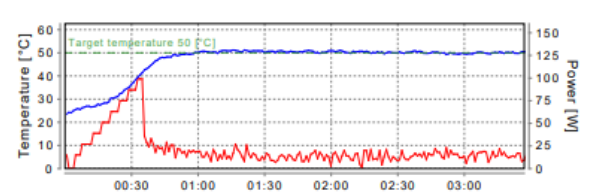

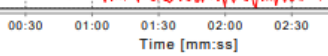

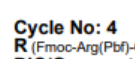

DIC/Oxyma rt. 2020-12-06 01:05

Reaction: Temp: Room Temperature Time (mm:ss): 60-00 Oscillating Mixer-

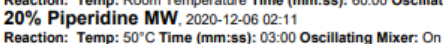

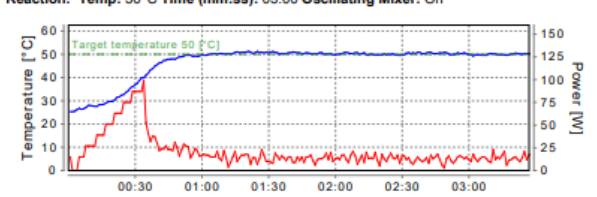

- Temperature - Power $[\mathrm{WW}]$
Cycle No: 2

N(Fmoc-Asn(Trit)-OH)

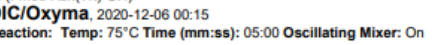

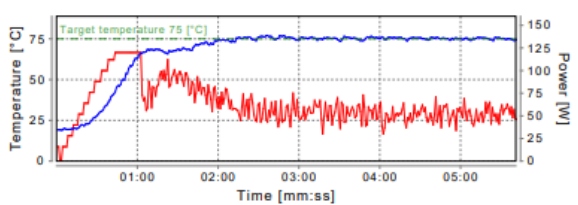

-Temperature - Power [V]

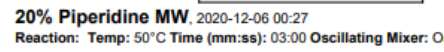

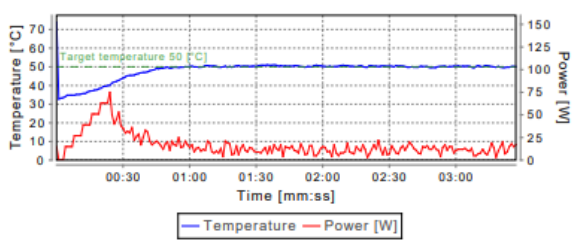

Cycle No: 5

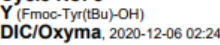

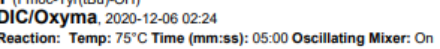

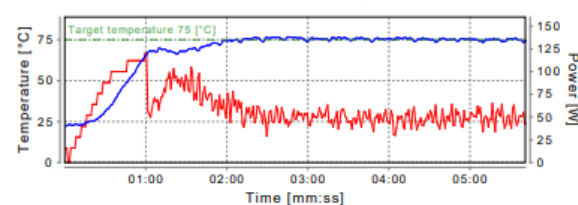

-Temperature - Power [W]

20\% Piperidine MW, 2020-12:06 02:36
Reaction: Temp: $50^{\circ} \mathrm{C}$ Time (mm:ss): 03:00 Oscillating Mixer: On

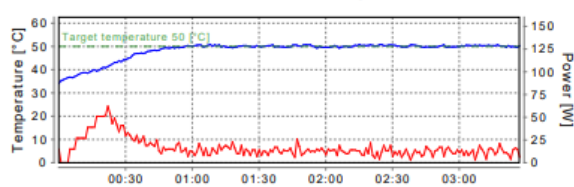

\begin{tabular}{c} 
Time [mm:ss] \\
\hline -Temperature - Power [W]
\end{tabular} 
Cycle No: 6

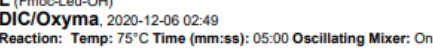

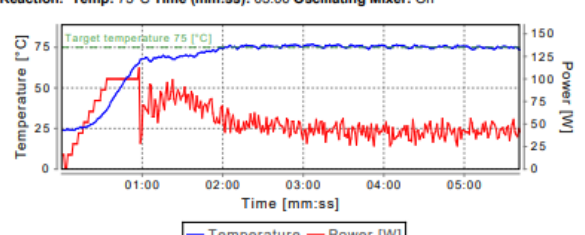

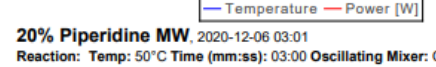

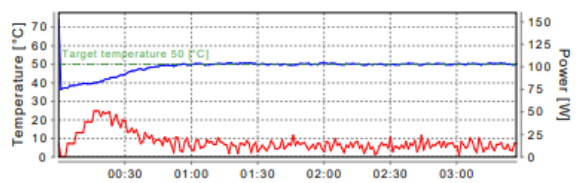

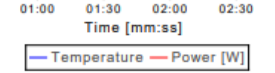

Capping Acetic anhydride, 2020-12-06 03:14

Capping Acetic an hydide, 2020-12-0000.14 Poscillating Mixer: on 
HIV-1 protease C-term, segment (9)

Cycle No: 1

S) (Fmoc-phe-OH)
Swealling DMF, 2020-11-17 21:16
Rection: Temp: $70^{\circ}$ Time (mm:ss): 20:00 0scillating Mixer: On

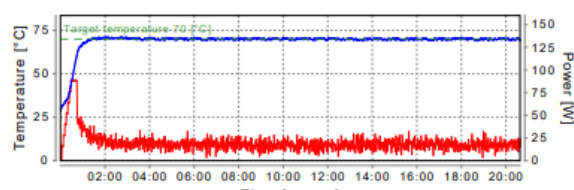

02:00 04:00 06:00 08:00 10:00 12:00 14:00 16:00 18:00 20:00

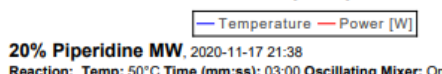

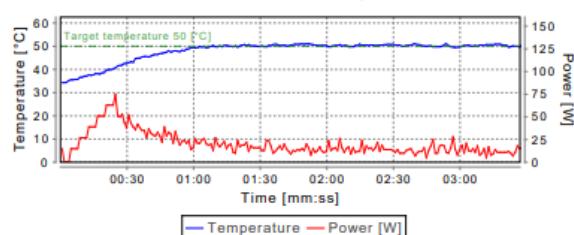

DIC/Oxyma, 2020-11-17 21:51
Reaction: Temp: $75^{\circ} \mathrm{CT}$ Time (mm:ss): 05:00 Oscillating Mixer: On

$$
\text { - Temperature }- \text { Power [W] }
$$

\section{Cycle No: 3
L(FmocLLeu-OH)}

DiCl/oxyma, 2020-11-17 22:43
Reaction: Temp: 75"C Time (mm:ss): 05:00 Oscillating Mixer: On

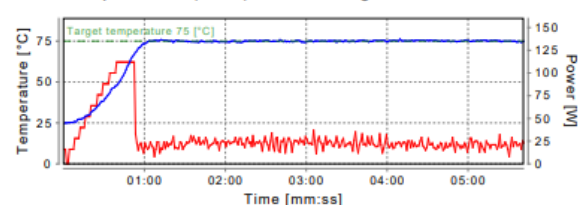

- Temperature - Power [W]

20\% Piperidine MW, 2020-11-17 22:54
Reaction: Temp: 50сC Time (mm:ss): 03:00 Oscillating Mixer: On

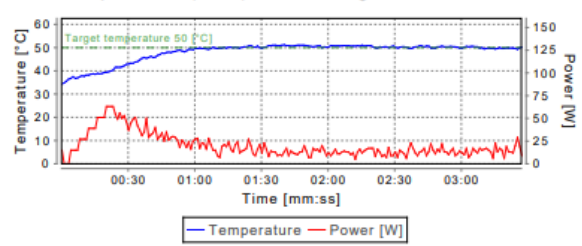

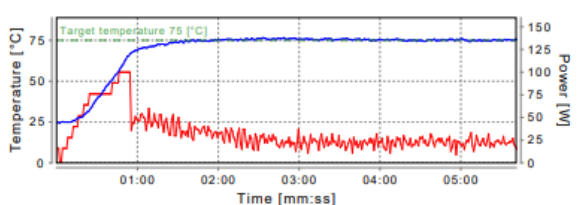

-Temperature - Power [W]

20\% Piperidine MW, 2020-11-17 22:05
Reaction: Temp: 50C Time (mm:ss): 03:00 0scillating Mixer: On

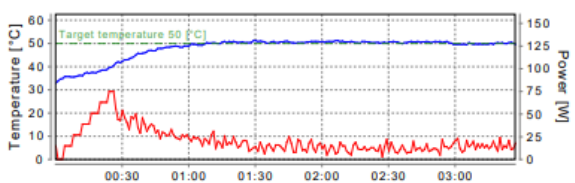

$\begin{array}{llllll}00: 30 & 01: 00 & 01: 30 & 02: 00 & 02: 30 & 03: 00\end{array}$

-Temperature - Power [W]

DiC/Oxyma, 2020-11-17 23:07

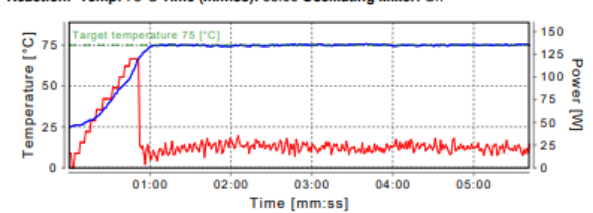

$-T$

20\% Piperidine MW, 2020-11-17 23:19
Reaction: Temp: 50' C Time (mm:ss): 03:00 Oscillating Mixer: 0

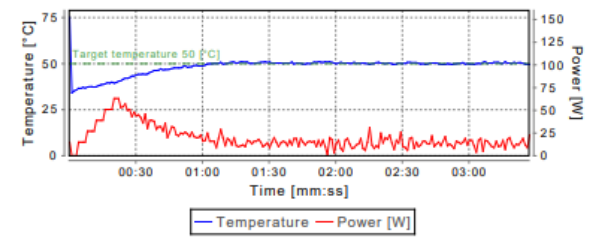

Cycle No: 2

DIC/Oxyma, 2020-11-17 22

(n) (mm:ss): 05:00 Oscillating Mixer: on

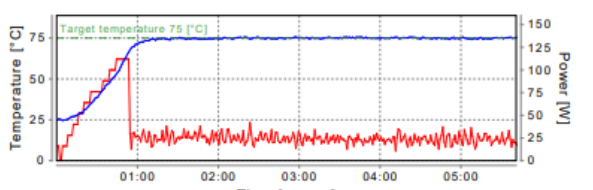

$\begin{array}{lllll}\text { 1:00 } & 02: 00 & 03: 00 & 04: 00 & 05: 00\end{array}$

$$
\begin{gathered}
\text { Time [mm:ss] } \\
\hline \text {-Temperature }- \text { Power [W] }
\end{gathered}
$$

20\% Piperidine MW. 2020-11-17 22:30

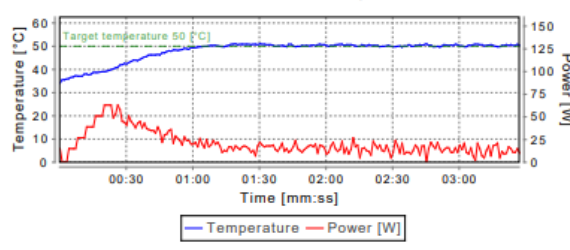

Cycle №: 5

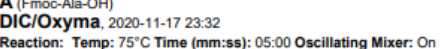

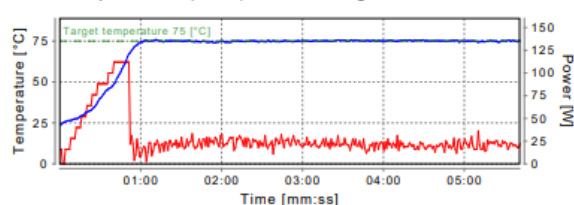

$-150$

20\% Piperidine MW, 2020-111-17 23:45
Reaction: Temp: 50 50 C Time (mm:ss): $03: 00$ oscillating Mixer:

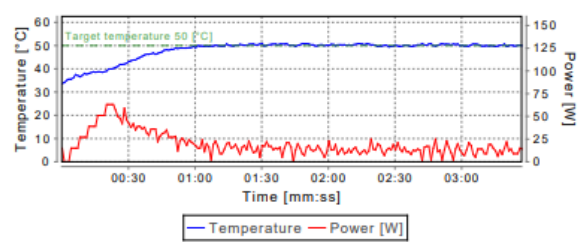




\section{Cycle No: 6}

DICIOxyma, 2020-11-17 23:59
Reaction: Temp: 75'C C Time (mm:ss): 05:00 oscillating Mixer: On

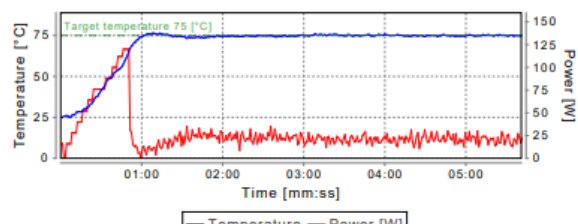

- Temperature - Power [W]

20\% Piperidine MW, 2020-11-18 00:10
Reaction: Temp: 50`C Time (mm:ss) :03:00 Oscillating Mixer:

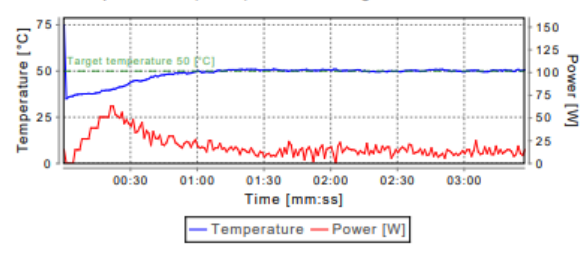

Cycle No: 9

Dicloxyma, 2020-11-18 01:14

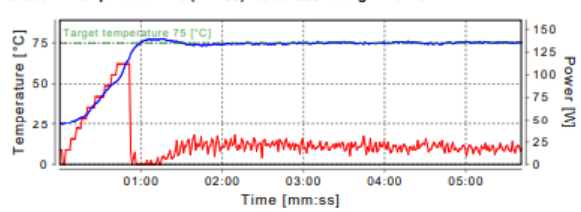

- Temperature - Power [W]
.

Reaction: Temp: $50^{\circ} \mathrm{C}$ Time (mm: (ms): 03.00 : oscillating Mixer: on

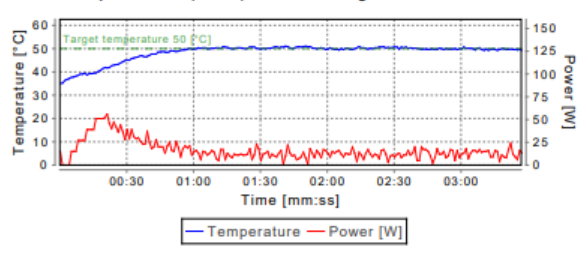

Cycle No: 7
I(Fmoc-lle-OH)

DIC/OXxyma, 2020-11-18 00:23
Reaction: Temp: $75^{\circ} \mathrm{C}$ Time (mm:ss): 05:00 Oscillating Mixer: On

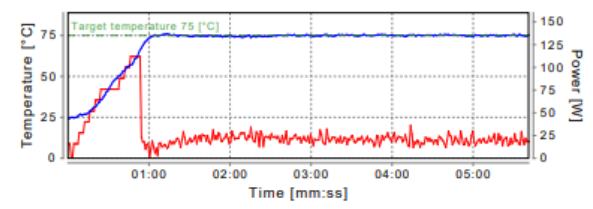

- Temperature - Power [W]

20\% Piperidine MW, 2020-11-18 00:35
Reaction: Temp: 50' C Time (mm: 185 ) : 03:00 Oscillating Mixer: O

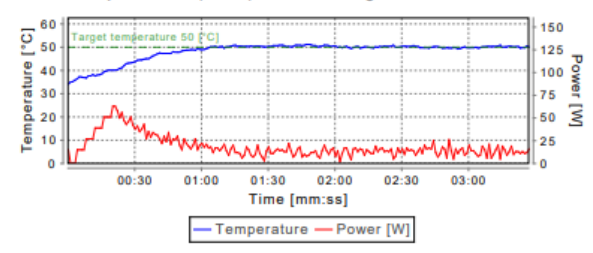

\section{Cycle No: 10}

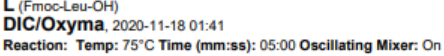

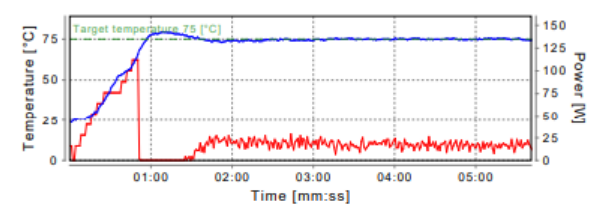

Temperature - Power [W]

20\% Piperidine MW, $2020-11-18$ 01:52
Reaction: Temp: $50^{\circ} \mathrm{C}$ Time (mm:ss): 03:00 Oscillating Mixer: On

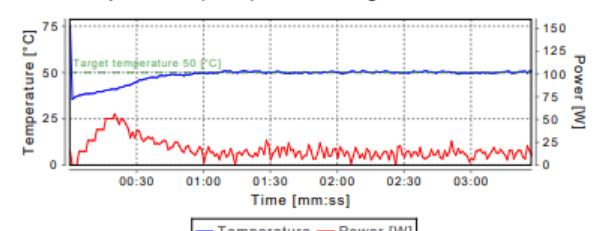

-Temperature - Power [W]
Cycle №: 8

RICaction: Temp: $75^{\circ} \mathrm{C}$ Time (mm:ss): 05:00 oscillating Mixer: On
Ret

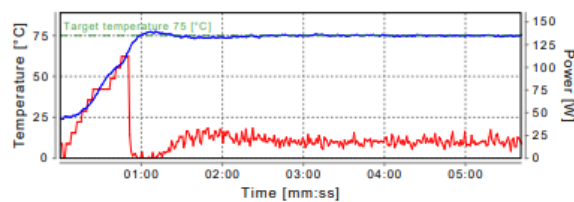

Temperature - Power [W]

20\% Piperidine MW. 2020-11-18 91:01
Reaction: Temp: 50"C Time (mm:ss): 03:00 oscillating Mixer:

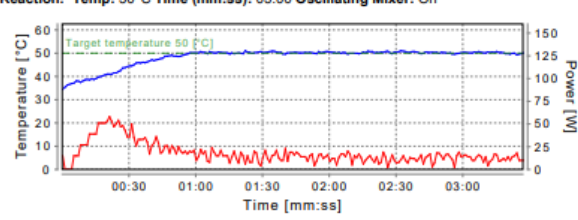

-Temperature - Power [W]

\section{Cycle No: 11}

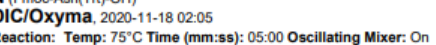

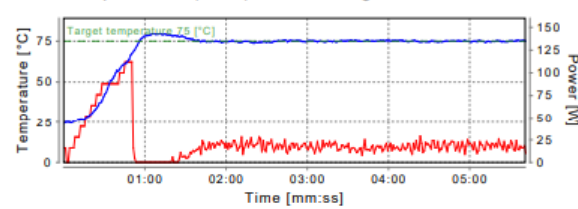

- Temperature - Power [W]

20\% Piperidine MW, 2020-11-18 02:-17
Reaction: Temp: 50C Time (mm:ss): 03:00 Oscillating Mixer:

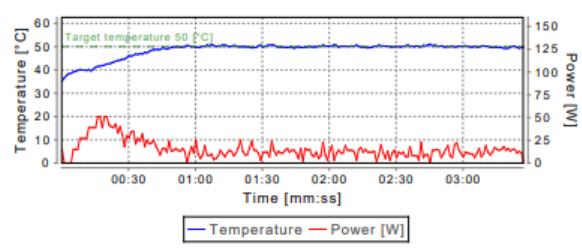




\section{Cycle No: 12
R(Fmoc-Arg (Pt)}

DIC/Oxyma rt. 2020-11-18 02:30

Reaction: Temp: Room Temperature Time (mm:ss): 60:00 Oscillating Mixer:

(1)

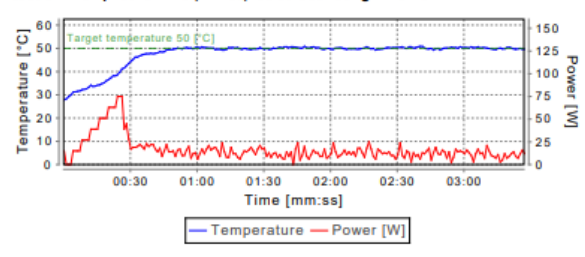

-Temperature - Power [W]

\section{Cycle No: 15
I(fmoc-lle-OH)
(ficos)}

DICOCxyma, 2020-11-18 04:39
Reaction: Temp: $75^{\circ} \mathrm{C}$ Time (mm:ss): 05:00 Oscillating Mixer: On

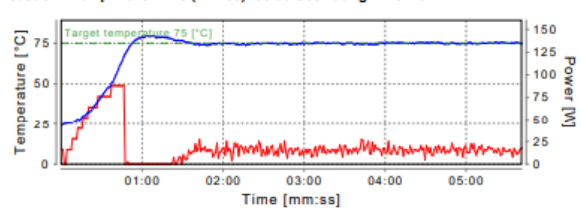

20\% Piperidine MW, 2020-11-18 04:51

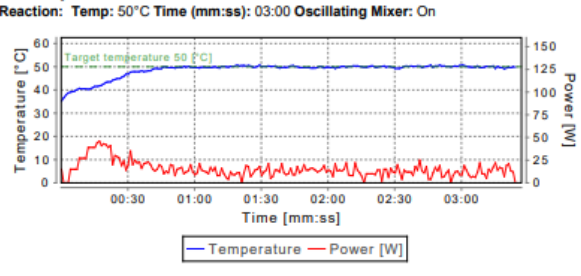

Cycle No: 13
G(Imo-Gily-OH)

DICl/C0xyma, 2020-11-18 03:50
Reaction: Temp: $75^{\circ} \mathrm{C}$ Time (mm:ss): 05:00 Oscillating Mixer: of

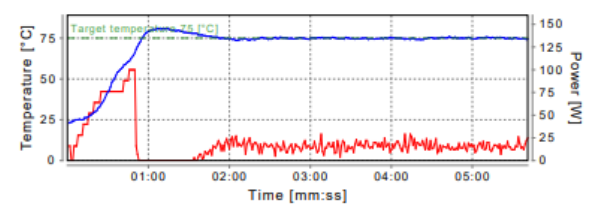

- Temperature - Power [W]

20\% Piperidine MW. 2020-11-18 04:02
Reaction: Temp: 50드. Time (mm:ss): 03:00 Oscillating Mixer: O

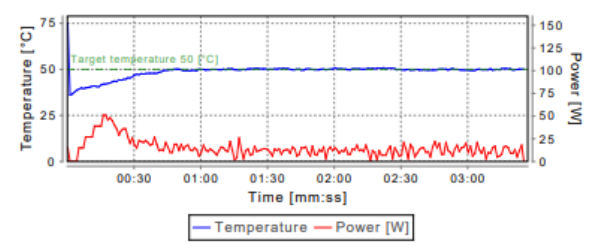

Cycle No: 16
N(Fmoc-Asn(Trt)-OH $)$

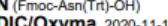

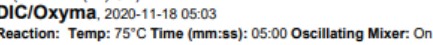

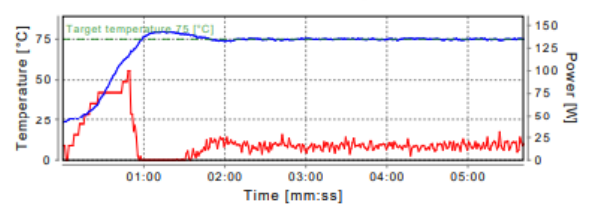

20\% Piperidine MW, 2020-11-18 05:17

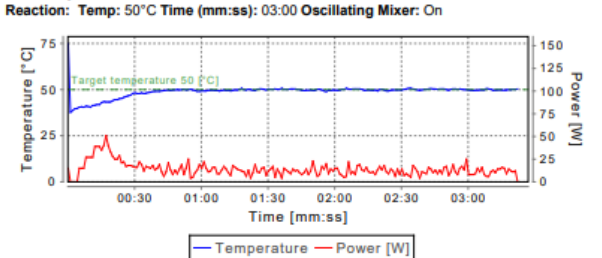

- Temperature - Power [W]
Cycle No: 14

DICIOxyma, 2020-11-18 84:15:
Reaction: Temp: $75^{\circ} \mathrm{C}$ Time (mm:ss): 05:00 Oscillating Mixer: On

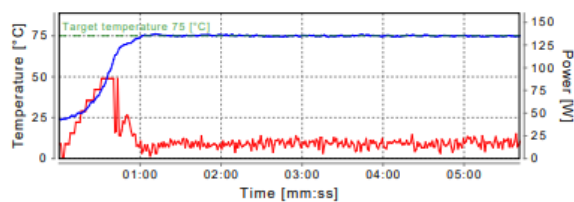

20\% Piperidine MW. 2020-11-18 80.26
Reaction: Temp: 50॰C Time (mM:s5): 03:00 0scillating Mixer:

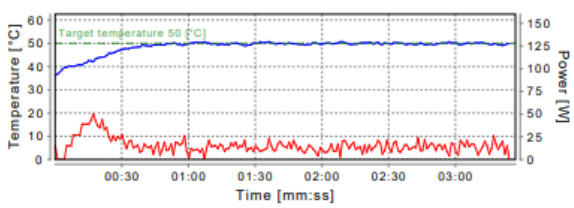

-Temperature - Power [W]

\section{Cycle No: 17}

DICOCxyma, 2020-11-18 05:30
Reaction: Temp: $75^{\circ} \mathrm{C}$ Time (mm:ss): 05:00 Oscillating Mixer: O

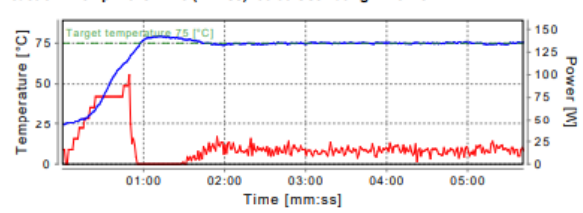

20\% Piperidine MW. $20202-11-18$ 05:41

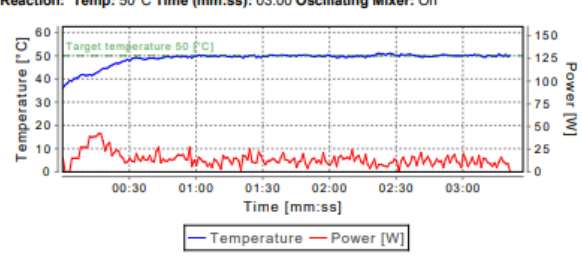




\section{Cycle №: 18}

DiC/OXyma, 2020-11-18 05:54
Reaction: Temp: $75^{\circ} \mathrm{C}$ Time (mm:ss): 05:00 Oscillating Mixer: On

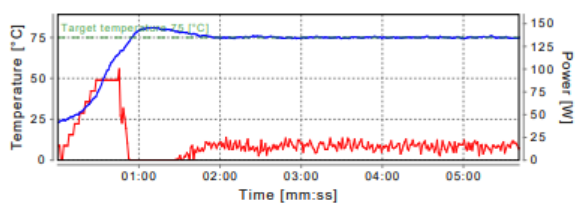

- Temperature - Power [W]

20\% Piperidine MW, 2020-11-1800:06
Reaction: Temp: 50"C Time (mm:ss): 03:00 Oscillating Mixer: On

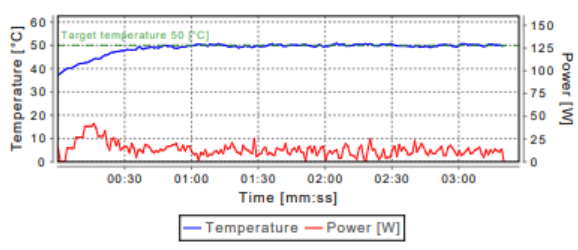

Cycle No: 21
G(Fmoc-Gly-OH)

DICl/oxyma, 2020-11-18 07:08

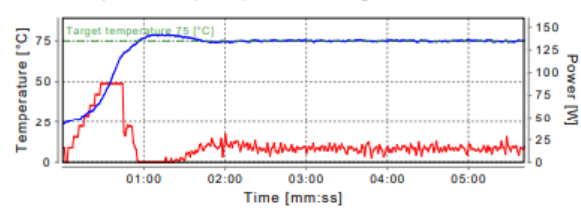

\begin{tabular}{c} 
02:00 \\
Time [mm:ss] \\
\hline -Temperature - Power [W]
\end{tabular}

20\% Piperidine MW, $2020-11-1.1807 .21$
Reaction: Temp: $50^{\circ} \mathrm{C}$ Time (mm:ss): 03:00 Oscillating Miver: On

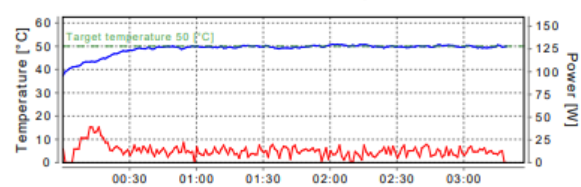

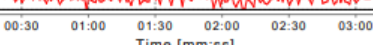
-Temperature - Power [W]

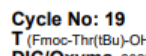

DICl/Xxyma. 2020-11-18 86:19
Reaction: Temp: $75^{\circ} \mathrm{C}$ Time (mm:ss): 05:00 Oscillating Mixer: On

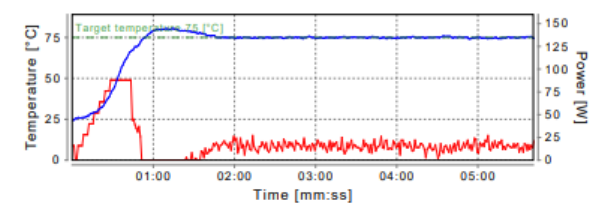

-Temperature - Power [W

20\% Piperidine MW, 2020-11-18 06:30
Reaction: Temp: 50 5 C Time (mm:ss): 03:00 Oscillating Mixer: On

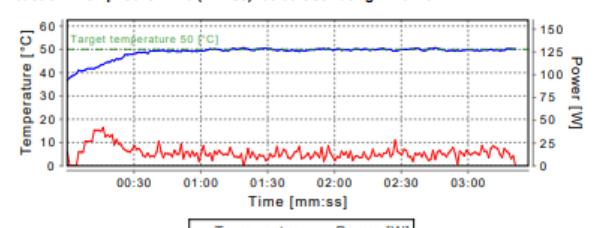

-Temperature - Power [W]

\section{Cycle No: 22}

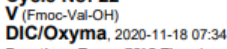

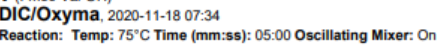

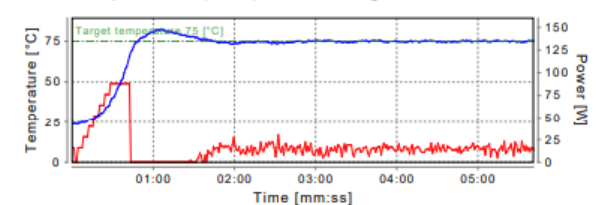

20\% Piperidine MW. $2020-11-18$ - 18 07:45 45

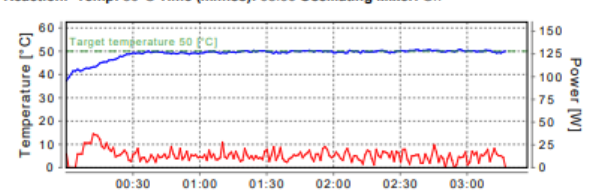

$\begin{array}{llllll}00: 30 & 01: 00 & 01: 30 & 02: 00 & 02: 30 & 03: 00\end{array}$

- Temperature - Power [W]
Cycle No: 20
P(Fmoc-Pro-OH)

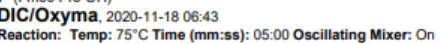

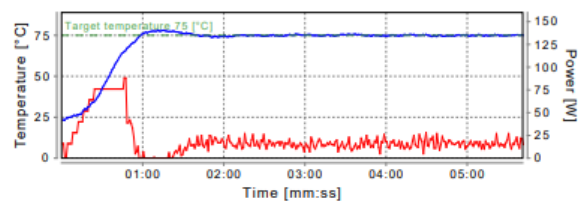

-Temperature - Power [W]

20\% Piperidine MW. 2020-11-18 06:56
Reaction: Temp: $50^{\circ} \mathrm{C}$ Time (mm:ss) :03:00 Oscillating Mixer: On

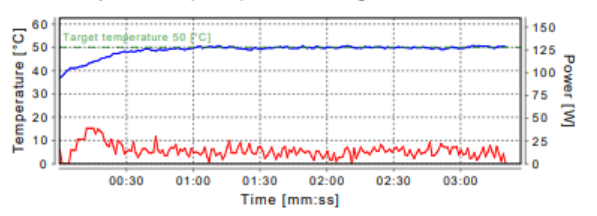

-Temperature - Power [W]

Cycle No: 23
L(Fmoo-Leu-OH)

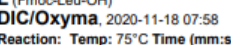

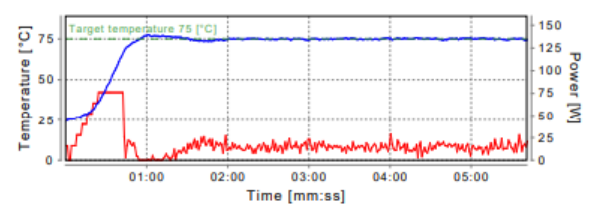

- Temperature - Power I

20\% Piperidine MW, 2020-11-18 08:11
Reaction: Temp: 50'C Time (mm:s5): 03:00 0scillating Mixer: On

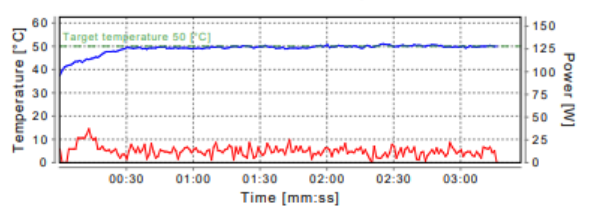

-Temperature - Power [W] 


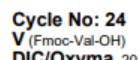

DIClOxyma, $2020-111-1808.24$
Reaction: Temp: $75^{\circ}$ C Time (mm:ss): 05:00 Oscillating Mixer: On

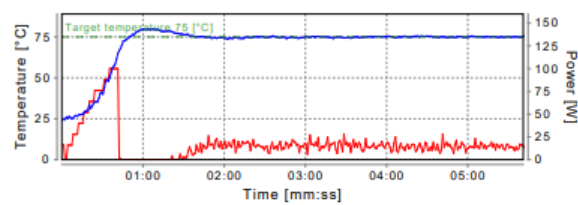

- Temperature - Power [W]

20\% Piperidine MW, 2020-11-18 08:37
Reaction: Temp: 50'C Time (mm:ss): 03:00 Oscillating Mixer: O

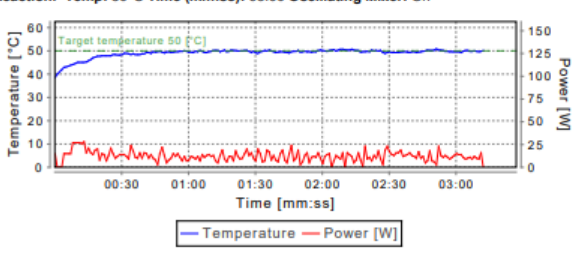

Cycle No: 27
I(Fmoc-llo-OH)

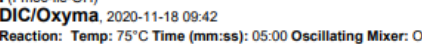

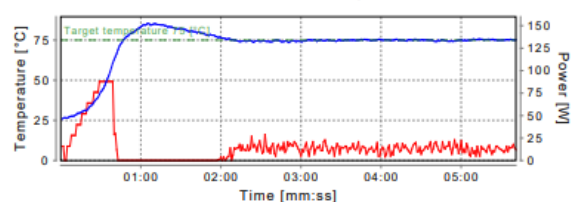

20\% Piperidine MW, 2020-11-18 00:56
Reaction: Temp: $50^{\circ} \mathrm{C}$ Time (mm:ss): 03:00 Oscillating Mixer:

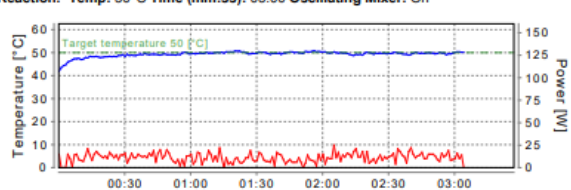

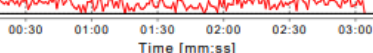

- Temperature - Power [W]
Cycle No: 25

T(Fmoc-Thrt 25

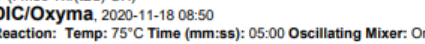

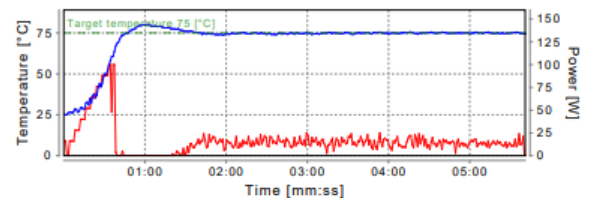

-Temperature - Power [W]

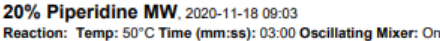

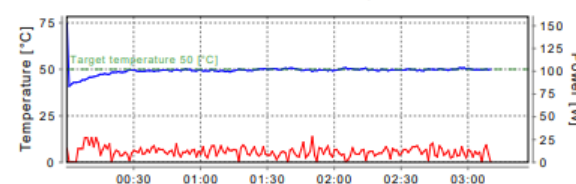

$\begin{array}{llll}00: 30 & 01: 00 & \begin{array}{c}01: 30 \\ \text { Time [mm:ss] }\end{array} & 02: 00 \\ & & 0\end{array}$

-Temperature - - Power [W]

\section{Cycle No: 28}

DIC/Oxyma rt. 2020-11-18 10:0e

:ss: 60:00 Oscillating Mixer: On

oscillating Mixer: On

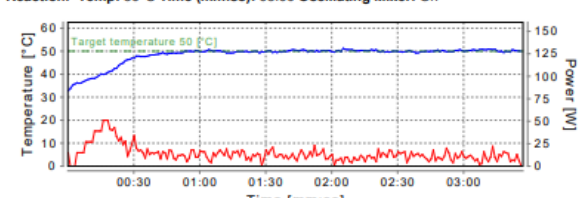

- Temperature - Power [W]
Cycle No: 26

DICl/0xyma, 2020-11-18 09:16
Reaction: Temp: 75 C C Time (mm:ss): 05:00 oscillating Mixer: On

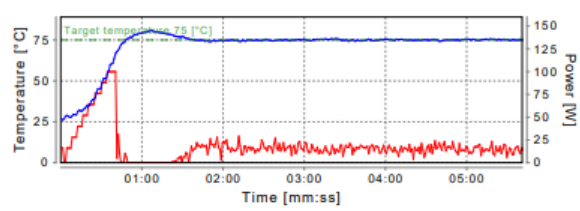

-Temperature - Power [W]

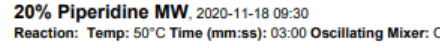

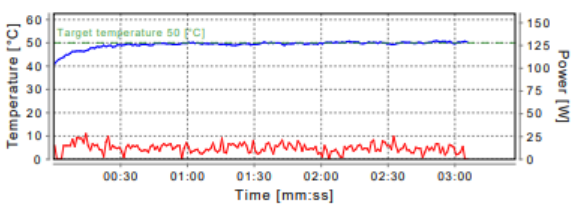

Time [mm:ss] 
Solubilizing tag (12)

\section{Cycle No: 1}

K(Fmoc-Lys(Boc)-OH)
Sweelling DMF 2020-11-17 14:29
Reaction: Temp: $70^{\circ} \mathrm{C}$ Time (mm:ss): 20:00 oscillating Mixer: O

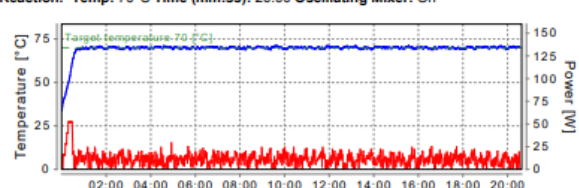

02:00 04:00 06:00 08:00 10:00 12:00 14:00 16:00 18:00 20:00

\begin{tabular}{c} 
Time [mm:ss] \\
\hline -Temperature - Power [W]
\end{tabular}

DIC/Oxyma, 2020-11-171 14:51
Reaction: Temp: $75^{\circ} \mathrm{C}$ Time (mm:ss): 05:00 oscillating Mixer: O

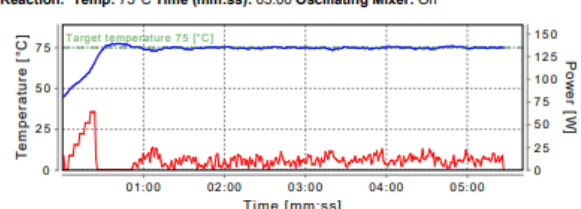

$$
- \text { Temperature }- \text { Power [W] }
$$

20\% Piperidine MW, 2020-111-17 15:03
Reaction: Temp: 50'C Time (mm:ss): 03:00 Oscillating Mixer: O

\section{Cycle No: 3}

IC/Oxyma, 2020-11-17 15:4

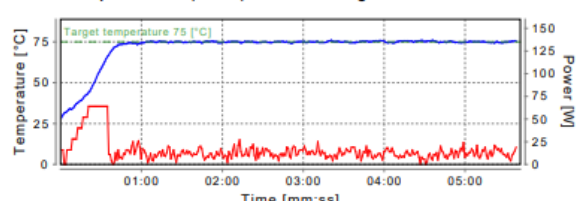

$$
\text { -Temperature }- \text { Power [W] }
$$

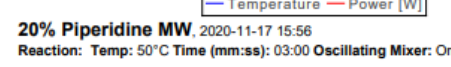

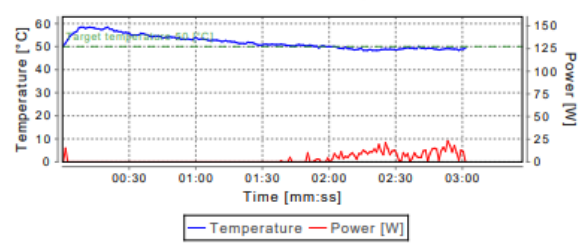

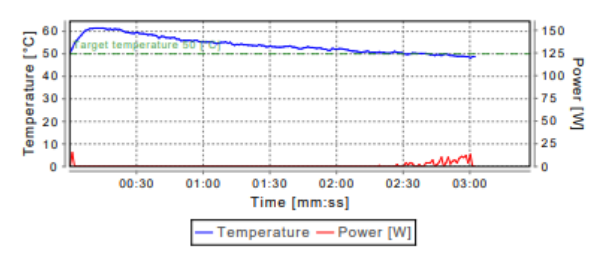

ycle No: 2

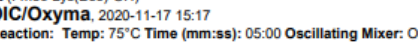

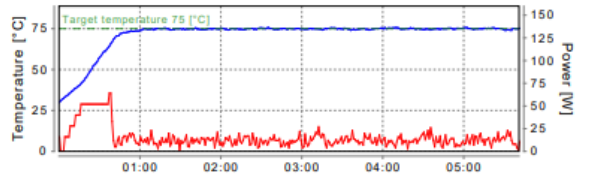$$
\begin{gathered}
{ }^{02: 00}{ }_{\text {Time [mm: }}^{03: 05]}{ }^{04: 00} \\
\text { - Temperature - Power [W] }
\end{gathered}
$$

20\% Piperidine MW, 2020-111-17 15:29
Reaction: Temp: 50"C Time (mm:ss): 03:00 oscillating Mixer: On

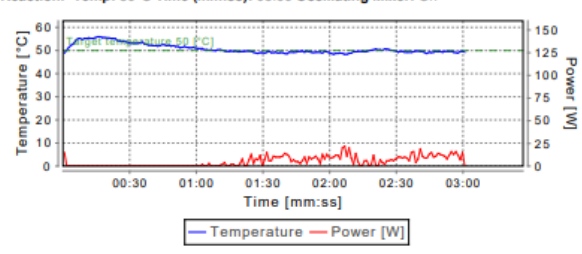

Cycle No: 5

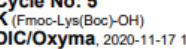

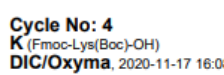

DIC/Oxyma, 2020-11-17 16:08
Reaction: Temp: $75^{\circ} \mathrm{CT}$ Time (mm:ss): 05:00 Oscillating
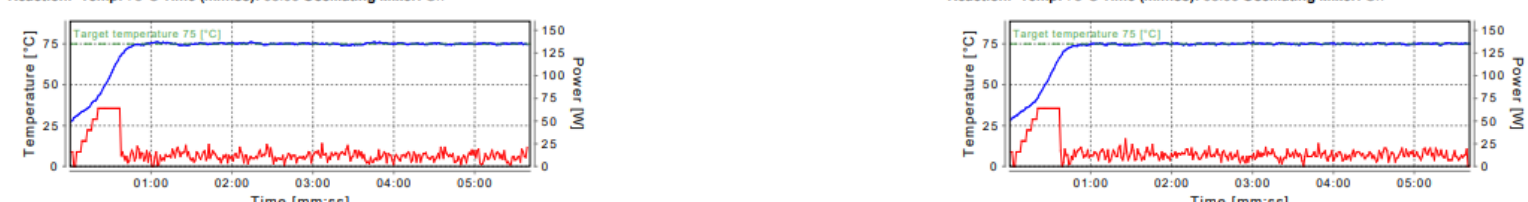

$$
- \text { Temperature - Power [W] }
$$

20\% Piperidine MW, 2020-111-17 16:20
Reaction: Temp: 50 50C Time (mm:ss): 03:00 Oscillating Mixer: O
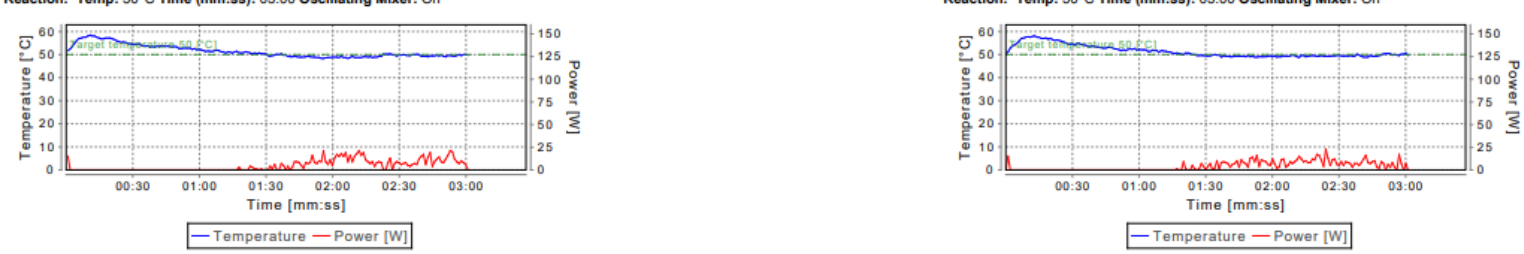


\section{Cycle No: 6}

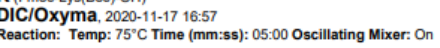

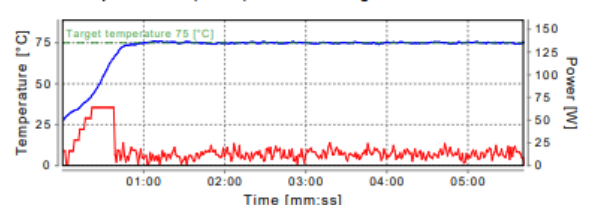

- Temperature - Power [W]

20\% Piperidine MW. 2020-11-17 177:08
Reaction: Temp: 50. C C Time (mm:ss): 03:00 0scillating Mixer: On

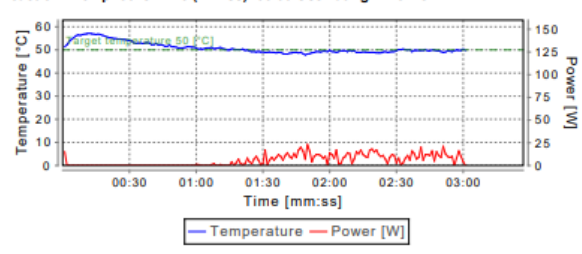

\section{Cycle No: 9}

K(Fmoc-Lys(Boc)-OH)
DIC/Oxyma, 2020-11-17

Reaction: Temp: 75 $75^{\circ} \mathrm{C}$ Time (mm:ss): 05:00 0scillating Mixer: O

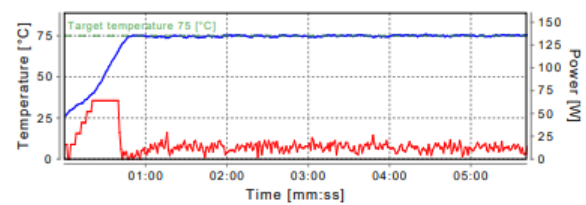

-Temperature - Power [W]

20\% Piperidine MW, 2020-11-17 17:21
Reaction: Temp: 50 50 C Time (mm:ss): 03:00 Oscillating Mixer: On

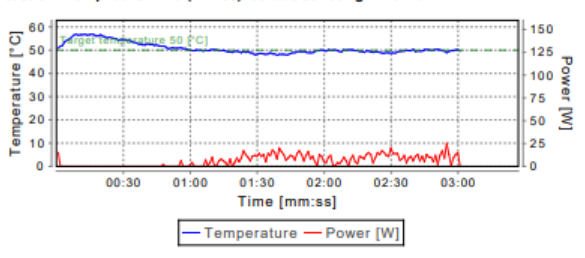

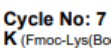

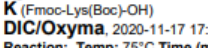

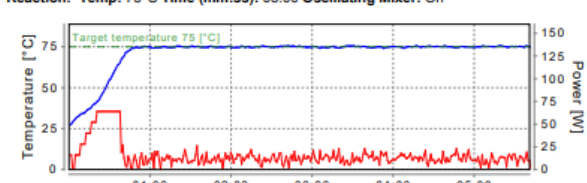

01:00 02:00 000

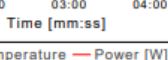

20\% Piperidine MW. $20202-11-17717: 33$
Reaction: Temp: 50 $50^{\circ} \mathrm{C}$ Time (mm:ss): 03:00 Oscillating Mixer: on

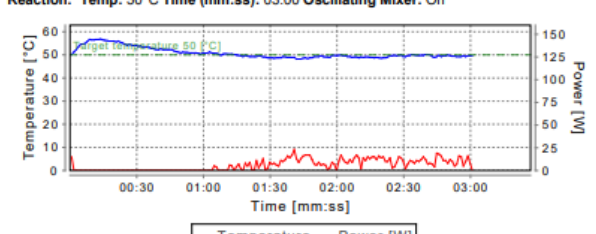

- Temperature - Power [W]

\section{Cycle No: 10}

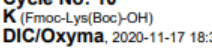

DIC/Oxyma, 2020-11-17 18:34
Reaction: Temp: $75^{\circ}$ Time (mm:ss): 05:00 0scillating Mixer: On

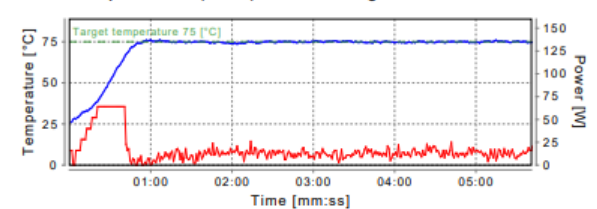

- Temperature - Power [W]

20\% Piperidine MW, 2020-11-17 18:46
Reaction: Temp: $50^{\circ} \mathrm{C}$ Time (mm:ss): 03:00 Oscillating Mixer: On

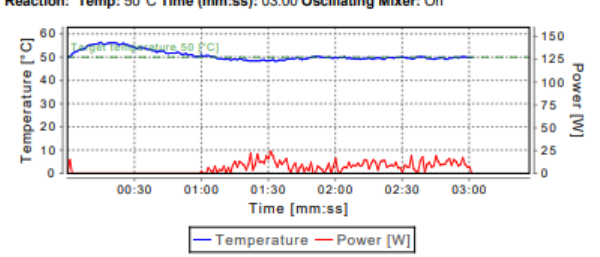

Cycle No: 8

DIC/Oxyma, 2020-11-17 17:45:
Reaction: Temp: 75'C Time (mm:ss): 05:00 oscillating Mixer: On

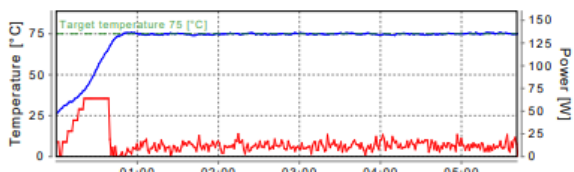

01:00 02:00 03:00:
Time [mm:ss]

-Temperature - Power

20\% Piperidine MW, 2020-11-17 17:57
Reaction: Temp: 50'C Time (mm:ss): 03:00 Oscillating Mixer: On

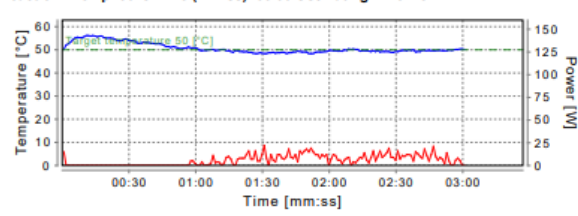

Time [mm:ss]

\section{Cycle No: 11}

4 (4.tomyl benzoic acid)
DIC/OXxyma, 2020-11-17 18

DIC/Oxyma, 2020-11-17 18:58
Reaction: Temp: $75^{\circ} \mathrm{C}$ Time (mm:ss): 05:00 0scillating Mixer: On

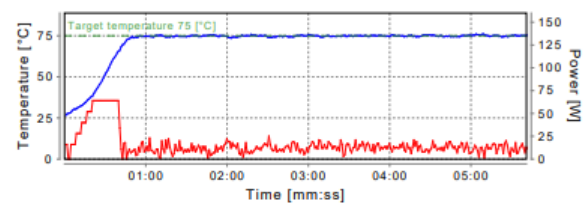

- Temperature - Power [N]

20\% Piperidine MW, 2020-11-17 19:10
Reaction: Temp: $50^{\circ} \mathrm{C}$ Time (mm:ss): 03:00 0scillating Mixer:

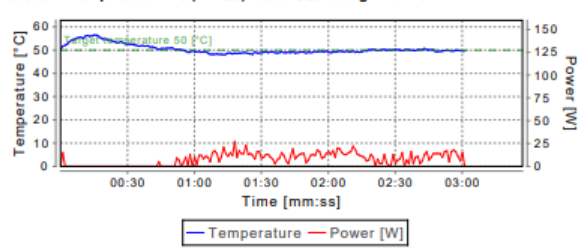

